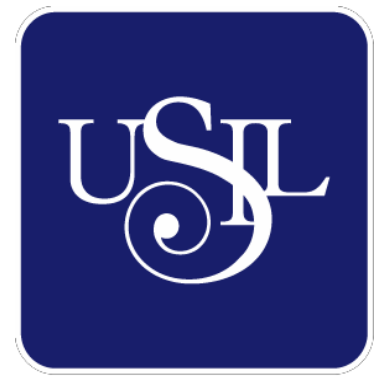

UNIVERSIDAD

SAN IGNACIO

DE LOYOLA

FACULTAD DE CIENCIAS EMPRESARIALES

Carrera de International Business

\title{
IMPACTO DEL DESEMPEÑO DE LA TERCERIZACIÓN DE SERVICIOS LOGÍSTICOS EN LAS MYPES EXPORTADORAS DE UVAS A EUA, 2020
}

Tesis para optar el Título Profesional de Licenciado en International Business

FRANCO ENRIQUE CADENILLAS CERNA (0000-0001-9253-

9537)

SOFIA YESEÑA FARGE DELGADO (0000-0002-3760-1534)

Asesor:

Mg. Oscar Federico Muro Doig 0000-0002-5183-8327

Lima - Perú

2020 


\section{DEDICATORIA}

A Dios por darnos salud y guiarnos en cada paso y meta que nos proponemos y así lograr nuestros objetivos.

A nuestros padres por habernos forjado como personas de bien sobre todas las cosas; muchos de mis logros se los debo a ustedes entre los que se incluye este.

A nuestros profesores de la universidad por avernos guiado de manera espléndida en la carrera que escogimos y poder ser competentes en nuestras vidas. 


\section{AGRADECIMIENTOS}

A las autoridades y catedráticos de la Universidad SAN IGNACIO DE LOYOLA, por mi formación académica y por darme la oportunidad para optar el Título Profesional de LICENCIADO en INTERNATIONAL BUSINESS, lo que coadyuvará a la mejora de mi calidad personal y profesional.

Al Mg. Oscar Muro Doig, por su valiosa cooperación en el presente trabajo monográfico. 


\section{Índice}

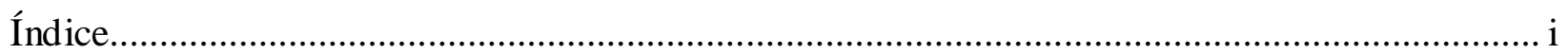

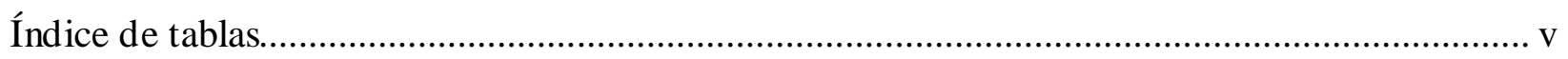

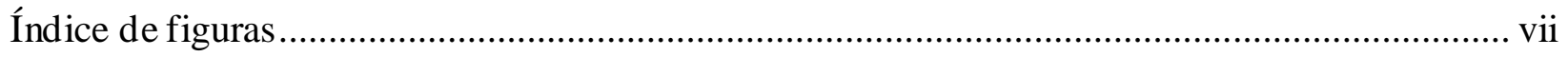

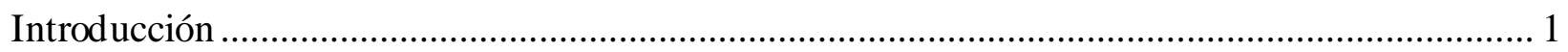

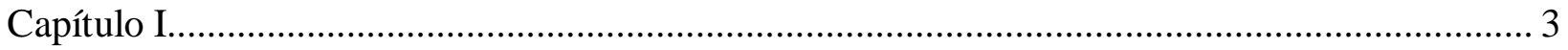

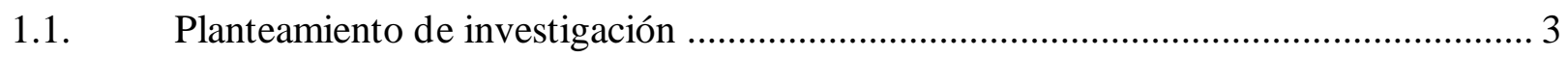

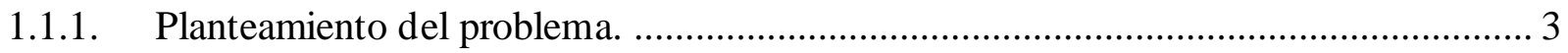

1.1.2. Formulación del problema....................................................................................... 4

1.1.2.1. Problema general....................................................................................... 4

1.1.2.2. Problemas específicos......................................................................................... 4

1.1.3. Justificación de la investigación. ....................................................................... 5

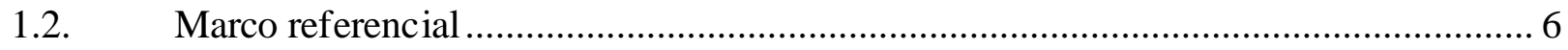

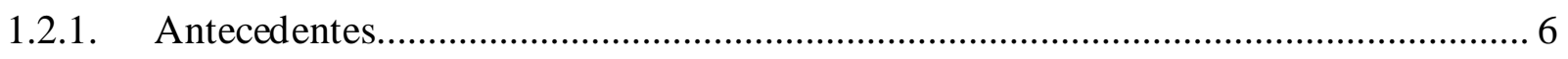

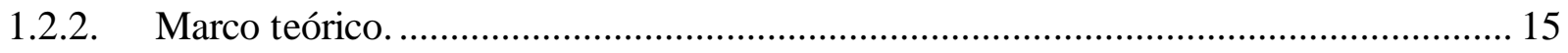

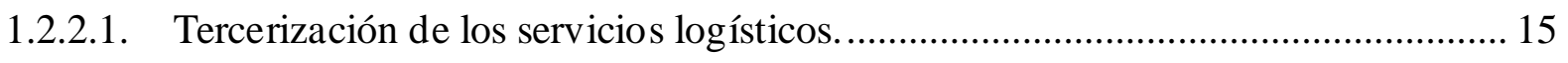

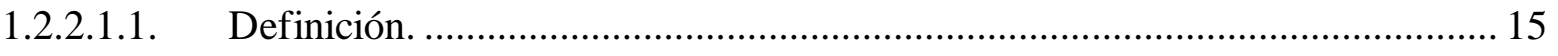

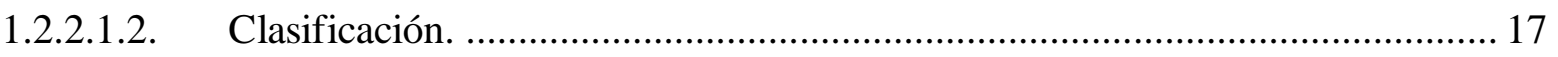

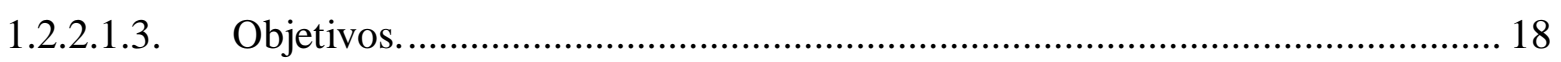

1.2.2.2. Desempeño de la tercerización de los servicios logísticos (3PL). .......................... 23

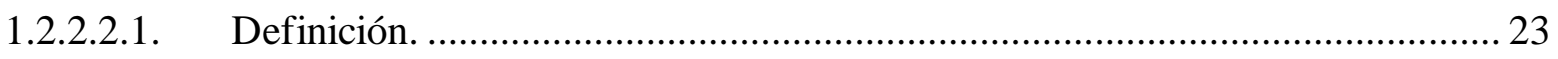

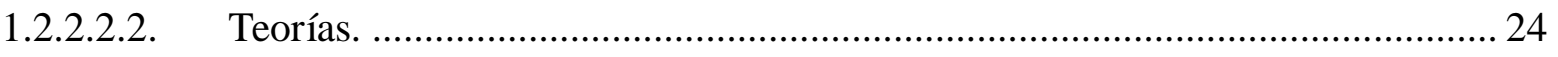

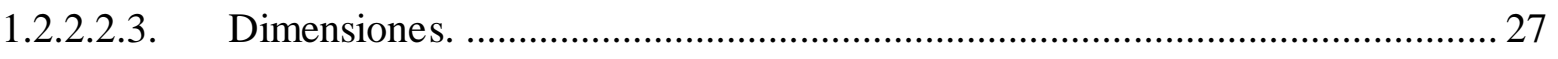




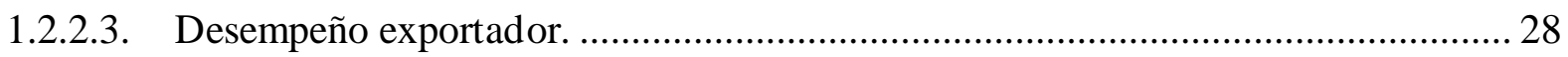

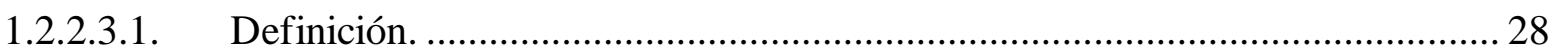

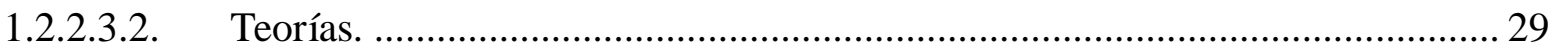

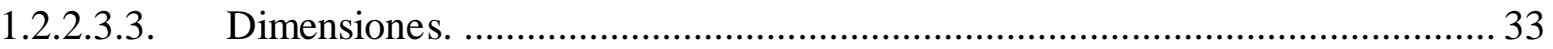

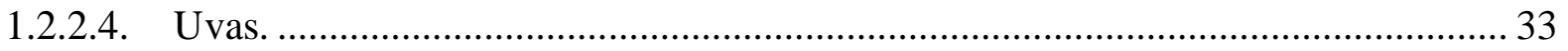

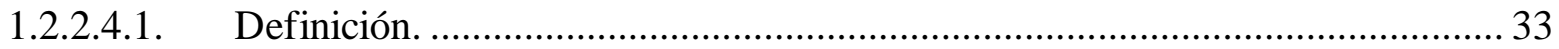

1.2.2.4.2. Principales destinos de la uva peruana. ........................................................... 33

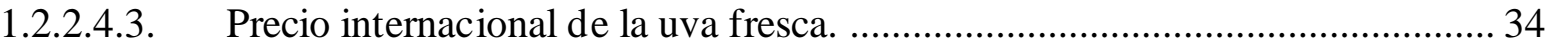

1.2.2.4.4. Países exportadores de uva fresca................................................................. 34

1.2.2.4.5. Empresas peruanas de exportación de uva fresca............................................ 35

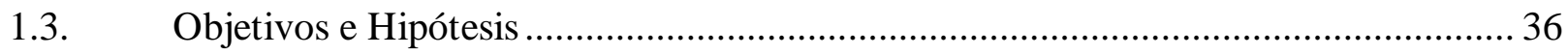

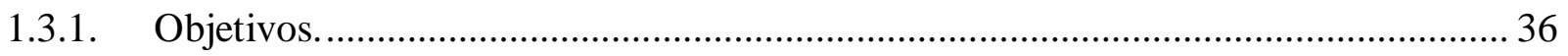

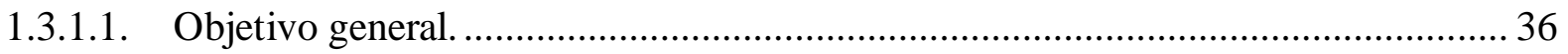

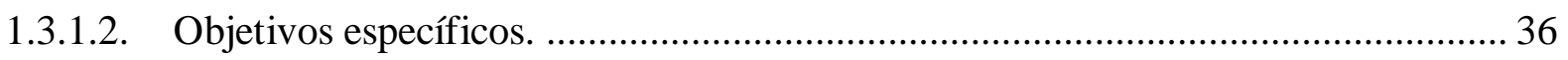

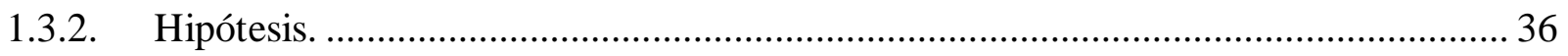

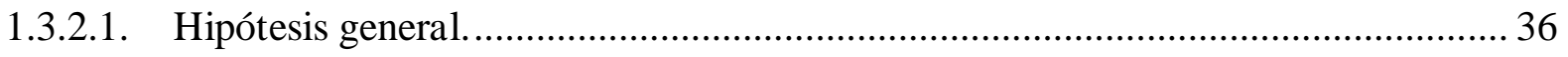

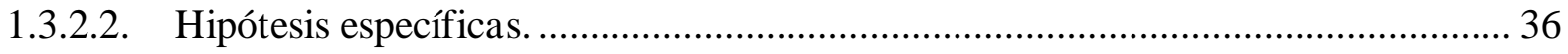

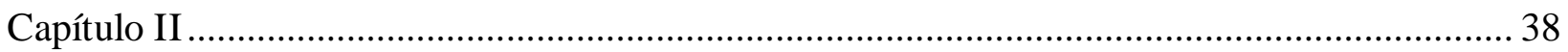

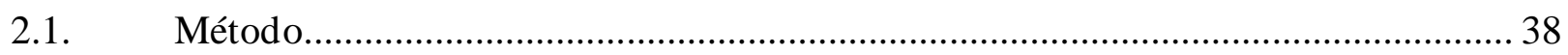

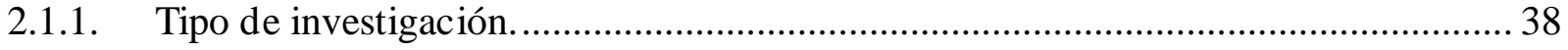

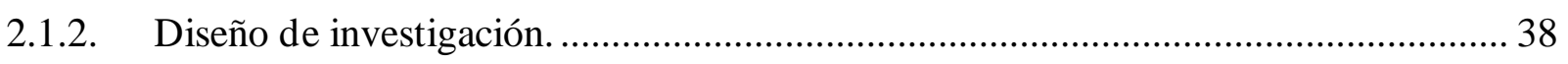

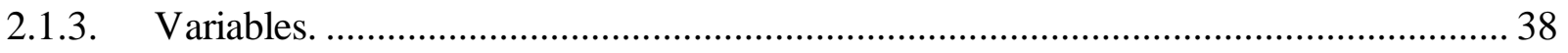

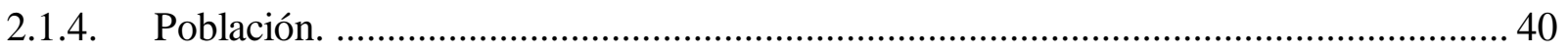




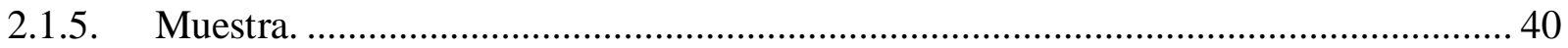

2.1.6. Instrumentos de investigación. ................................................................................ 42

2.1.7. Procedimientos de recolección de datos.................................................................. 43

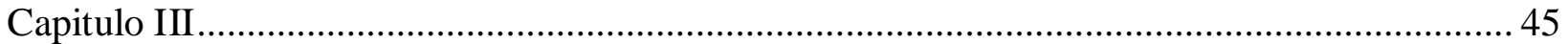

3.1. Análisis de los resultados de los cuestionarios ........................................................... 45

3.1.1. Análisis de resultados de desempeño de la tercerización de los servicios logísticos . 45

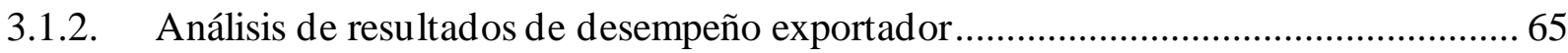

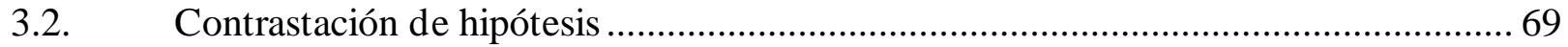

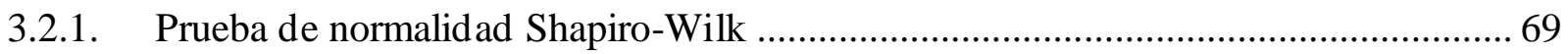

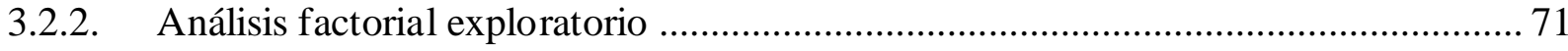

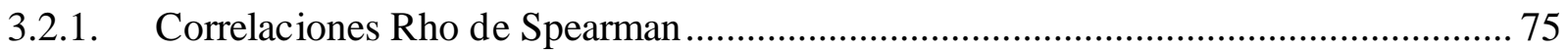

3.2.2. Contrastación de las hipótesis.................................................................................. 77

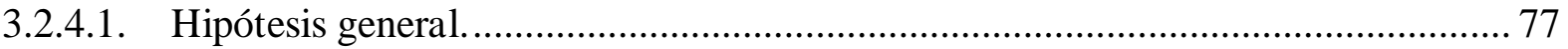

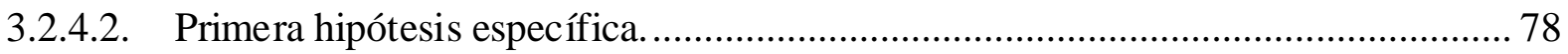

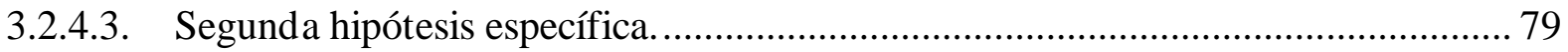

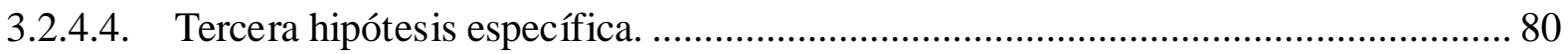

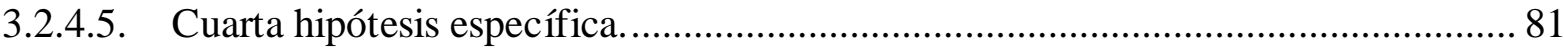

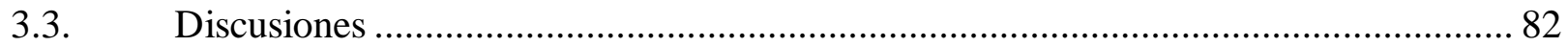

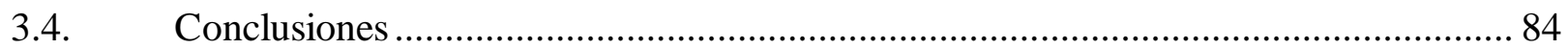

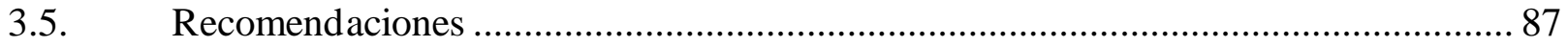

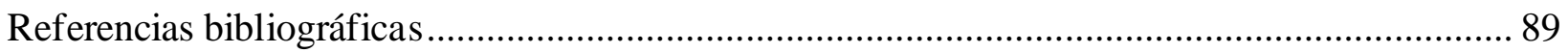

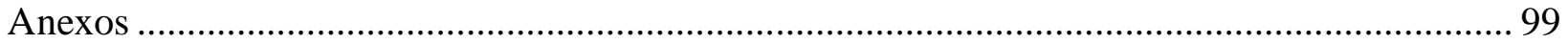

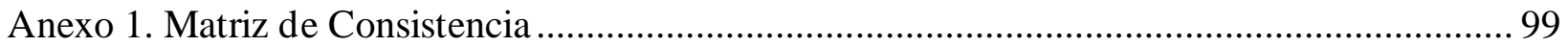




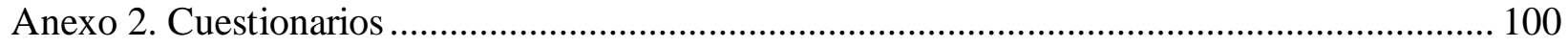

Anexo 3. Prueba de Shapiro-Wilk .............................................................................. 103

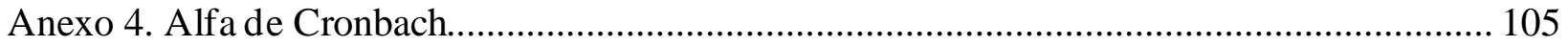

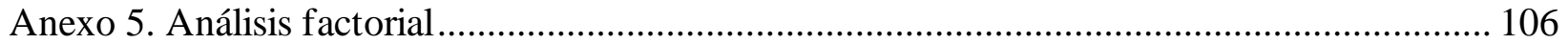

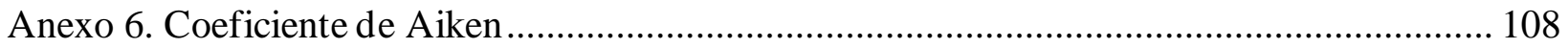

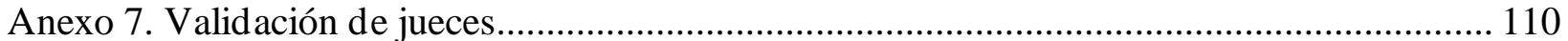




\section{Índice de tablas}

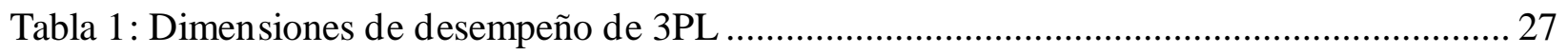

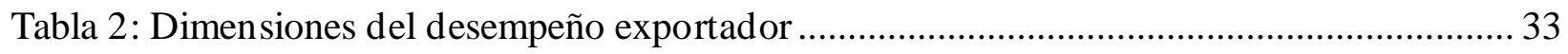

Tabla 3: Principales destinos de la uva fresca peruana ................................................................... 34

Tabla 4: Precio de la uva fresca en el extranjero ...................................................................... 34

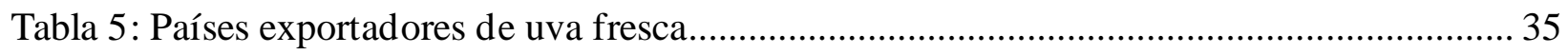

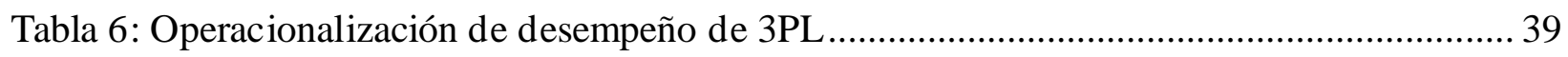

Tabla 7: Operacionalización de desempeño exportador ............................................................ 40

Tabla 8: Cantidad de empresas exportadoras de uvas frescas ...................................................... 40

Tabla 9: Muestra de empresas exportadoras de uvas frescas Perú ............................................... 42

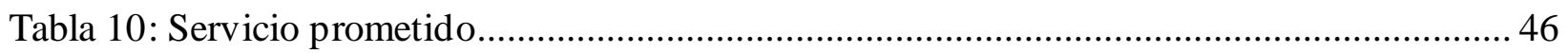

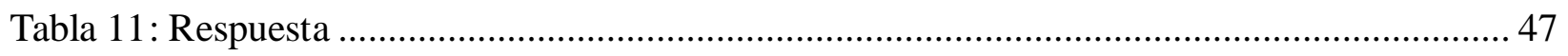

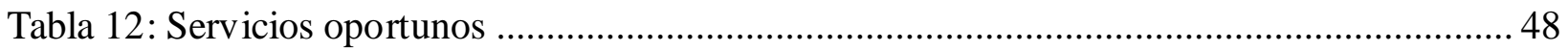

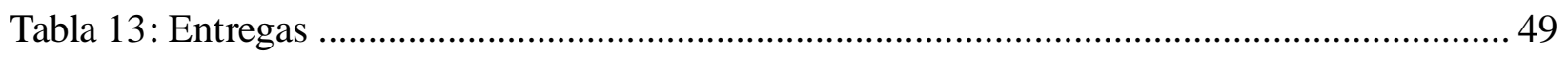

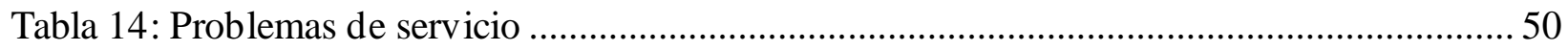

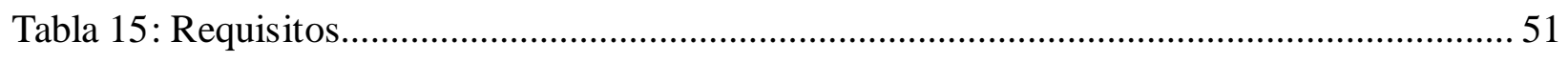

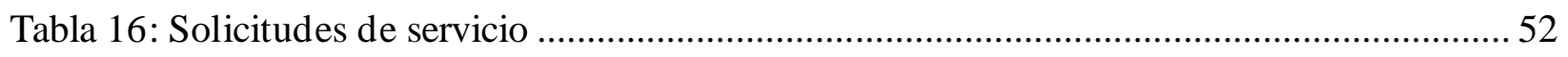

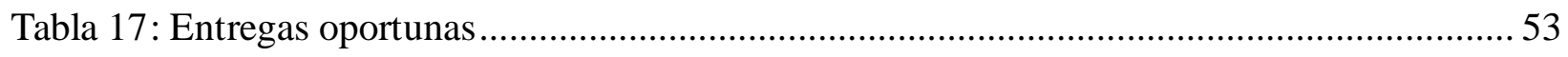

Tabla 18: Mejora de operatividad ........................................................................................ 54

Tabla 19: Soluciones creativas ................................................................................................. 55

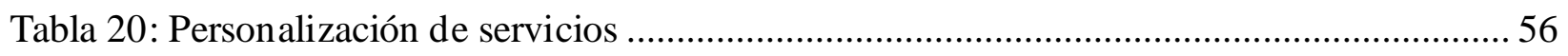

Tabla 21: Conocimiento profesional....................................................................................... 57

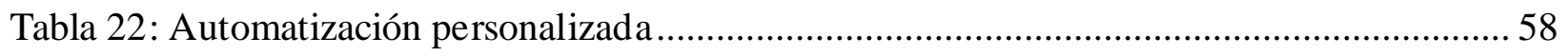




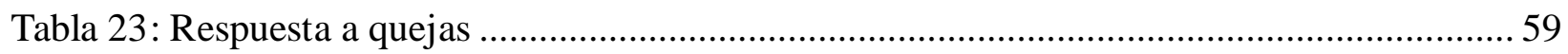

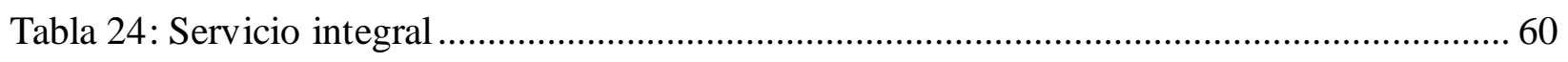

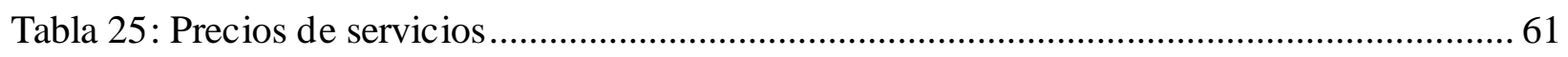

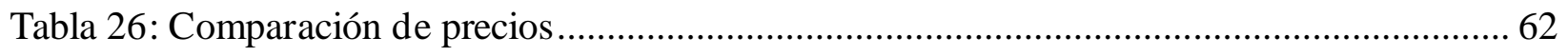

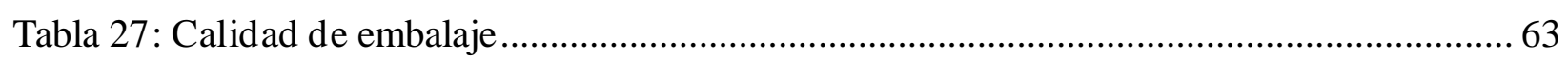

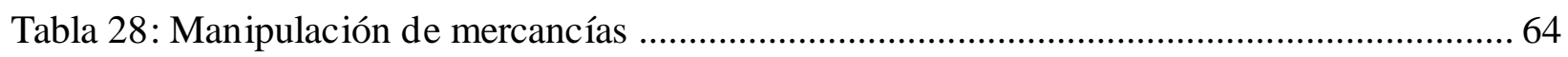

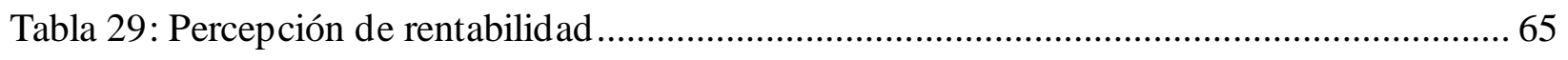

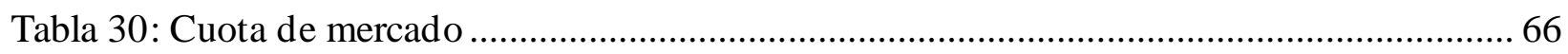

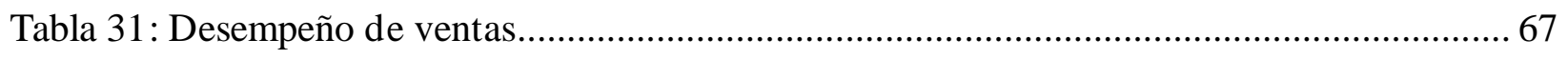

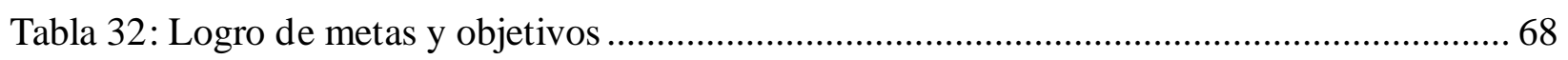

Tabla 33: Prueba de normalidad Shapiro-Wilk - desempeño de la tercerización de los servicios

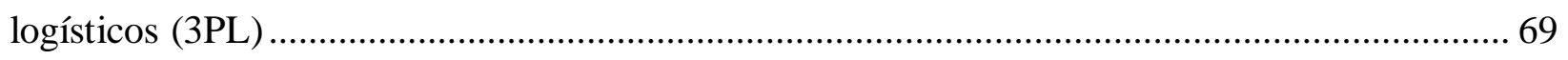

Tabla 34: Prueba de normalidad Shapiro-Wilk - desempeño exportad or................................. 70

Tabla 35: "Prueba de KMO, Bartlett y Método de extracción”- desempeño de la tercerización de

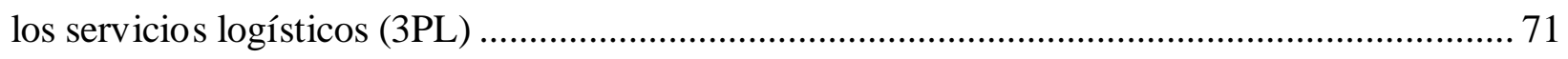

Tabla 36: "Varianza Total Explicada"- desempeño de la tercerización de los servicios logísticos

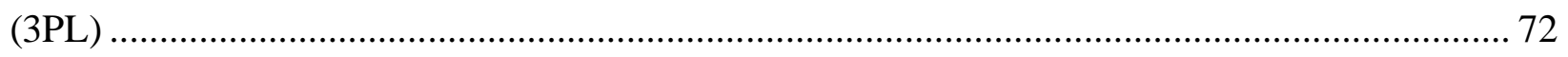

Tabla 37: “Método de rotación: Varimax con normalización Kaiser”- desempeño de la

tercerización de los servicios logísticos (3PL) ................................................................ 73

Tabla 38: "Prueba de KMO, Bartlett y Método de extracción"”- desempeño exportador ............. 74

Tabla 39: "Varianza Total Explicada"- desempeño exportador .............................................. 74

Tabla 40: “Método de rotación: Varimax con normalización Kaiser”- desempeño exportador... 75

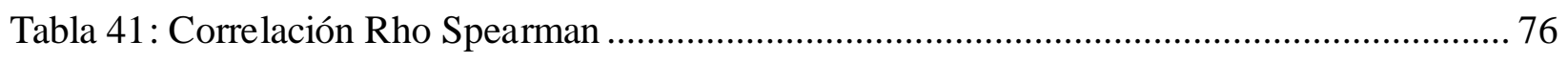


Tabla 42: Hipótesis general - Resultado de Rho de Spearman ....................................................... 77

Tabla 43: Primera hipótesis específica - Resultado de Rho de Spearman...................................... 78

Tabla 44: Segunda hipótesis específica - Resultado de Rho de Spearman ..................................... 79

Tabla 45: Tercera hipótesis específica - Resultado de Rho de Spearman ...................................... 80

Tabla 46: Cuarta hipótesis específica - Resultado de Rho de Spearman......................................... 81

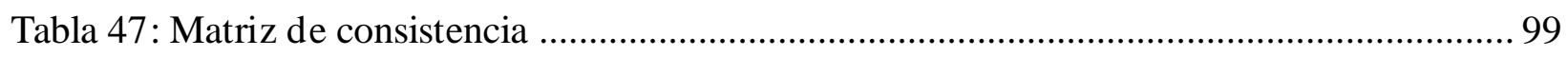

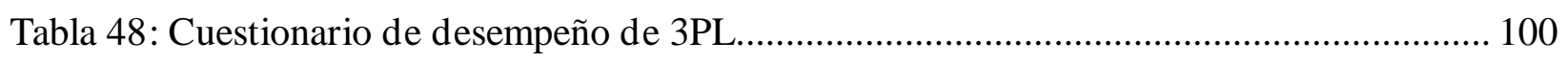

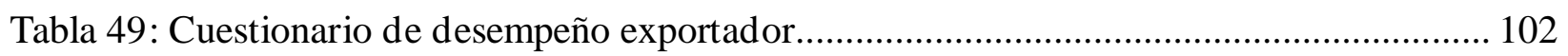

\section{Índice de figuras}

Figura 1. Empresas peruanas de exportación de uvas frescas...................................................... 35

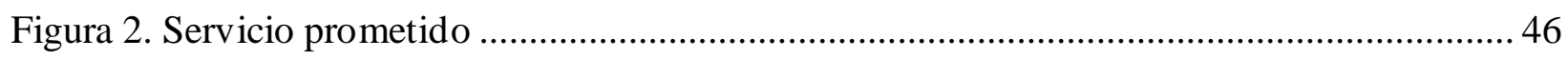

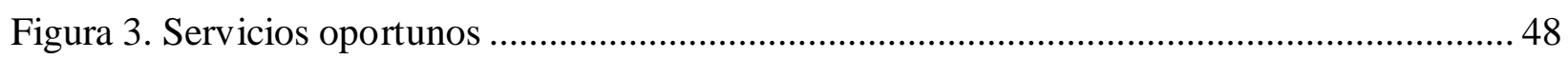

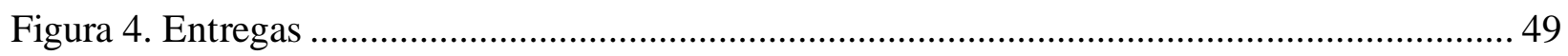

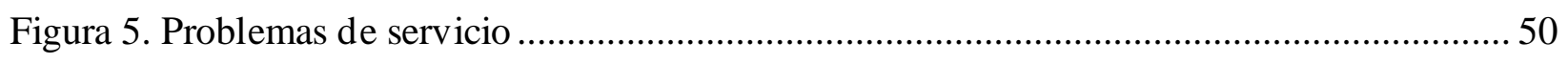

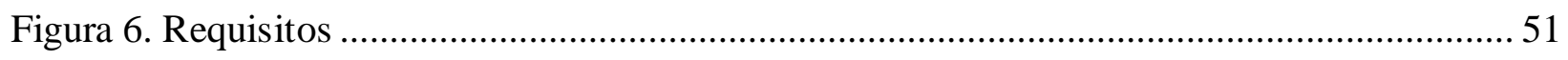

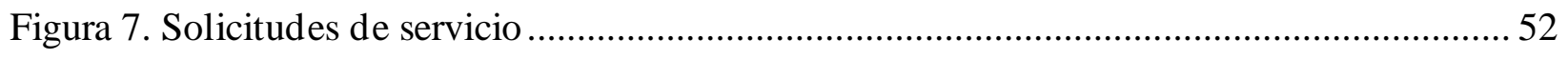

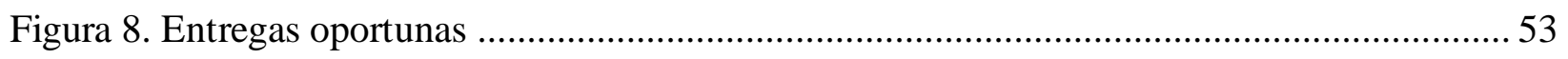

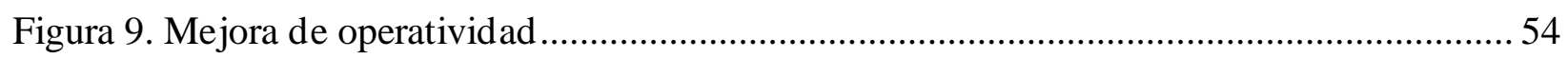

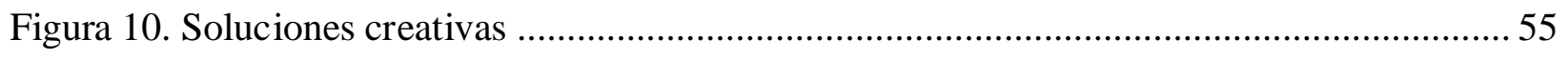

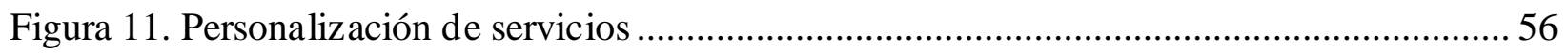

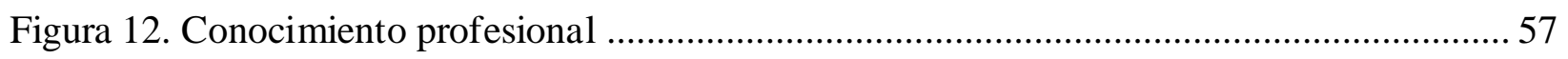

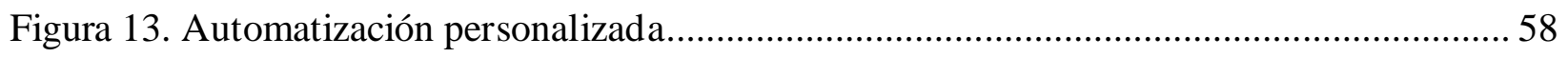

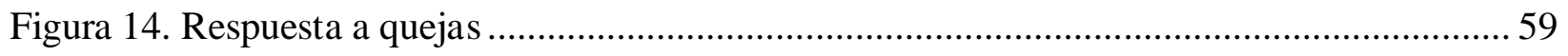




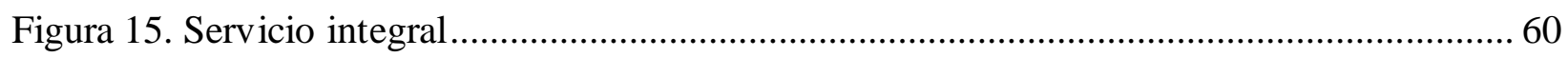

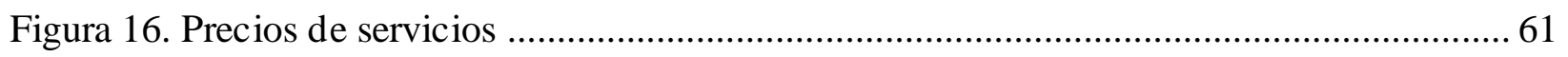

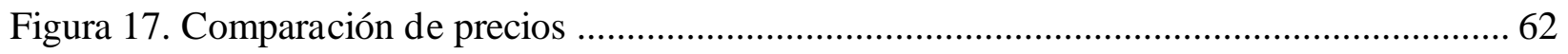

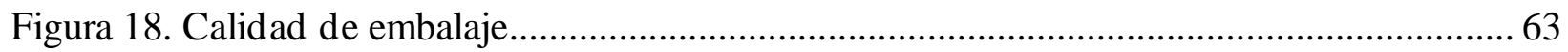

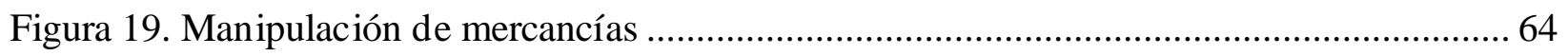

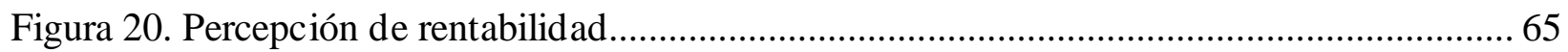

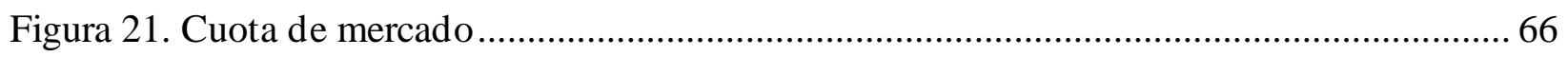

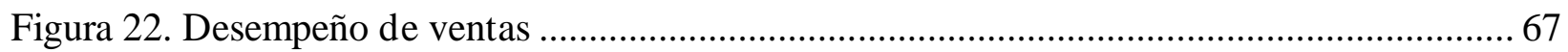

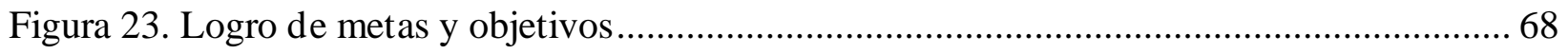




\section{Introducción}

La relación entre la empresa y el tercero proporciona cotizaciones más personalizadas y una gama más amplia de ocupaciones de servicio, que es una relación a largo plazo y de beneficio mutuo. Con el floreciente comercio mundial, la feroz competencia, las mayores expectativas de los clientes y las cadenas de suministro en constante expansión en todo el mundo, los proveedores externos de logística (3PL) desempeñan un papel cada vez más importante en el entorno dinámico y volátil imperante (Yeung, Zhou, Yeung \& Cheng, 2012).

La tendencia reciente de centrarse en la competencia central también ha contribuido a la popularidad de la subcontratación logística, las empresas confían en especialistas en logística externos para entregar productos a los clientes para que puedan concentrarse en sus propios negocios centrales, pueden crear una ventaja competitiva al formar relaciones a largo plazo con los proveedores de 3PL (Gani, 2017).

En la industria de servicios logísticos, los proveedores de 3PL agregan valor a los usuarios al mejorar la eficiencia de las operaciones y/o compartir recursos e información; actuando sobre la información proporcionada por los usuarios, los proveedores de 3PL no solo pueden reducir el inventario de los usuarios y los costos de desabastecimiento, sino que también pueden ayudar a los usuarios a navegar mejor a través de la web de regulaciones gubernamentales y obtener el despacho de aduanas para evitar demoras innecesarias (Domingues, Reis \& Macário, 2015).

Es por estas razones que en este trabajo de investigación se tuvo como objetivo el determinar el impacto del desempeño de la tercerización de los servicios logísticos sobre el desempeño de las empresas MYPES exportadoras de uvas frescas a Estados Unidos. 
En el primer capítulo, se determinan los puntos clave para plantear diferentes sugerencias, se conoce y se plantea el problema en esta investigación. Asimismo, se exponen los antecedentes de diferentes investigadores y se desarrolla el marco teórico, objetivos e hipótesis (generales y específicos).

En el segundo capítulo se explica el método que se usó, haciendo énfasis en el tipo y diseño de investigación, así como la población y la muestra, las variables tomadas en cuenta, los instrumentos de investigación y el procedimiento de recolección de datos.

En el tercer capítulo se muestran el análisis de los resultados de ambos cuestionarios, la contrastación de hipótesis, donde se desarrolló la prueba de normalidad Shapiro-Wilk, el análisis factorial exploratorio, las correlaciones Rho de Spearman y las contrastaciones de las hipótesis, así mismo las discusiones, las conclusiones y las recomendaciones. Terminando con las referencias bibliográficas y los anexos (matriz de consistencia y cuestionarios). 


\section{Capítulo I}

\subsection{Planteamiento de investigación}

\subsubsection{Planteamiento del problema.}

El Perú ha podido posicionarse dentro de los rankings de principales exportadores a nivel mundial, como es el caso de las uvas. Según datos de Aduanas (2020), Perú exportó el año pasado aproximadamente 350.000 toneladas de la uva fresca. Asimismo, los envíos superaron los 900 millones de dólares. "La uva fresca es la principal fruta de exportación del Perú, por delante del arándano, la palta o el espárrago", sostuvo Fernando Cillóniz (2020), presidente de la consultora Inform@cción.

Ica fue la principal región exportadora de uvas con 165,000 toneladas, luego de Piura con 137,000 toneladas. En tercer lugar, se situó Lambayeque con 27.800 toneladas y en cuarto lugar La Libertad con 18.100 toneladas. Desde la perspectiva de las empresas, Cillóniz (2020) resaltó que las cinco primeras en términos de la campaña pasada fueron Sociedad Agrícola Rapel, El Pedregal, Beta, Ecosac y Agrícola Andrea. Hasta el 2019, Estados Unidos ha sido el principal mercado para esta fruta peruana, con 150,000 toneladas de uvas importadas, ya que el sector estaba mostrando una dependencia del mercado chino con la variedad "red globe" (Ministerio de Agricultura y Riego, 2020).

Los proveedores logísticos de terceros (3PL) vienen dominando el mercado de la logística y de la cadena de suministros de diversas empresas, debido más que todo por la influencia en la interacción entre los clientes y las empresas, lo que lleva a tener un impacto importante en el desempeño de las empresas de diferentes sectores que decidan realizar sus procesos logísticos con este tipo de proveedores 3PL, puesto que los problemas logísticos se relacionan cada vez menos con la gestión, infraestructura y con las instalaciones o almacenes, focalizándose en la actualidad 
con la calidad de las entregas que tienen que realizar las empresas, la puntualidad, precios y el tipo de servicio que se ofrece (Honorato, 2016).

En el caso de la puntualidad en la mayoría de las ocasiones, el problema se muestra al momento de contratar un proveedor logístico o tercerización, ya que no está claro cuál es el proceso que las empresas exportadoras necesitan como, el tiempo de entrega de su mercadería. En la actualidad las empresas 3PL deberían de dar una variedad de servicios como el gestionar los pedidos, servicio al cliente, soporte de las ventas, integración de las tecnologías de información, entre otras. Pero en la mayoría de los casos esto es sinónimo de costos elevados para las mismas empresas exportadoras (Honorato, 2016)

En relación con la calidad de la entrega de los productos se observa que son operados de manera inapropiada y su embalaje es de muy mala calidad, produciendo que se pierda tiempo y dinero a las empresas exportadoras. En el caso de los servicios complementarios a medida se encuentra que muchas de las empresas 3PL no responden a los reclamos de los clientes de una forma adecuada, que no actualizan los servicios de tecnologías de la información y que a su vez los trabajadores no poseen la experiencia necesaria ni tienen los conocimientos apropiados (Asociación de Productores y Exportadores de Uva del Perú, 2020).

\subsubsection{Formulación del problema.}

\subsubsection{Problema general.}

¿Cuál es la relación del desempeño de proveedores logísticos de terceros con el desempeño de las empresas MYPES exportadoras de uvas a Estados Unidos 2020?

\subsubsection{Problemas específicos.}

¿Cuál es la relación de la puntualidad de los servicios con el desempeño de las empresas MYPES exportadoras de uvas a Estados Unidos 2020? 
¿Cuál es la relación de los servicios complementarios a medida con el desempeño de las empresas MYPES exportadoras de uvas a Estados Unidos 2020?

¿Cuál es la relación del factor de precios con el desempeño de las empresas MYPES exportadoras de uvas a Estados Unidos 2020?

¿Cuál es la relación de la calidad de entrega con el desempeño de las empresas MYPES exportadoras de uvas a Estados Unidos 2020?

\subsubsection{Justificación de la investigación.}

En este trabajo de investigación el objetivo principal es analizar la relación que tiene el desempeño de la tercerización de los servicios logísticos en el desempeño de las empresas MYPES exportadoras de uvas frescas a Estados Unidos, así como el impacto de las dimensiones del desempeño de la tercerización de los servicios logísticos (calidad de entrega, factor de precios, servicios complementarios a medida y puntualidad de los servicios) en el desempeño exportador de las mismas empresas, con la finalidad de que sus economías se vean beneficiadas, y saber cuál de las dimensiones impacta con mayor fuerza. Esto será de ayuda para poder determinar si el desempeño de la tercerización de los servicios logísticos puede ayudara las empresas exportadoras logren mejorar su desempeño y a su vez a que reduzcan sus gastos.

De acuerdo a las relaciones encontradas entre el desempeño de la tercerización de los servicios logísticos y el desempeño de las empresas MYPES exportadoras de uvas frescas a Estados Unidos, se está en la posición de elaborar estrategias novedosas para que las mismas empresas exportad oras puedan obtener grandes beneficios, basados en las medidas que tomen las personas encargadas en relación a la evaluación del desempeño de la tercerización de los servicios logísticos.

Cabe mencionar que el desempeño de la tercerización de los servicios logísticos puede convertirse en una pieza significativa para el desempeño de las empresas MYPES exportadoras de 
uvas frescas a Estados Unidos, siempre y cuando se utilizara de una manera idónea, por tal razón es que las empresas exportadoras de uvas frescas serán las primeras en beneficiarse con los resultad os que se lleguen a alcanzar en este trabajo de investigación, ya que se les dejara constancia de todos los resultados que se alcancen acerca de la relación que tiene el desempeño de la tercerización de los servicios logísticos con el desempeño de las empresas exportadoras, con la finalidad de que puedan cumplir con sus objetivos y sus metas, así como que vean crecer sus exportaciones.

Así mismo otro de los beneficiados con los resultados que se obtengan en este trabajo de investigación será el sector agroexportador, ya que muchos de los problemas que se presentan en las MYPES exportadoras de uvas frescas a Estados Unidos, se muestran en otras empresas del mismo sector. Asimismo, se puede esperar que se realicen más investigaciones en los próximos años para determinar la relación entre el desempeño de la tercerización de los servicios logísticos y el desempeño exportador de diferentes empresas y sectores en el Perú.

\subsection{Marco referencial}

\subsubsection{Antecedentes.}

Según la investigación de Yeung (2006) titulada "The impact of third-party logistics performance on the logistics and export performance of users: an empirical study" la gestión eficaz de las operaciones logísticas puede ser costosa, los fabricantes tienden a concentrar sus recursos en el ensamblaje de productos y recurren a especialistas externos para todas o parte de sus necesidades logísticas (Stock \& Lambert, 1992). Hum (2000) obtuvo hallazgos similares de compañías que se están moviendo hacia la externalización de sus actividades logísticas para que puedan concentrar sus esfuerzos en sus negocios centrales. Sheffi (1990) reveló que, si bien algunas empresas prefieren centrarse en su negocio principal, el desarrollo de experiencia y 
sistemas dedicados para apoyar las actividades logísticas aún está fuera del alcance de otros. El objetivo principal de este estudio fue investigar la influencia del desempeño de 3PL en el desempeño logístico y de exportación de los usuarios. Con base en los datos recopilados de los exportadores en Hong Kong, esta investigación proporciona evidencia empírica de que la puntualidad de los servicios de los proveedores de 3PL y sus precios están relacionados positivamente con el desempeño logístico de los usuarios. En consecuencia, sugerimos que las empresas presten más atención a la puntualidad del servicio, los precios; y calidad de entrega al seleccionar un proveedor de servicios logísticos. Los proveedores de servicios a su vez deben asegurarse de que su rendimiento y precios sean atractivos para los clientes.

De acuerdo con la investigación de Yeung, Zhou, Yeung y Cheng (2012) denominada "The impact of third-party logistics providers' capabilities on exporters' performance" La relación con terceros es la relación entre la empresa y el tercero, que en comparación con el servicio básico, proporciona cotizaciones más personalizadas y funciones de servicio más amplias. Esta es una relación a largo plazo y de beneficio mutuo (Africk \& Calkins, 1994). Con el floreciente comercio mundial, la feroz competencia, las mayores expectativas delos clientes y las cadenas de suministro en constante expansión en todo el mundo, los proveedores externos de logística (3PL) desempeñan un papel cada vez más importante en el entorno dinámico y volátil imperante (Hsiao, Kemp, Van der Vorst, \& Omta, 2010; Murphy \& Daley, 2001). Antes de enviar los cuestionarios de la encuesta, realizamos un estudio piloto con seis empresas, a través del cual verificamos la relevancia de los indicadores de medición para sus construcciones correspondientes, la adecuación de la redacción del cuestionario y la claridad de las instrucciones para completar la encuesta. Luego seleccionamos al azar 350 empresas exportadoras de las listas compiladas por el Consejo de Desarrollo Comercial de Hong Kong. Una de las principales preocupaciones de RBV es cómo una 
empresa desarrolla sus recursos para crear su posición competitiva, lo que, a su vez, afecta su desempeño (McIvor, 2009). Basado en el SEM deRBV, combinado con datos de 150 exportadores en Hong Kong y la región del Delta del Río Perla, analiza la relación entre el posicionamiento estratégico de los exportadores de los proveedores 3PL, las capacid ades de los proveedores 3PL y las ventajas competitivas de los exportadores y el desempeño de exportación del exportador. Los resultados de SEM muestran que (1) el posicionamiento estratégico de los exportadores de los proveedores 3PL tiene relaciones positivas significativas tanto con la capacidad básica de los proveedores de 3PL como con la capacidad aumentada, (2) solo la capacidad aumentada de los proveedores de 3PL tiene una relación positiva significativa con la ventaja competitiva de los exportadores, y (3) la ventaja competitiva de los exportadores tiene una relación positiva significativa con su propio desempeño exportador.

Hausman, Lee y Subramanian (2013) en su investigación denominada "The impact of logistics performance on trade."Se tuvo como propósito calibrar el efecto de métricas logísticas específicas (costo, tiempo y confiabilidad) en los patrones comerciales bilaterales. Nos centramos en el tiempo y el costo de importar y exportar un contenedor FCL típico de 20 pies con productos de valor medio para 80 países. También incluimos, por primera vez, una dimensión de tiempo más compleja: la variabilidad en el tiempo de entrega. La entrega confiable de bienes dentro de plazos limitados, con una incertidumbre mínima, puede ser incluso más importante que el tiempo promedio de entrega para la capacidad de una empresa de competir en regímenes justo a tiempo. El documento primero analiza datos completos de encuestas para el desempeño logístico global de 80 países. Los datos del comercio mundial se han tomado de la División de Estadística de las Naciones Unidas, base de datos de estadísticas de comercio de productos básicos de las Naciones Unidas, ajustada a dólares estadounidenses internacionales por paridad de poder adquisitivo. 
Según el grupo de datos elaborado por el Grupo del Banco Mundial, el conjunto de datos tiene tiempo, costo y un número específico de indicadores cuantitativos del desempeño logístico que cambian con el tiempo. Se descubre que el desempeño logístico está relacionado de manera estadísticamente significativa con el volumen de comercio bilateral entre 80 naciones. Además, se estima el impacto de la mejora del desempeño logístico en el crecimiento de la comercialización. Los descubrimientos pueden incitar a las instituciones privadas y públicas que poseen control indirecto o directo sobre el desempeño logístico a enfocarse en las variables que tienen más probabilidades de aumentar la capacidad de su país para pugnar en la economía global actual.

La investigación de Leuschner, Carter, Gold sby y Rogers (2014) titulada “Third-party logistics: a meta-analytic review and investigation of its impact on performance." tuvo dos objetivos principales. Empezand o con la profundización en la literatura existente de 3PL, investigando el impacto del servicio al cliente de 3PL en el desempeño de la empresa, con un examen de la estructura de gobierno relacional de 3PL-cliente como un antecedente potencial del servicio al cliente. Aplicamos tanto la economía de costos de transacción como la visión basada en recursos para desarrollar hipótesis que propongan este conjunto de relaciones. El segundo objetivo de la investigación es identificar otras construcciones clave que rodean la relación 3PL-cliente que se han estudiado en la literatura existente e investigar los patrones de posibles relaciones entre estas construcciones. El valor de hacerlo será una mejor comprensión entre la comunidad de investigación sobre las relaciones que aún no se han examinado, así como las relaciones que se han estudiado lo suficiente como para no justificar una investigación futura, al menos de manera lineal y directa. La muestra de fuentes primarias se reunió en dos pasos. Primero, se realizó una revisión manual de cuatro revistas de logística / gestión de la cadena de suministro bien conocidas que se centran en la investigación empírica (International Journal of Logistics Management, 
International Journal of Physical Distribution and Logistics Management, Journal of Business Logistics y Journal of Supply Chain Management ) Se recopilaron e inspeccionaron estudios empíricos de la industria 3PL para buscar palabras clave apropiadas para la búsqueda integral de palabras clave. Se seleccionaron cinco palabras clave: "3PL", "logística de terceros", "tercerización de logística", "servicio de logística" y "proveedor de servicios delogística". La base de datos de artículos contenía 864 artículos, y de estos, 241 artículos fueron seleccionados para un examen más detallad y ya que eran artículos que usaban una muestra empírica de 3PL e informaban resultados cuantitativos. Este documento describe la dirección futura de la investigación 3PL basada en los resultados de la investigación.

Según la investigación de Puertas, Martí y García (2014) titulado “Logistics performance and export competitiveness: European experience." En la actualidad, el comercio internacional requiere la organización y sincronización de flujos a través de nodos y redes estratégicas que proporcionan almacenamiento, conservación o cualquier otro tipo de servicio de valor agregado que requieren las características de los bienes transportados. Ha habido muchas mejoras: terminales, rutas regionales y de larga distancia, infraestructuras (ampliación y modernización de puertos y aeropuertos, junto con amplias vías de acceso a los nodos logísticos) y plataformas logísticas y centros de distribución han ubicado la oferta, la demanda y las áreas óptimas para inter modalidad en mente. Todas estas mejoras han facilitado notablemente el comercio de bienes y también han llevado a una reducción significativa en los costos. El marco teórico examinado es la base perfecta para estudiar el efecto del desempeño logístico en los flujos comerciales, a pesar de que la falta de disponibilidad de variables (o variables proxy) que pueden incluirse ha retrasado este análisis. Por esta razón, el LPI publicado por el Banco Mundial es una nueva fuente valiosa que amplía el modelo de gravedad al incorporar un determinante de las exportaciones de los 
Estados miembros de la UE. Como se mencionó anteriormente, este índice es uno de los referentes para comparar la logística de los países. En resumen, podemos concluir que los países menos desarrollados en términos de logística están haciendo un esfuerzo significativo para mejorar su situación, que está impulsando el comercio internacional y su propio crecimiento económico. Cuando el Banco Mundial publique los nuevos datos de LPI en un futuro próximo, sería interesante verificar si el progreso evidente mostrado durante el período 2005-2010 continúa y es coherente con el clima económico de los países incluidos en la muestra.

La investigación de Maes (2015) titulada "Contribution of third-party-logistics providers to export performance.” Está organizado de la siguiente manera: primero, tomar el objetivo principal de esta investigación como introducción, luego revisar la literatura sobre exportaciones y logística de terceros; a continuación, una descripción de los métodos utilizados en la investigación, y la siguiente discusión de los resultados de la investigación cualitativa. Se discutió la percepción de actividades transfronterizas, continuado de las tres etapas de creación de acciones de exportación, luego se explicó la subcontratación de actividades que no son esenciales, y se finalizó con la aportación de proveedores logísticos externos al desempeño exportador de sus empresas clientes. Se reconocieron las limitaciones y se hicieron algunas sugerencias para investigaciones futuras.

Para Karia, Wong, Asaari y Lai (2015) en su trabajo nombrado "The effects of resource bundling on third-party logistics providers' performance." El reciente mercado global halal ha aumentado la demanda en la industria halal, lo que ha traído nuevos desafíos a los proveedores de logística de terceros (3PL) en Malasia. Los clientes de 3PL esperan nuevos servicios llamados servicios halal cuando los necesitan, y que a veces se extienden más allá de las capacidades de 3PL. En consecuencia, los 3PL se enfrentan a una nueva situación dinámica: cada cliente tiene requisitos halal únicos y diferentes. Esto crea desafíos estratégicos para que los 3PL exploten los 
recursos logísticos de manera más productiva como un recurso competitivo en un entorno tan complejo e impredecible. La muestra para esta investigación se extrae al azar del Directorio de Logística de Malasia. De las 354 empresas 3PL, 123 participaron y completaron los cuestionarios, lo que representa una tasa de respuesta del 35\%. Los resultados muestran que el excelente desempeño competitivo de la empresa de logística 3PL proviene de la interfase de gestión de la demanda, los recursos de comprensión y la tecnología avanzada y las capacidades de los equipos. Los efectos de rendimiento de dichos recursos se ven reforzados por otros recursos, como los recursos relacionales y la tecnología y equipos básicos. Si bien algunos estudios anteriores indican que algunos recursos podrían agruparse para mejorar el rendimiento de una empresa 3PL, esta investigación identifica y explica aún más cómo se pueden agrupar diferentes recursos, avanzando el uso de la teoría de la visión basada en recursos (RBV).

El trabajo de investigación de Skender, Host y Nuhanovic (2016) nombrada "The role of logistics service providers in international trade." Tuvo como objetivo el analizar los diferentes tipos de proveedores / intermediarios de servicios logísticos, las maneras en que se clasifican, sus funciones, la forma en que facilitan las operaciones comerciales para las empresas internacionales y, lo más importante, su influencia en el comercio internacional. El objetivo del documento es analizar los proveedores de servicios logísticos / diarios intermedios más importantes e identificar claramente sus tareas y objetivos. Los mediadores logísticos tienen diversas formas y nombres, pero todos poseen semejante objetivo: en cierta medida, brindar asistencia a un precio a las empresas en el almacenamiento, transporte, distribución de la mercancía y envío desde el proveedor hasta el consumidor final o comprador. Este estudio se realiza en relación a mediadores logísticos en el comercio internacional, como los transitarios internacionales, 3PL, 4PL o LLP. El propósito de este documento es analizar los diferentes tipos de intermediarios logísticos, su 
funciones, clasificación y la forma en que promueven las operaciones comerciales de las empresas extranjeras, y señalar los beneficios de sus promesas y las similitudes y diferencias entre ellos.

La investigación de Nuhanović (2016) titulada "The role of logistics service providers in international business." Esta tesis de maestría proporciona el análisis de los inicios de la logística, la evolución dela situación actual y algunos aspectos decómo puede cambiar en el futuro. La tesis muestra las posibles formas en que los intermediarios logísticos pueden hacer que los negocios internacionales sean mucho más fáciles para diferentes empresas y entidades. Al comienzo de la tesis introducida se encuentran los puntos básicos que deben conocerse sobre el desarrollo logístico y la perspectiva moderna del mismo. Después de comprender qué significa realmente la logística para el mundo de los negocios internacionales, se presentan los intermediarios. A lo largo de la tesis, estos intermediarios se denominan "proveedores de servicios logísticos". En las siguientes páginas se presentan muchos tipos de proveedores de servicios logísticos. En la literatura siempre hay diferentes clasificaciones de tipos y formas de estos intermediarios. Pero, terminan siend o muy similares solo por ser diferentes en términos. En esta tesis de maestría, la clasificación se realiza de acuerdo con H.J. Schramm y K.N. Gourdin, los cuales mencionan aspectos similares de este tema. H.J. Schramm habla sobre intermediarios comerciales, financieros, de transporte y logística y proveedores de servicios. En cuanto a K.N. Gourdin, su clasificación incluye agentes de carga internacionales, transportistas comunes que no operan buques, compañías de gestión de exportaciones, compañías de comercio de exportación, empacadores de exportación y agentes de aduanas. La sección que explica el agente de carga internacional queda para el final, ya que son uno de los intermediarios más conocidos e importantes. Los agentes de carga organizan el movimiento de mercancías y proporcionan otros servicios relacionados con las operaciones logísticas. Pueden actuar como intermediarios, pero también como agentes. Es importante 
mencionar también la evolución de los transitarios que llamamos hoy 3PL, 4PL o incluso 5PL. Los proveedores de servicios logísticos son muy importantes porque crean e implementan una serie de soluciones logísticas para los clientes, desde la oferta de servicios físicos hasta el punto en que agregan valor a los productos.

Según la investigación de Gani (2017) titulada "The logistics performance effect in international trade." El aumento continuo del comercio mundial es dependiente de la eficacia de las organizaciones de soporte al comercio (como los servicios logísticos). Si bien la logística juega un papel indispensable en el sostén a las actividades comerciales, generalmente los profesionales del comercio tienen un inferior nivel de observación e investigación sobre políticas comerciales. Este artículo examina el impacto del desempeño logístico en el comercio internacional. El análisis está basado en el desempeño logístico general y métricas categorizadas para datos específicos de logística para una gran cantidad de países/regiones. El análisis empírico implica la evaluación de ecuaciones estándar de importación y exportación, incluidos los indicadores de desempeño logístico. Los resultados exponen que el desempeño logístico general se relaciona positivamente con las importaciones y exportaciones, lo cual es estadísticamente significativo. Este análisis se puede ampliar investigando si la particularidad de la logística es importante para el comercio internacional. Los resultados muestran que las ventajas de varios aspectos del desempeño logístico tienen efectos positivos estadísticamente significativos, principalmente en las exportaciones. La principal implicación política es que la inversión continua en infraestructura y servicios logísticos puede tener un impacto positivo en el comercio internacional.

De acuerdo con los investigadores Barakat, Haikal, Ali y Eid (2018) en su trabajo denominado "Enhancing Exports through Managing Logistics Performance: Evidence from Middle East and African Countries." Las actividades logísticas y sus costos influyen en las operaciones comerciales 
diarias y, en última instancia, influyen en la economía del país. Si los países logran encargarse eficazmente del desempeño logístico, entonces lograrán participar mejor a nivel internacional. El objetivo principal de esta investigación es utilizar modelos de regresión para estudiar la relación entre el índice de desempeño logístico y su composición y exportaciones, con un enfoque en países de Oriente Medio y África. Los resultados de este artículo muestran que el índice de desempeño logístico ha mejorado de manera positiva las exportaciones del país. También, los mecanismos de los indicadores de desempeño logístico incluyen: infraestructura, aduanas, la puntualidad y transporte internacional poseen un impacto significativo, además de la competencia, calidad logística, seguimiento y ubicación. El documento tiene como objetivo apoyar a los líderes de políticas económicas para mejorar la toma de decisiones económicas en el sector logístico.

\subsubsection{Marco teórico.}

\subsubsection{Tercerización de los servicios logísticos.}

\subsection{Definición.}

El término 3PL siempre se ha usado indistintamente con otros términos, como logística de contratos, subcontratación logística, distribución de contratos y alianza logística (Gao, 2013). Cualquiera sea el nombre que se adopte, todos tienen el mismo significado, el de la práctica organizativa de subcontratar parte o todas las actividades logísticas que se realizaron previamente en la empresa (Gadde \& Hulthén, 2009).

En los últimos años, 3PL ha recibido considerable atención tanto de académicos como de profesionales, lo que ha resultado en un auge de la investigación y los escritos en el campo, sin embargo, en la práctica, 3PL puede significar el abastecimiento tradicional de actividades simples, como la "subcontratación". transporte y/o almacenamiento, o, en otros casos, actividades más sofisticadas, como externalizar toda la función logística a un proveedor de servicios externo 
(Hilletofth, Hilmola \& Finland, 2010). Esto ha provocado que surjan algunas definiciones diferentes de 3PL desde diferentes perspectivas en la literatura, que se pueden agrupar en tres categorías, a saber, amplia, estrecha e híbrida. Estas definiciones pueden ayudar a explicar los diversos ámbitos atribuidos a 3PL (Knemeyer \& Murphy, 2004).

\section{La amplia categoría}

Gadde y Hulthén (2009) definieron 3PL como “el uso de compañías externas para realizar funciones logísticas que tradicionalmente se han realizado dentro de una organización. Las funciones realizadas por la tercera parte pueden abarcar todo el proceso logístico o actividades seleccionadas dentro de ese proceso". Esta definición amplia tiende a sugerir que las empresas podrían externalizar cualquier forma de actividad logística que se llevara a cabo internamente a un

proveedor de servicios 3PL, ya sea en una instancia de abastecimiento tradicional o una instancia más compleja de subcontratación.

\section{La categoría estrecha}

Knemeyer y Murphy (2004) definieron 3PL como "una relación entre un remitente y un tercero, que, en comparación con los servicios básicos, tiene of ertas más personalizadas, abarca un número más amplio de funciones de servicio y se caracteriza por una relación a largo plazo y más beneficiosa para ambas partes". Esta definición limitada parece vincular a 3PL con ciertas características distintivas de las relaciones de outsourcing logístico, y en ella, también señalaron lo que distingue a 3PL de las activid ades de outsourcing tradicionales, es decir, la provisión de una gama más amplia de servicios, una relación contractual a largo plazo y servicios logísticos personalizados.

\section{La categoría híbrida}


Hilletofth y Hilmola (2010) definieron 3PL como "relaciones entre interfaces en la cadena de suministro y proveedores logísticos de terceros, donde se ofrecen servicios logísticos, desde los básicos hasta los personalizados, en una relación a corto o largo plazo, con el objetivo de efectividad y eficiencia". Esta definición está más o menos en el medio de las más angostas y amplias, por la sencilla razón de que el autor no definió el alcance de 3PL, ya sea simplemente servicios personalizados y si las relaciones a corto y largo plazo se consideran 3PL. Sin embargo, mencionó que el objetivo de 3PL es lograr un resultado eficaz y eficiente tanto para los clientes como para los proveedores de servicios.

\subsection{Clasificación.}

Según Murphy y Wood (2008), la decisión de usar 3PL podría ser más táctica que estratégica. Afirmaron además que, cuando son tácticas, las organizaciones generalmente tienen una red de distribución ineficaz, una incapacidad para controlar los costos internos, una fuerza de trabajo costosa o inflexible, instalaciones de almacén obsoletas o sistemas de información obsoletos. Continuaron argumentando que cuando la decisión es estratégica, está impulsada por la idea de que la transformación debe tener lugar. Llegaron a la conclusión de que debería reconocerse que una organización no tiene suficientes capacid ades internas para abordar los problemas en cuestión.

Según García-León y Bermeo-Andrade (2011), el suministro de servicios logísticos es reconocido por cuatro tipos de operadores logísticos que se describen a continuación:

Proveedor de logística de primera parte (1PL): es una empresa que realiza su propia actividad logística;

Proveedor de logística de segunda parte (2PL): es un proveedor de servicios que no requiere servicios altamente especializados y ofrece servicios de transporte y almacenamiento; 
Proveedor de logística de tercera parte (3PL): es reconocido como un proveedor de logística integrado, que ofrece una gama de servicios de valor agregado además del transporte y almacenamiento, puede cumplir con actividades de mantenimiento, control de inventario, servicios de aduanas, logística inversa, procesamiento de pedidos, entre otros:

Proveedor de logística de cuarta parte (4PL): es conocido como el coordinador de logística y puede llevar a cabo operaciones internacionales en exportaciones e importaciones, contratar los servicios de otros operadores y administrar eficientemente la logística de principio a fin.

\subsection{Objetivos.}

\section{Centrarse en las competencias básicas}

La competencia central de un negocio son sus joyas de la corona, por lo que debe ser cuidadosamente cuidado y cuidado (Hafeez, Zhang \& Malak, 2002). Quinn (1999) definió las competencias básicas como no ser productos o aquellas cosas que hacemos relativamente bien, sino que son esas actividades: "generalmente actividades o sistemas de servicios basados intelectualmente, que la compañía realiza mejor que cualquier otra empresa, son los conjuntos de habilidades y sistemas que una empresa hace en los mejores niveles del mundo y a través de los cuales una empresa crea un valor excepcionalmente alto para los clientes”. Razzaque y Sheng (1998) afirmaron que, a través de sus competencias básicas, las empresas pueden ganar eficiencia y estabilidad y reducir costos al enfocar sus recursos en lo que mejor hacen.

\section{Para responder a los desafíos de la globalización}

Además, la subcontratación es claramente una actividad económica importante y ciertamente una respuesta clave a la globalización. El outsourcing es un término frecuente en la literatura de la globalización. Young (1994) descubrió que las compañías líderes ya han reconocido oportunidades para aumentar la participación en el mercado y los ingresos y lograr la eficiencia a través del 
abastecimiento global y la fabricación en el extranjero, y por lo tanto, a pesar de que la logística global es una actividad mucho más compleja que la de hacerlo a nivel nacional, para estos negocios, se ha convertido en un objetivo necesario. En la misma línea, Wouters (2010) señaló que, dado que la globalización se ha convertido en una fuerza importante que da forma a las estrategias comerciales, y ha llevado a las empresas a diseñar productos que se adapten al mercado global en lugar de a un país o pocas regiones, ha llegado a El hecho de que la falta deconocimiento específico de aduanas, regulaciones fiscales e infraestructura de los países seleccionados ha llevado a esas mismas empresas internacionales a beneficiarse de la especialización de los proveedores de servicios 3PL. Es cierto que la globalización es uno de los principales impulsores de la industria 3PL, especialmente en mercados emergentes como China. Los proveedores de servicios 3PL que tienen presencia global pueden ayudar a las empresas a expandir su alcance geográfico debido a su familiaridad con los gobiernos locales, las estructuras reguladoras, las normas comerciales y las culturas de diferentes países (Mitra \& Bagchi, 2008). Según Wang, Zantow, Lai y Wang (2006), algunas empresas redujeron los costos de logística en un 30\% a 40\% y racionalizaron en gran medida sus procesos logísticos globales.

\section{Mejorar la rentabilidad}

Quinn (1999) indicó que históricamente, cuando las empresas se desarrollan, la tentación es contratar más personal, ampliar las instalaciones y llevar más negocios a la empresa, donde las empresas esperan controlar mejor los costos, mientras que, en el entorno empresarial actual, hay innumerables oportunidades para que las empresas aumenten sus ganancias a través de la subcontratación. Además, la competencia es más intensa que nunca y los márgenes de beneficio están disminuyendo, por lo que las empresas deben utilizar proveedores de servicios 3PL para 
reducir los costos de logística a fin de mantener la rentabilidad a un nivel razonable (Huang \& Kadar, 2002).

Razzaque y Sheng (1998) explicaron que la tercerización, si se usa adecuadamente, puede contribuir a las ganancias a través de:

- permitir a los usuarios obtener una ventaja competitiva

- agregar valor medible a los productos

- mejorar el servicio al cliente

- ayudar a abrir nuevos mercados y proporcionar recursos dedicados (p.92)

Jiang, Frazier y Prater (2006) agregaron varias otras formas en que los proveedores de servicios 3PL pueden ayudar al aumento de la rentabilidad:

- Proporcionan personal en función de la necesidad, evitando así la necesidad de costosos beneficios para el personal.

- Pueden poner las mejores capacidades y tecnología a disposición de la empresa sin que la empresa tenga que pagar por ellas.

- Pueden tener instalaciones en todo el mundo para usar cuando sea necesario sin que la empresa establezca costosas instalaciones logísticas.

Bettis, Bradley y Hamel (1992) también descubrieron que situaciones comerciales como perder ventaja competitiva y ver esto reflejado en una disminución de la rentabilidad también conducen a la subcontratación.

\section{Reducir la inversión de capital}

La reducción de la inversión de capital es otro motor importante para las decisiones de subcontratación. Como explicó Sangam (2007), la externalización de logística cubre diversas actividades, como la externalización de instalaciones, equipos e infraestructura, y al externalizar 
los aspectos correctos, las empresas pueden pasar de ser basadas en activos a no basad as en activos, lo que luego genera más capital disponible para las competencias básicas y, a su vez, aumenta el rendimiento de los activos. Esto es particularmente cierto cuando las empresas eligen un proveedor de servicios 3PL basado en activos, "que ofrecen servicios de logística física dedicados principalmente mediante el uso de sus propios activos, generalmente una flota de camiones o un grupo de almacenes o ambos" (Razzaque \& Sheng, 1998).

\section{Para reducir costos}

El tema de la reducción de costos se puede encontrar en casi todos los artículos sobre 3PL, lo que refleja directa y obviamente su importancia para los usuarios de 3PL. De hecho, según Huang y Kadar (2002), la necesidad de reducir los costos o la cantidad de capital invertido sigue siendo la principal prioridad para los transportistas que externalizan sus actividades logísticas, como señaló un director de fabricación de electrodomésticos: "la competencia es feroz y los márgenes están disminuyendo, por lo que estamos buscando proveedores de logística externos para reducir nuestros costos de logística con el fin de mantener la rentabilidad”. Además, más de dos tercios (69\%) de los proveedores de servicios 3PL consideraron que los cargadores están más motivados por el precio que por cualquier otra cosa. Según Mitra y Bagchi (2008), la mayoría de las empresas que tienen relaciones comerciales con 3PL han sido positivas o muy positivas sobre la cantidad de costo reducido, debido a que los proveed ores de servicios 3PL, como resultado de la consolidación de envíos provenientes de diferentes fuentes, disfrutan de economías de escala, lo que les permite utilizar mejor la capacidad y distribuir los costos de logística, y puede resultar en ahorros sustanciales en las operaciones de logística para cada negocio contratado, todo lo cual puede ser difícil de lograr para un negocio individual. Wouters (2010) también expresó una opinión similar, quien dijo que el principal beneficio de usar 3PL es aumentar el valor neto a través de los costos 
reducidos que resultan de la economía de escala y la economía de alcance. Parashkevova (2007) ha cuantificado la reducción de costos de las empresas que usan 3PL en Europa en términos de las estadísticas que se muestran a continuación:

- reducción de los costos de gestión de inventario en un 15-30\%

- reducción de los costes logísticos en un 8,2\%.

- reducción de activos logísticos fijos al 15,6\%

- redujo la duración del ciclo de pedido promedio de 10.7 a 8.4 días.

- reducción de los inventarios generales en un 5,3\%.

\section{En la mejora de la eficiencia operativa}

Muchas empresas exitosas han adoptado una estrategia de justo a tiempo (JIT) de centrarse en las áreas en sus competencias básicas, contratar áreas no centrales a un proveedor externo para mejorar la eficiencia operativa, y las funciones logísticas son normalmente el primer candidato para la subcontratación (Spencer, Rogers \& Daugherty, 1994). Esto se debe a que, en la filosofía JIT, el control de inventario y logística se ha vuelto aún más crucial para las operaciones de fabricación y distribución. Las complejidades y los requisitos más altos de la operación de la cadena de suministro en un entorno JIT están empujand o a quienes lo adoptan a complementar sus propios recursos y experiencia con los de los servicios 3PL (Razzaque \& Sheng, 1998), ya que los proveedores de servicios 3PL están dispuestos a invertir en recortes tecnologías de punta y nuevos equipos para mejorar su ventaja competitiva y aumentar la eficiencia operativa con el fin de ganar más contratos de los cargadores y lograr, al final, eficiencia con dos motivos, en primer lugar, ganar más contratos y, en segundo lugar, lograr una escala económica. Como señaló Wang (2010), la colaboración con los proveedores de 3PL es un elemento clave, ya que, debido a ello, los 
jugadores de nivel superior pueden operar el sistema JIT con mayor frecuencia de entrega, menor tamaño de lote de entrega, etc.

\subsubsection{Desempeño de la tercerización de los servicios logísticos (3PL).}

\subsection{Definición.}

A medida que el mercado global se vuelve más sofisticado, la diferencia entre las operaciones que una empresa quiere lograr y lo que una empresa logra realizar internamente está aumentando. La tendencia entre las empresas de todos los sectores es externalizar sus actividades logísticas que son más costosas y requieren más tiempo para entidades externas, es decir, en logística, proveedores de logística externos (3PL) (Lambert et al., 2006). Las empresas 3PL brindan una variedad de servicios relacionados con la logística, que incluyen, por ejemplo, transporte, almacenamiento, distribución y consolidación de carga. La externalización de estas actividades permite a las empresas reducir costos y centrarse en sus actividades principales, donde crean una ventaja competitiva sobre los adversarios (Christopher, 2005). Sin embargo, elegir la asociación adecuada suele ser una decisión compleja.

La literatura muestra que la toma de decisiones de outsourcing generalmente está altamente estructurada (Aktas, Agaran, Ulengin \& Onsel, 2011; Feng, Fan \& Li, 2011; Fill \& Visser, 2000; Nielsen, Mitchell \& Nørreklit, 2014). La selección de empresas de outsourcing implica varias etapas (observación, recopilación de datos, análisis y discusión) con respecto a la evaluación de la información contable junto con datos sobre calidad, servicio al cliente y flexibilidad, por nombrar algunos. Por lo tanto, el sistema de medición del desempeño juega un papel importante para facilitar la decisión de subcontratación, ya que proporciona datos históricos de desempeño con respecto a varias categorías (por ejemplo, puntualidad, calidad y servicio al cliente) que ofrecen una retroalimentación exhaustiva sobre los socios de subcontratación. A pesar de su utilidad, existe 
un cuerpo limitado de literatura sobre el sistema de medición de desempeño de 3PL, en particular con respecto a los servicios de tercerización de 3PL.

Yeung (2006) precisa que el desempeño de 3PL como la manera en cómo se mide las actividades del outsourcing que of recen las empresas encargad as de los procesos logísticos de otras empresas. El desempeño de 3PL puede definirse como la medida de los servicios de un proveedor de servicios logísticos únicos o múltiples de las actividades logísticas de una empresa cliente por contrato (Lai, 2004). De acuerdo con Virum (1993) el desempeño de la tercerización de los servicios logísticos son la forma en que se califican los servicios ofrecidos por un intermediario en el canal logístico que se ha especializado en proporcionar, por contrato, durante un período de tiempo determinado, todas o un número considerable de actividades logísticas para otras empresas. Harding (1998) precisa que el desempeño de 3PL como la medida de los servicios de una empresa que por lo menos proporciona gestión de transporte y almacenamiento. El desempeño de desempeño de la tercerización de los servicios logísticos es la forma en que mide la eficiencia y eficacia de los servicios prestados y variados de una empresa con la finalidad de reducir costos, enfocarse en las actividades de diferenciación centrales y, en consecuencia, a permitirles alcanzar niveles más altos de desempeño (Domingues, Reis \& Macário, 2015).

\subsection{Teorías.}

\section{Teoría de la visión basada en recursos}

La teoría de la visión basada en recursos de la empresa trata a una empresa como un paquete de capitales (Barney \& Clark, 2007). Por lo tanto, para mejorar el rendimiento operativo, la teoría afirma que una organización necesita asegurar un paquete eficiente y el flujo del tipo correcto de recursos de su entorno. El enfoque basado en recursos se concentra en aclarar las circunstancias que deben existir para que los recursos den lugar a una ventaja competitiva sostenida. También 
afirma que la ventaja competitiva resulta de la propiedad de activos inimitables, innovaciones y barreras de recursos que permiten a una organización mejorar fácilmente la posición en el mercado. La propiedad en este caso se refiere al "control operativo de" los recursos frente al "título legal de". Estos recursos también son valiosos, raros, únicos y difíciles de sustituir (Barney, 2001).

Estos recursos son activos clave en lo que respecta a las rutinas internas superiores y las actividades de gestión, incluidos el transporte, el almacenamiento, la gestión de inventario y los problemas relacionados con la cantidad de lotes, el procesamiento de pedidos y el servicio al cliente. También es importante tener en cuenta que el perfil de recursos de las organizaciones tiende a influir en la medida en que se externaliza todo o parte del proceso logístico. Bromiley y Rau (2016) señalaron que una visión basada en los recursos es particularmente apropiada para examinar el outsourcing logístico porque las empresas esencialmente usan el outsourcing como una estrategia para obtener acceso a los valiosos recursos de otras empresas.

La teoría de la vista basada en recursos se ha utilizado en la literatura estratégica para el análisis del rendimiento empresarial. La capacidad de implementar efectivamente una estrategia de outsourcing logístico se puede considerar como un activo intangible, que representa un mecanismo por el cual las organizaciones aprenden y acumulan nuevas habilidades y capacidades (Mclvor, 2009). Por ejemplo, Mwangangi, 2016 señaló que la teoría RBV es apropiada para las investigaciones de la cadena de suministro y la gestión logística. Parte de la literatura utilizó la teoría RBV para examinar el impacto del flujo de información en la ventaja competitiva de los proveedores de 3PL (Lai, Li, Wang \& Zhao, 2008), mientras que otros examinaron los efectos de las capacidades logísticas en el rendimiento de la empresa (Yang, Marlow \& Lu, 2009). En consecuencia, una visión basada en los recursos es particularmente apropiada para examinar el outsourcing logístico porque las empresas esencialmente usan el outsourcing como una estrategia 
para obtener acceso a los valiosos recursos de otras empresas (Wong \& Karia, 2010). La Teoría de la vista basada en recursos se utilizó como base teórica en estudios que buscaban identificar la efectividad de los proveed ores de 3PL en el desempeño de las empresas exportadoras.

\section{Logística basada en recursos (RBL, por sus siglas en inglés)}

Logística basada en recursos reconoce que los recursos tangibles y los recursos intangibles son igualmente importantes porque cada uno de ellos puede proporcionar directa o indirectamente una ventaja competitiva específica a una empresa (Ray, Barney \& Muhanna, 2004; Karia \& Wong, 2013). De la literatura de la logística, los recursos tangibles como los recursos físicos, la tecnología de la información y los recursos humanos se encuentran entre los antecedentes comúnmente identificados del desempeño de los 3PL (por ejemplo, Skjoett-Larsen, 2000; Mentzer, Min \& Bobbitt, 2004). Los recursos intangibles, como los recursos de conocimiento, la experiencia administrativa, los recursos organizacionales y los recursos relacionales (Panayides, 2007; Wong \& Karia, 2010; Karia \& Wong, 2013) también mejoran el rendimiento de los 3PL. Estos hallazgos son respaldados por los teóricos de RBL que sostienen que los recursos y capacidades valiosos, raros e inimitables de una empresa son los determinantes de su ventaja competitiva (Penrose, 2009; Wernerfelt, 1984; Barney, 1991). Sin embargo, el rendimiento de estos 3PL solo puede ser sostenible cuando los recursos y capacidades distinguidos se combinan de manera específica, por lo que es muy costoso y difícil ser imitado por los competidores o sustituido por otros recursos (Amit \& Schoemaker, 1993; Barney, 1991; Teece, Pisano \& Shuen, 1997). Del mismo modo, los 3PL necesitan constantemente obtener acceso y combinar ciertos recursos y capacidades para proporcionar servicios logísticos novedosos y seguir siendo competitivos en costos. Por lo tanto, la teoría RBL es una base teórica apropiada para la muy necesaria comprensión de los efectos agrupados de los recursos logísticos (Olavarrieta \& Ellinger, 1997; Skjoett-Larsen, 1999). 
Además, esta investigación argumenta que las métricas de rendimiento de los 3PL miden principalmente las capacidades operativas, pero no siempre representan el rendimiento competitivo general de los 3PL. En el entorno competitivo de hoy, entregar pedidos de clientes por sí solos es insuficiente para competir; necesitan innovar en la provisión de servicios y proporcionar y seguir siendo competitivos en costos de manera constante para que pued an retener clientes y atraer nuevos clientes (Mentzer et al., 2004). Por lo tanto, esta investigación considera el liderazgo en costos (CL) y la innovación en el servicio al cliente (CSI) como las métricas de desempeño competitivo para 3PL. En CSI, esta investigación incluye confiabilidad de entrega (Stainer, 1997), calidad de entrega (Stainer, 1997), flexibilidad (Myers, Fawcett \& Smith, 1996; Stainer, 1997) y servicio de valor agregado (Lai, Li, Wang \& Zhao, 2008). Se requiere CSI para lograr la ventaja de variedad de servicio (Mentzer et al., 2004; Lai et al., 2008). Mientras tanto, CL significa que los 3PL pueden reducir los costos de transporte, inventario y almacenamiento (Daugherty \& Pittman, 1995) y lograr una ventaja de costos que se refleja en un menor costo de servicio y cargo en relación con los competidores (Lai, 2004; Mentzer et al., 2004).

\subsection{Dimensiones.}

Tabla 1:

Dimensiones de desempeño de $3 P L$

\begin{tabular}{ll}
\hline Autores & \multicolumn{1}{c}{ Dimensiones } \\
\hline Harding & Liderazgo en costos \\
& Innovación de servicios \\
& Logistica receptiva \\
& Servicios al cliente de alta calidad \\
& Entrega rápida y confiable. \\
& Puntualidad de los servicios \\
& Servicios complementarios a medida \\
& Factores de precios \\
& Calidad de entrega. \\
\hline
\end{tabular}

Fuente: Harding, F. E. (1998); Yeung, A. C. (2006).

Elaboración: Cadenillas y Farge (2020) 
Para la explicación de las dimensiones del desempeño de 3PL, en la presente investigación se utilizará la versión de los investigadores Yeung (2006), puesto que son quienes explican de una mejor forma dicha variable.

Puntualidad de los servicios: medición de las empresas el servicio ofrecido, del tiempo de las entregas y de la respuesta.

Servicios complementarios a medida: es cuando la empresa mide los servicios que ofrecen en cuanto al profesionalismo y de la experiencia que se tiene, la efectividad, los procedimientos que tienen para resolver problemas y la respuesta a las quejas.

Factores de precios: medición de las empresas el servicio ofrecido en cuanto a los precios según la calidad de dichos servicios, comparándolo con las demás empresas del rubro.

Calidad de entrega: medición de las empresas el servicio ofrecido en cuanto a cómo los productos son manejados y al embalaje de estos al ser entregados.

\subsubsection{Desempeño exportador.}

\subsection{Definición.}

Según Yeung (2006) el desempeño exportador se explica como la medida que hace la empresa de los beneficios producidos por su participación en los mercados extranjeros o por el número de insumos exportados por parte de una empresa exportadora. No obstante, Navas et al. realizo el análisis de cómo es que impactan las importaciones en las exportaciones utilizando una teoría de gravedad y logro descubrir que las importaciones de bienes intermedios logran afectar de manera positiva al desempeño de las exportaciones, y además de observar efectos negativos de la distancia de las exportaciones crece a medida de la participación de los bienes intermedios que son exportados. Yeung (2006) hallo que la inversión extranjera impacta en las exportaciones, así como las importaciones. 
Aaby y Slater (1993) determinan el desempeño de las exportaciones como la tasa decrecimiento en las ventas de exportación y porcentaje de las ventas totales representadas por las exportaciones. Guan y Ma (2003) señalaron que cuando la empresa y el entorno se ven afectados por diversos situaciones específicas, el desempeño de las exportaciones es una consecuencia del resultado de la conducta de las exportaciones. Cavusgil y Zou (1994) definieron el desempeño exportador como la solución transcendental de la empresa a la relación defuerzas externas y internas. Además, Roxo (2014) lo identificó como el logro de los objetivos económicos y estratégicos en exportaciones de los productos de la empresa a mercados externos en cierta medida a través de la organización y realización de tácticas de marketing.

\subsection{Teorías.}

\section{Teoría de dependencia de recursos}

De acuerdo con la visión basada en los recursos de las empresas como paquetes de recursos únicos que conducen a una ventaja competitiva, la teoría de la dependencia de los recursos se centra en la capacidad de la empresa para establecer relaciones para acceder a los recursos (Van Witteloostuijn \& Boone, 2006). La teoría de la dependencia de los recursos supone que la organización toma decisiones activas para lograr los objetivos. Un principio fundamental de la teoría de la dependencia de los recursos es la escasez de recursos, lo que resulta en múltiples organizaciones que compiten por el mismo conjunto de recursos escasos o similares. Seguimos a Barney y Arikan (2001) al definir los recursos como los "activos tangibles e intangibles que las empresas utilizan para concebir e implementar sus estrategias". Según la teoría de la dependencia de los recursos, las empresas dependen de otros actores en el "entorno de tareas" inmediato para obtener recursos. Para sobrevivir, las empresas necesitan obtener recursos del (actores en) entorno externo. La organización focal actuará para reducir o aumentar su nivel de dependencia de esos 
actores, a través de acciones como alianzas o empresas conjuntas. Por ejemplo, a medida que los clientes buscan cada vez más un abastecimiento coordinado globalmente (Kotabe, 1992), las empresas responden creando alianzas para fortalecer las relaciones con clientes clave (Pfeffer \& Salancik, 1978) y proveedores, incluido el seguimiento de estos clientes en el extranjero.

La teoría de la dependencia de recursos también se puede aplicar para considerar la necesidad de una empresa de obtener los recursos necesarios para exportar (Tesfom, Lutz \& Ghauri, 2004). En este sentido, la teoría de la dependencia de los recursos explica cómo la ubicación de una empresa en un mercado interno deseable puede ayudar a la acumulación de recursos necesarios para exportar. Un gran cuerpo de investigación empírica investiga cómo una base de recursos actual de las MYPE impacta la actividad de exportación (por ejemplo, Cavusgil \& Nevin, 1981; Akoorie \& Enderwick, 1992; Chang, 1995; Westhead, 1995; Keeble, Lawson, Smith, Moore \& Wilkinson, 1998; Autio, Sapienza \& Almeida, 2000; Tesfom et al. 2004); sin embargo, se sabe poco sobre la relación entre la disponibilidad de recursos en el mercado interno y el comportamiento de exportación de la empresa.

Sobre la base de la teoría de la dependencia de los recursos, esperamos que las MYPE dependan del mercado interno para obtener los recursos necesarios para la exportación y pued an beneficiarse cuando los entornos domésticos sean favorables y contengan recursos valiosos. Esperamos que, dado que las MYPE tienen recursos firmes limitados, particularmente en comparación con las grandes multinacionales, pueden depender particularmente de los recursos percibidos como disponibles en su país de origen.

\section{Teoría institucional}

Según la teoría institucional, las organizaciones operan dentro de un marco social de normas, valores y suposiciones sobre lo que constituye un comportamiento apropiado (Oliver, 1997; Scott, 
1995). Seguimos a Scott (1995) al definir las instituciones como "estructuras sociales que han alcanzado un alto grado de resiliencia" que están "compuestas de elementos culturales, cognitivos, normativos y reguladores que, junto con las actividades y recursos asociados, proporcionan estabilidad y significado para la vida social". Los contextos institucionales "prescriben y proscriben alternativas organizacionales" (Hinings \& Greenwood, 1988). Las decisiones se toman no tanto de acuerdo con criterios técnicos o económicos, sino sobre la base de lo que es aceptable y legítimo dentro de un entorno particular o "campo de organización" que generalmente se mueve hacia estructuras y procesos comunes debido a expectativas coercitivas, imitativas y normativas (DiMaggio \& Powell, 1983).

Tradicionalmente, los investigadores institucionales exploraron instituciones externas como las normas, las estructuras reguladoras y las agencias, sin embargo, el campo se ha ampliado para incluir otras empresas en la misma industria o unidades dentro de la misma empresa. Las unidades de negocio estratégicas que exportan, empresas conjuntas o licencias tienen altos niveles de isomorfismo externo en el país anfitrión y los entornos institucionales internos (Davis, Desai \& Francis, 2000).

Las empresas se enfrentan a tirones isomórficos competitivos de los campos de la organización local y global (Gimeno, Hoskisson, Beal \& Wan, 2005). Históricamente, una empresa se identifica con otros actores en su economía local. Cada vez más, a medida que los mercados financieros, los competidores y los clientes se vuelven más globales, la empresa puede considerarse miembro de un campo de organización global (Westney, 2001). La implicación es que cuanto mayor sea la atracción del campo de la organización global, más probable es que la empresa exporte al extranjero. 
Con base en la teoría institucional, sugerimos que en la medida en que una empresa se vea a sí misma como parte de un campo de organización global (en lugar de local), la empresa adoptará progresivamente los comportamientos y procesos que proporcionan legitimidad dentro de ese campo. Por lo tanto, las empresas pueden seguir directamente a su país de origen y sustituir a competidores, clientes y proveedores en el extranjero, y este proceso puede incluir caminos indirectos. Además, una mayor presencia de actores extranjeros, como proveedores y clientes extranjeros en el entorno de tareas directas de la empresa, indica un campo de organización cada vez más global y, posteriormente, puede proporcionar a la empresa legitimidad para atender los mercados en el extranjero.

La idea de que una empresa puede estar más inclinada a participar en actividades de exportación si está expuesta a las actividades internacionales de otros actores económicos también se encuentra en la literatura emergente sobre los efectos indirectos de las exportaciones sobre el impacto de las empresas multinacionales extranjeras en la actividad de exportación de las empresas nacionales (por ejemplo, Aitken, Hanson \& Harrison, 1997; Greenaway, Sousa \& Wakelin, 2004; Kneller \& Pisu 2007; De Clercq, Hessels \& Van Stel, 2008). La literatura sobre efectos indirectos de exportación complementa la perspectiva de la teoría institucional al proporcionar una perspectiva más amplia de los canales a través de los cuales se producen los efectos indirectos. Más específicamente, la investigación sobre efectos indirectos de exportación reconoce un efecto de demostración o imitación (como lo sugiere la teoría institucional) y sugiere que los vínculos comerciales, la capacitación y la mayor competencia de un actor internacional pueden aumentar la probabilidad de exportación de una empresa nacional. 


\subsection{Dimensiones.}

Tabla 2:

Dimensiones del desempeño exportador

\begin{tabular}{cl}
\hline Autores & \multicolumn{1}{c}{ Dimensiones } \\
\hline Guan y Ma & $\begin{array}{l}\text { Objetivas } \\
\text { Subjetivas }\end{array}$ \\
Yeung & $\begin{array}{l}\text { Logro de metas y objetivos de exportación } \\
\text { Desempeño de exportación del usuario }\end{array}$ \\
\hline
\end{tabular}

Fuente: Guan y Ma (2003); Yeung, A. C. (2006).

Elaboración: Cadenillas y Farge (2020)

Para explicar las dimensiones del desempeño exportador se toma como base la versión de Yeung (2006), la cual se basa en la medición numérica. De acuerdo con Yeung (2006) este tipo de medida da la oportunidad de evaluar el desempeño de las exportaciones de las empresas por medio del logro de las metas y de los objetivos de las exportaciones, así como del desempeño de las exportaciones de los usuarios (participación en el mercado, percepción de la rentabilidad de las exportaciones y las ventas de exportación).

\subsubsection{Uvas.}

\subsection{Definición.}

De acuerdo con MINAGRI (2020) es una fruta que se obtiene de la vid, y crece en racimos (6 y 300 uvas) y se usa para poder producir agraz, mosto, brandy, pisco, vino y vinagre. Además, pueden venir en diferentes colores (morada, rosada, verde, negra, amarilla, anaranjado, purpura, dorada).

\subsection{Principales destinos de la uva peruana.}

De acuerdo con Trademap (2020) los principales destinos que se exporta la uva fresca peruana son los siguientes: 
Tabla 3:

Principales destinos de la uva fresca peruana

\begin{tabular}{|c|c|c|c|c|c|}
\hline \multirow[b]{2}{*}{ Importadores } & 2015 & 2016 & 2017 & 2018 & 2019 \\
\hline & $\begin{array}{l}\text { Cantidad } \\
\text { exportada, } \\
\text { Toneladas }\end{array}$ & $\begin{array}{l}\text { Cantidad } \\
\text { exportada, } \\
\text { Toneladas }\end{array}$ & $\begin{array}{l}\text { Cantidad } \\
\text { exportada, } \\
\text { Toneladas }\end{array}$ & $\begin{array}{l}\text { Cantidad } \\
\text { exportada, } \\
\text { Toneladas }\end{array}$ & $\begin{array}{l}\text { Cantidad } \\
\text { exportada, } \\
\text { Toneladas }\end{array}$ \\
\hline \multicolumn{6}{|c|}{ 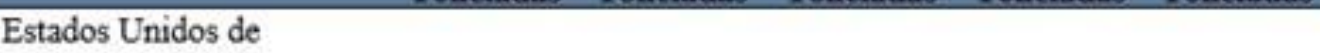 } \\
\hline América & 69009 & 85575 & 90640 & 103473 & 128951 \\
\hline Paises Bajos & 45618 & 37319 & 37941 & 65119 & 54161 \\
\hline Hong Kong, China & 39032 & 31562 & 32317 & 33526 & 33429 \\
\hline China & 41287 & 27372 & 16524 & 17174 & 18970 \\
\hline Reino Unido & 13708 & 11490 & 10995 & 19433 & 17174 \\
\hline México & 2371 & 8973 & 6824 & 8127 & 14711 \\
\hline Canadà & 8513 & 7982 & 4708 & 5996 & 10339 \\
\hline España & 3164 & 2792 & 5467 & 7324 & 8424 \\
\hline Rusia & 11243 & 8089 & 9073 & 8102 & 8187 \\
\hline República de Corea & 8363 & 6561 & 6516 & 8146 & 8098 \\
\hline
\end{tabular}

\subsection{Precio internacional de la uva fresca.}

De acuerdo con Siicex (2020) el precio de la uva fresca (partida 080610) en dólares por kilogramo en el periodo 2015 - 2019 es el siguiente:

Tabla 4:

Precio de la uva fresca en el extranjero

\begin{tabular}{|c|c|c|c|c|c|}
\hline \multirow{2}{*}{ Descripción del producto } & 2015 & 2016 & 2017 & 2018 & 2019 \\
\hline & $\begin{array}{c}\text { Valor } \\
\text { unitario } \\
\text { exportada, } \\
\text { Dólar } \\
\text { Americano } \\
\text { /Kilogram } \\
\text { os }\end{array}$ & $\begin{array}{c}\text { Valor } \\
\text { unitario } \\
\text { exportada, } \\
\text { Dólar } \\
\text { Americano } \\
\text { /Kilogram } \\
\text { os }\end{array}$ & $\begin{array}{c}\text { Valor } \\
\text { unitario } \\
\text { exportada, } \\
\text { Dólar } \\
\text { Americano } \\
\text { Kilogram } \\
\text { os }\end{array}$ & $\begin{array}{c}\text { Valor } \\
\text { unitario } \\
\text { exportada, } \\
\text { Dólar } \\
\text { Americano } \\
\text { /Kilogram } \\
\text { os }\end{array}$ & $\begin{array}{c}\text { Valor } \\
\text { unitario } \\
\text { exportada, } \\
\text { Dólar } \\
\text { Americano } \\
\text { Kilogramos }\end{array}$ \\
\hline Uvas frescas & 2,25 & 2,25 & 2,42 & 2,37 & 2,33 \\
\hline
\end{tabular}

\subsection{Países exportadores de uva fresca.}

De acuerdo con Trademap (2020) los países que más exportan la uva fresca en el mundo son los siguientes: 
Tabla 5:

Países exportadores de uva fresca

\begin{tabular}{lrrrrr}
\hline \multirow{2}{*}{ Exportadores } & \multicolumn{1}{c}{$\mathbf{2 0 1 5}$} & $\mathbf{2 0 1 6}$ & $\mathbf{2 0 1 7}$ & $\mathbf{2 0 1 8}$ & $\mathbf{2 0 1 9}$ \\
\cline { 2 - 6 } & $\begin{array}{r}\text { Cantidad } \\
\text { exportada, } \\
\text { Toneladas }\end{array}$ & $\begin{array}{r}\text { Cantidad } \\
\text { exportada, } \\
\text { Toneladas }\end{array}$ & $\begin{array}{r}\text { Cantidad } \\
\text { exportada, } \\
\text { Toneladas }\end{array}$ & $\begin{array}{r}\text { Cantidad } \\
\text { exportada, } \\
\text { Toneladas }\end{array}$ & $\begin{array}{c}\text { Cantidad } \\
\text { exportada, } \\
\text { Toneladas }\end{array}$ \\
\hline Chile & 845603 & 799846 & 794684 & 821883 & 740837 \\
Italia & 469166 & 484633 & 493825 & 465204 & 424676 \\
Estados Unidos de América & 392821 & 386389 & 384814 & 419905 & 377011 \\
Paises Bajos & 296887 & 324500 & 369785 & 363448 & 375806 \\
China & 210233 & 254453 & 280418 & 277162 & 366524 \\
Perú & 307987 & 285559 & 269662 & 322087 & 348846 \\
Sudáfrica & 324004 & 305123 & 337168 & 324084 & 321297 \\
India & 74308 & 147012 & 185172 & 171719 & 241115 \\
Hong Kong, China & 166908 & 205387 & 202228 & 200913 & 210357 \\
Turquia & 175189 & 172838 & 277743 & 180238 & 205732 \\
\hline Furyyyyyy
\end{tabular}

Fuente: Trademap (2020)

Elaboración: Cadenillas y Farge (2020)

\subsection{Empresas peruanas de exportación de uva fresca.}

Las mayores empresas peruanas que exportan la uva fresca son (Adex Data Trade, 2020):

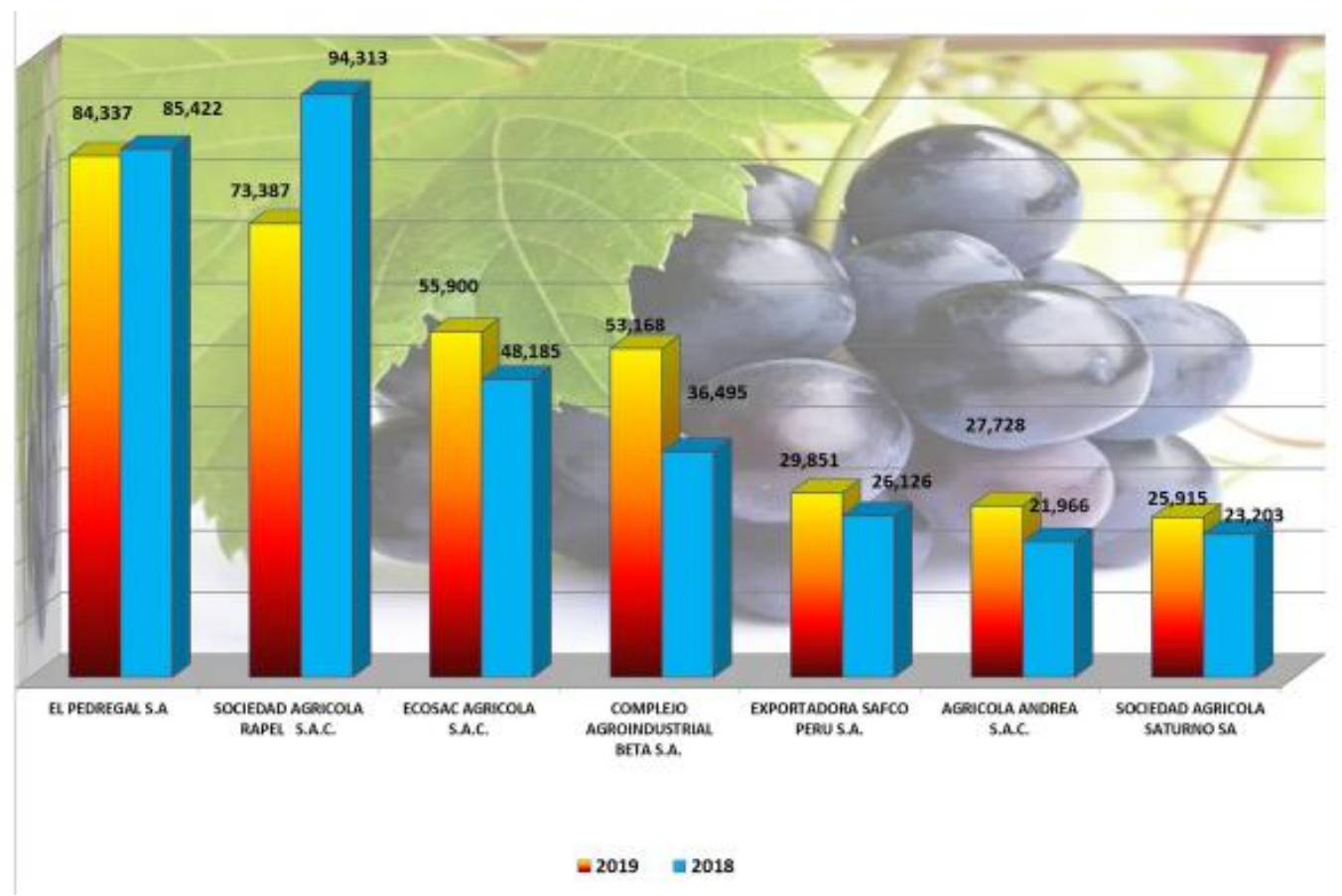

Figura 1. Empresas peruanas de exportación de uvas frescas

Fuente: Adex Data Trade (2020) 


\subsection{Objetivos e Hipótesis}

\subsubsection{Objetivos.}

\subsubsection{Objetivo general.}

Analizar la relación del desempeño de proveedores logísticos de terceros con el desempeño de las empresas MYPES exportadoras de uvas a Estados Unidos 2020.

\subsubsection{Objetivos específicos.}

Analizar la relación de la puntualidad de los servicios con el desempeño de las empresas MYPES exportadoras de uvas a Estados Unidos 2020.

Analizar la relación de los servicios complementarios a medida con el desempeño de las empresas MYPES exportadoras de uvas a Estados Unidos 2020.

Analizar la relación del factor de precios con el desempeño de las empresas MYPES exportadoras de uvas a Estados Unidos 2020.

Analizar la relación de la calidad de entrega con el desempeño de las empresas MYPES exportadoras de uvas a Estados Unidos 2020.

\subsubsection{Hipótesis.}

\subsubsection{Hipótesis general.}

El desempeño de proveedores logísticos de terceros se relaciona con el desempeño de las empresas MYPES exportadoras de uvas a Estados Unidos 2020.

\subsubsection{Hipótesis específicas.}

La puntualidad de los servicios se relaciona con el desempeño de las empresas MYPES exportadoras de uvas a Estados Unidos 2020.

Los servicios complementarios a medida se relaciona con el desempeño de las empresas MYPES exportadoras de uvas a Estados Unidos 2020. 
El factor de precios se relaciona con el desempeño de las empresas MYPES exportadoras de uvas a Estados Unidos 2020.

La calidad de entrega se relaciona con el desempeño de las empresas MYPES exportadoras de uvas a Estados Unidos 2020. 


\section{Capítulo II}

\subsection{Método}

La metodología usada fue el enfoque cuantitativo basado en el uso de cuestionarios como instrumentos de recolección de datos, los cuales están constituidos por preguntas estándar con la intención de cuantificar los datos recolectada.

\subsubsection{Tipo de investigación.}

El tipo de investigación que se utilizó es el enfoque cuantitativo de tipo correlacional, que de acuerd o con Hernández, Fernández y Baptista(2014) es en donde se intenta recolectar información que pueda ratificar las hipótesis que se plantean basados en pruebas estadísticas y mediciones numéricas, y de la medición de las variables consideradas y aprender de la relación que se encuentren, con el propósito de predecir un valor cercano.

\subsubsection{Diseño de investigación.}

En este estudio se empleó un diseño no experimental, transversal y correlacional, basado en lo citado por Sánchez y Reyes (2000) “las variables no serán maniobradas por los investigadores, por lo que la investigación se puede realizar en el entorno origina”.

Según con Hernández et al. (2014) es transversal ya que los datos se recolectan en un momento exacto, y correlacional se estudian las relaciones que se puedan encontrar para poder entender su conducta.

\subsubsection{Variables.}

Variable $\mathrm{X}_{1}$ : desempeño de $3 \mathrm{PL}$

Yeung (2006) precisa que el desempeño de 3PL como la manera en cómo se mide las actividades del outsourcing que ofrecen las empresas encargadas de los procesos logísticos de otras empresas. Y cita que contiene cuatro dimensiones, las cuales son: 
- $\mathrm{X}_{1 \mathrm{~A}}$ : puntualidad de los servicios

- $\mathrm{X}_{1 \mathrm{~B}}$ : servicios complementarios a medida

- $\mathrm{X}_{1 \mathrm{C}}$ : factor de precios

- $\mathrm{X}_{1 \mathrm{D}}$ : calidad de entrega

Tabla 6:

Operacionalización de desempeño de $3 P L$

\begin{tabular}{|c|c|c|c|}
\hline \multirow{2}{*}{$\begin{array}{l}\text { DEFINICION } \\
\text { CONCEPTUAL: } \\
\text { Variable }\end{array}$} & \multicolumn{2}{|c|}{$\begin{array}{l}\text { Yeung (2006) precisa que el desempeño de 3PL como } \\
\text { la manera en cómo se mide las actividades del } \\
\text { outsourcing que ofrecen las empresas encargadas de los } \\
\text { procesos logisticos de otras empresas. }\end{array}$} & \multirow[t]{2}{*}{ ITEM } \\
\hline & Dimensión & Indicadores & \\
\hline \multirow{19}{*}{$\begin{array}{l}\text { DEFINICION } \\
\text { OPERACIONAL } \\
\text { DESEMPEÑO DE LA } \\
\text { TERCERIZACIÓN DE } \\
\text { LOS SERVICIOS } \\
\text { LOGISTICOS }\end{array}$} & \multirow{8}{*}{ puntualidad de los servicios } & Servicio prometido & 1 \\
\hline & & Respuesta & 2 \\
\hline & & Servicios oportunos & 3 \\
\hline & & Entregas & 4 \\
\hline & & Problemas de servicio & 5 \\
\hline & & Requisitos & 6 \\
\hline & & Solicitudes de & 7 \\
\hline & & Entregas oportunas & 8 \\
\hline & \multirow{7}{*}{$\begin{array}{l}\text { servicios complementarios a } \\
\text { medida }\end{array}$} & Mejora de & 9 \\
\hline & & Soluciones creativas & 10 \\
\hline & & Personalización de & 11 \\
\hline & & Conocimiento & 12 \\
\hline & & Automatización & 13 \\
\hline & & Respuesta a quejas & 14 \\
\hline & & Servicio integral & 15 \\
\hline & \multirow{2}{*}{ factor de precios } & Precios de servicios & 16 \\
\hline & & Comparación de & 17 \\
\hline & \multirow{2}{*}{ calidad de entrega } & Calidad de embalaje & 18 \\
\hline & & Manipulación de & 19 \\
\hline Escala valorativa & Ordinal & & \\
\hline
\end{tabular}

Variable X2: desempeño exportad or

Según Yeung (2006) el desempeño exportador se explica como la medida que hace la empresa de los beneficios producidos por su participación en los mercados extranjeros o por el número de insumos exportados por parte de una empresa exportadora. Y cita que contiene dos dimensiones, las cuales son: 
- X2A: desempeño de exportación del usuario

- X2B: logro de metas y objetivos de exportación.

Tabla 7:

Operacionalización de desempeño exportador

\begin{tabular}{|c|c|c|c|}
\hline \multirow{2}{*}{$\begin{array}{l}\text { DEFINICION } \\
\text { CONCEPTUAL: } \\
\text { Variable }\end{array}$} & \multicolumn{2}{|c|}{$\begin{array}{l}\text { Según Yeung (2006) el desempeño exportador se explica } \\
\text { como la medida que hace la empresa de los beneficios } \\
\text { producidos por su participación en los mercados extranjeros o } \\
\text { por el número de insumos exportados por parte de una } \\
\text { empresa exportadora. }\end{array}$} & \multirow[t]{2}{*}{ ITEM } \\
\hline & Dimensión & Indicadores & \\
\hline $\begin{array}{l}\text { DEFINICION } \\
\text { OPERACIONAL } \\
\text { DESEMPEÑO } \\
\text { EXPORTADOR }\end{array}$ & $\begin{array}{l}\text { Desempeño de exportación del } \\
\text { usuario }\end{array}$ & $\begin{array}{c}\text { Percepción de } \\
\text { rentabilidad } \\
\text { Cuota de mercado } \\
\text { Desempeño de ventas }\end{array}$ & $\begin{array}{l}1 \\
2 \\
3\end{array}$ \\
\hline & $\begin{array}{l}\text { Logro de metas y objetivos de } \\
\text { exportación }\end{array}$ & $\begin{array}{l}\text { Logro de metas y } \\
\text { objetivos }\end{array}$ & 4 \\
\hline Escala valorativa & Ordinal & & \\
\hline
\end{tabular}

\subsubsection{Población.}

La población para esta investigación está conformada por 74 administradores o gerentes de las empresas MYPES exportadoras peruanas de uvas frescas que exportan a Estados Unidos (SIICEX, 2020), las cuales son segmentadas de la siguiente manera:

Tabla 8:

Cantidad de empresas exportadoras de uvas frescas

\begin{tabular}{lc}
\hline Tipo de empresa & Cantidad de empresas \\
\hline Micro & 29 \\
Pequeña & 45 \\
\hline Total & 74 \\
\hline Fuente: SIICEX (2020) & \\
Elaboración: Cadenillas y Farge (2020) &
\end{tabular}

\subsubsection{Muestra.}

La muestra se halla a través de la fórmula para muestras aleatorias estratificadas en poblaciones finitas, con el propósito de hallar el subgrupo representativo de la población necesario para poder desarrollar este trabajo de investigación (Scheaffer, Mendenhall \& Ott, 2006). 


$$
n=\frac{\left(\sum_{h=1}^{H} N_{h} \sqrt{p_{h}\left(1-p_{h}\right)}\right)^{2}}{\left(N^{2}\left(\varepsilon^{2} / Z_{1-\frac{\alpha}{2}}^{2}\right)+\Sigma_{h=1}^{H} N_{h} P_{h}\left(1-p_{h}\right)\right.}
$$

Datos:

- $\quad \mathrm{N}=$ Cantidad de la población: 74 empresas MYPES exportadoras de uvas frescas a Estados Unidos.

- $\mathrm{n}$ = Cantidad de la muestra de las empresas MYPES exportadoras de uvas frescas a Estados Unidos.

- $\boldsymbol{N}_{\boldsymbol{h}}$ : Cantidad de empresas en el estrato h.

- $\quad \boldsymbol{Z}^{2}{ }_{1-\frac{\alpha}{2}}=1.96$, con un nivel de confiabilidad del $95 \%$

- $\boldsymbol{p}_{\boldsymbol{h}}=\mathbf{0 . 5}$ : proporción de empresas MYPES exportadoras de uvas frescas a Estados Unidos con buen desempeño en el estrato $h$, se ha considerado un valor de 0.5 .

- $\varepsilon=0.05:$ error de estimación máximo.

$$
n=\frac{(29 \sqrt{0.5 \times 0.5}+45 \sqrt{0.5 \times 05})^{2}}{74^{2}\left(\frac{0.05^{2}}{1.96^{2}}\right)+(29 \times 0.5 \times 0.5+45 \times 0.5 \times 0.5)}
$$

Tras haber realizado los cálculos apropiados, como se demuestra con la formula presentada línea arriba, se toman en cuenta a 63 gerentes o administradores de las empresas MYPES exportadoras de uvas frescas del Perú hacia Estados Unidos, es por esto, después de haber efectuado el muestreo probabilístico estratificado se establece que la cantidad de empresas exportadoras de uvas frescas del Perú según al tipo de empresa es como a continuación se muestra:

$$
\begin{aligned}
& n_{1}=\frac{N_{1}}{N} \times n=\frac{29}{74} \times 63=24.68 \cong 25 \\
& n_{2}=\frac{N_{2}}{N} \times n=\frac{45}{74} \times 63=38.31 \cong 38
\end{aligned}
$$




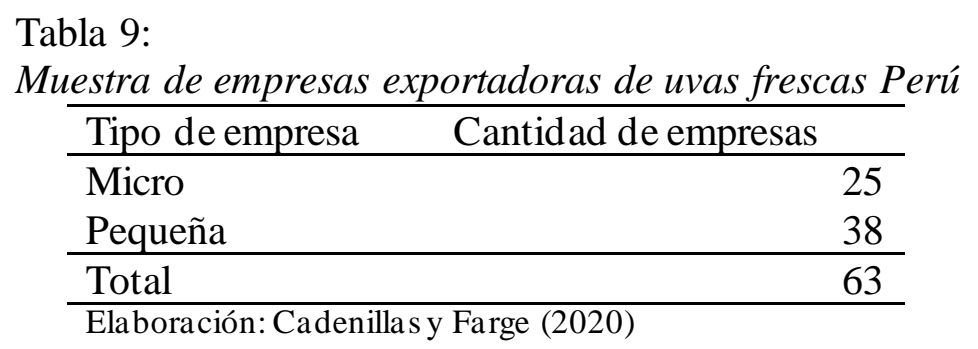

\subsubsection{Instrumentos de investigación.}

Como instrumentos para poder recolectar la información necesaria para el desarrollo de este trabajo de investigación se utilizaron dos cuestionarios; empezando con el cuestionario del investigad or Yeung (2006) para medir el desempeño de 3PL formado por 19 ítems repartido entre sus cuatro dimensiones, puntualidad de los servicios (8 ítems), servicios complementarios a medida (7 ítems), factor de precios ( 2 ítems) y calidad de entrega ( 2 ítems), y con una escala de Likert del 1 al 5 donde 5 es muy excelente, 4 es excelente, 3 es ni pobre ni excelente, 2 es pobre y 1 es muy pobre.

- Ficha técnica de cuestionario de desempeño de 3PL

\begin{tabular}{ll}
\hline Nombre: & Cuestionario de desempeño de 3PL \\
Autor: & Yeung \\
Año: & 2006 \\
Procedencia: & Hong Kong \\
Ámbito de aplicación: & Adultos \\
Forma de aplicación: & Individual - Colectivo \\
Edades de aplicación: & Mayores de 18 años \\
Duración: & 15 a 20 minutos \\
Versión: & Inglés \\
Cantidad de preguntas: & 19 \\
Confiabilidad: & Alfa de Cronbach $=0.875$ \\
Validez: & Coeficiente de Aiken $=0.93$ \\
\hline Fuente: Yeung (2006) & \\
Elaboración: Cadenillas y Farge (2020)
\end{tabular}

Continuando con el cuestionario del investigador Yeung (2006) para medir el desempeño exportador formado por 4 ítems dividido entre sus dos dimensiones, desempeño de exportación del usuario (3 ítems) y logro de metas y objetivos de exportación (1 ítems) con una escala de Likert 
del 1 al 5, donde 5 es muy excelente, 4 es excelente, 3 es ni pobre ni excelente, 2 es pobre y 1 es muy pobre.

- Ficha técnica de cuestionario de desempeño exportador

\begin{tabular}{ll}
\hline Nombre: & Cuestionario de desempeño exportador \\
Autor: & Yeung \\
Año: & 2006 \\
Procedencia: & Hong Kong \\
Ámbito de aplicación: & Adultos \\
Forma de aplicación: & Individual - Colectivo \\
Edades de aplicación: & Mayores de 18 años \\
Duración: & 15 a 20 minutos \\
Versión: & Inglés \\
Cantidad de preguntas: & 4 \\
Confiabilidad: & Alfa de Cronbach $=0.868$ \\
Validez: & Coeficiente de Aiken $=0.93$ \\
\hline Fuente: Yeung (2006) & \\
Elaboración: Cadenillas y Farge $(2020)$
\end{tabular}

Se aprobaron los dos cuestionarios a través del juicio de tres expertos (anexo 7) y fueron verificados a través del coeficiente de Aiken (anexo 6), y se comprobó la confianza a través del Alfa de Cronbach (desempeño de la tercerización de los servicios logísticos: 0.943; desempeño exportador: 752). Igualmente, las hipótesis se contrastaron a través de la prueba de Spearman, que según con Hernández et al. (2014) es utilizado para demostrar la correlación de dos variables o más.

\subsubsection{Procedimientos de recolección de datos.}

Para proceder con la recolección de los datos requeridos se siguieron los siguientes pasos; los cuestionarios se aplicaron a cada gerente o administrador de las empresas MYPES exportadoras de uvas frescas del Perú a Estados Unidos que forman parte de la muestra, del 20 de agosto del 2020 hasta el 4 de septiembre del 2020, previa coordinación de la hora y la manera (vía correo electrónico) en que se les envió los dos cuestionarios con la intención de obstaculizar con sus tareas diarias, con la intención de poder darle solución a dichos cuestionarios, seguido de la tabulación por medio del programa SPSS 2, el cual se usó para poder encontrar alguna relación entre las 
variables tomadas en consideración y demostrar las hipótesis planteadas por medio de la prueba de Spearman. Los dos programas que sirvieron de apoyo para corroborar los resultados son el Excel, que se usó para la exposición de las tablas, y el SPSS 22, que sirve para tabular los cuestionarios. 


\section{Capitulo III}

En una investigación se pueden hallar diversos tipos de errores, dentro de los cuales se presentan el de $1 \%$ y el $5 \%$, donde el tipo de error de $5 \%$ es el que con mayor frecuencia se presenta.

En este trabajo de investigación se considera la significancia del 5\%, y el responsable de esta investigación tiene un $95 \%$ de confiabilidad y puede resumir los resultados como correctos (Hernández et al., 2014).

En este capítulo se presenta el análisis basado en el cuestionario de desempeño de 3PL y desempeño exportador, también se hace una contrastación de hipótesis, aquí se desarrolla el test de normalidad de Shapiro-Wilk, análisis factorial exploratorio, correlación hipotética. Así como la discusión, conclusiones y recomendaciones.

\subsection{Análisis de los resultados de los cuestionarios}

Seguidamente, se exponen los resultados de los 63 cuestionarios que se aplicaron a cadagerente o administrador de las empresas MYPES exportadoras peruanas de uvas frescas hacia los Estados Unidos, en relación a la relación que posee el desempeño de 3PL con el desempeño exportador de las mismas empresas.

\subsubsection{Análisis de resultados de desempeño de la tercerización de los servicios}

\section{logísticos}




\section{Puntualidad de los servicios}

Tabla 10:

Servicio prometido

\begin{tabular}{|c|c|c|c|c|c|}
\hline \multicolumn{6}{|c|}{$\begin{array}{l}\text { TPLl. La empresa tercerizadora de servicios logísticos (3PL) realiza el servicio prometido } \\
\text { satisfactoriamente. }\end{array}$} \\
\hline & & Frecuencia & Porcentaje & $\begin{array}{l}\text { Porcentaje } \\
\text { válido }\end{array}$ & $\begin{array}{l}\text { Porcentaje } \\
\text { acumulado }\end{array}$ \\
\hline \multirow{5}{*}{ Valido } & Totalmente en desacuerdo & 13 & 20.6 & 20.6 & 20.6 \\
\hline & En desacuerdo & 17 & 27.0 & 27.0 & 47.6 \\
\hline & Indiferente & 18 & 28.6 & 28.6 & 76.2 \\
\hline & De acuerdo & 15 & 23.8 & 23.8 & 100.0 \\
\hline & Total & 63 & 100.0 & 100.0 & \\
\hline
\end{tabular}

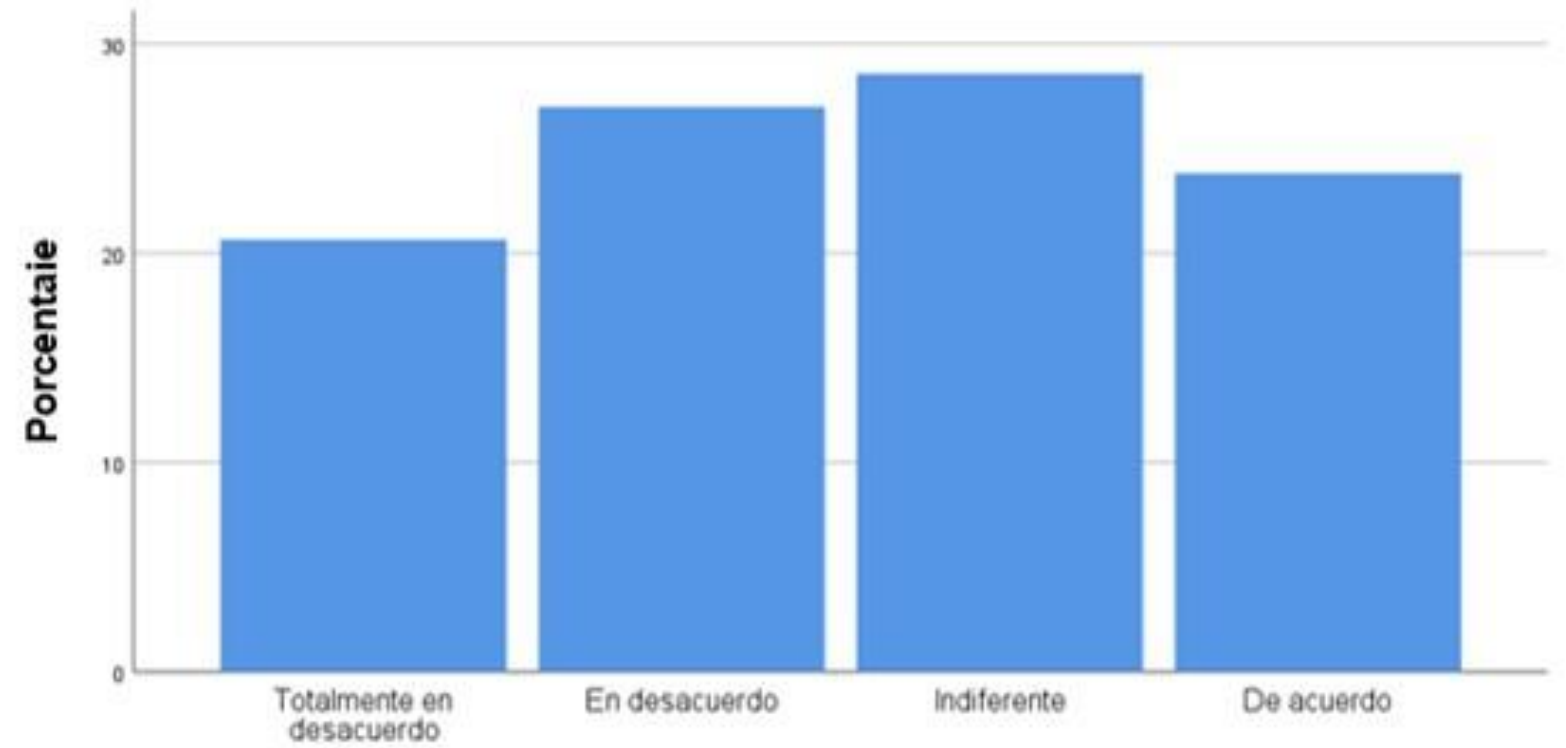

Figura 2. Servicio prometido

Interpretación: la tabla 10 muestra como del total de los apoderados de las empresas, el 23.8\% está de acuerdo con el ítem "La empresa tercerizadora de servicios logísticos (3PL) realiza el servicio prometido satisfactoriamente", el $28.6 \%$ está indiferente y el $47.6 \%$ está en desacuerdo y totalmente en desacuerdo. Es por esto que se llega a la determinación que la mayoría afirma que la empresa tercerizadora de servicios logísticos (3PL) no realiza el servicio prometido satisfactoriamente. 
Tabla 11:

Respuesta

TPL2. La empresa tercerizadora de servicios logisticos (3PL) responde de manera oportuna y precisa.

\begin{tabular}{llrrrr}
\hline & Frecuencia & Porcentaje & \multicolumn{2}{c}{$\begin{array}{c}\text { Porcentaje } \\
\text { válido }\end{array}$} & $\begin{array}{r}\text { Porcentaje } \\
\text { acumulado }\end{array}$ \\
\hline \multirow{5}{*}{ Valido } & En desacuerdo & 13 & 20.6 & 20.6 & 20.6 \\
& Indiferente & 19 & 30.2 & 30.2 & 50.8 \\
& De acuerdo & 16 & 25.4 & 25.4 & 76.2 \\
& Totalmente de acuerdo & 15 & 23.8 & 23.8 & 100.0 \\
\cline { 2 - 6 } & Total & 63 & 100.0 & 100.0 & \\
\hline
\end{tabular}

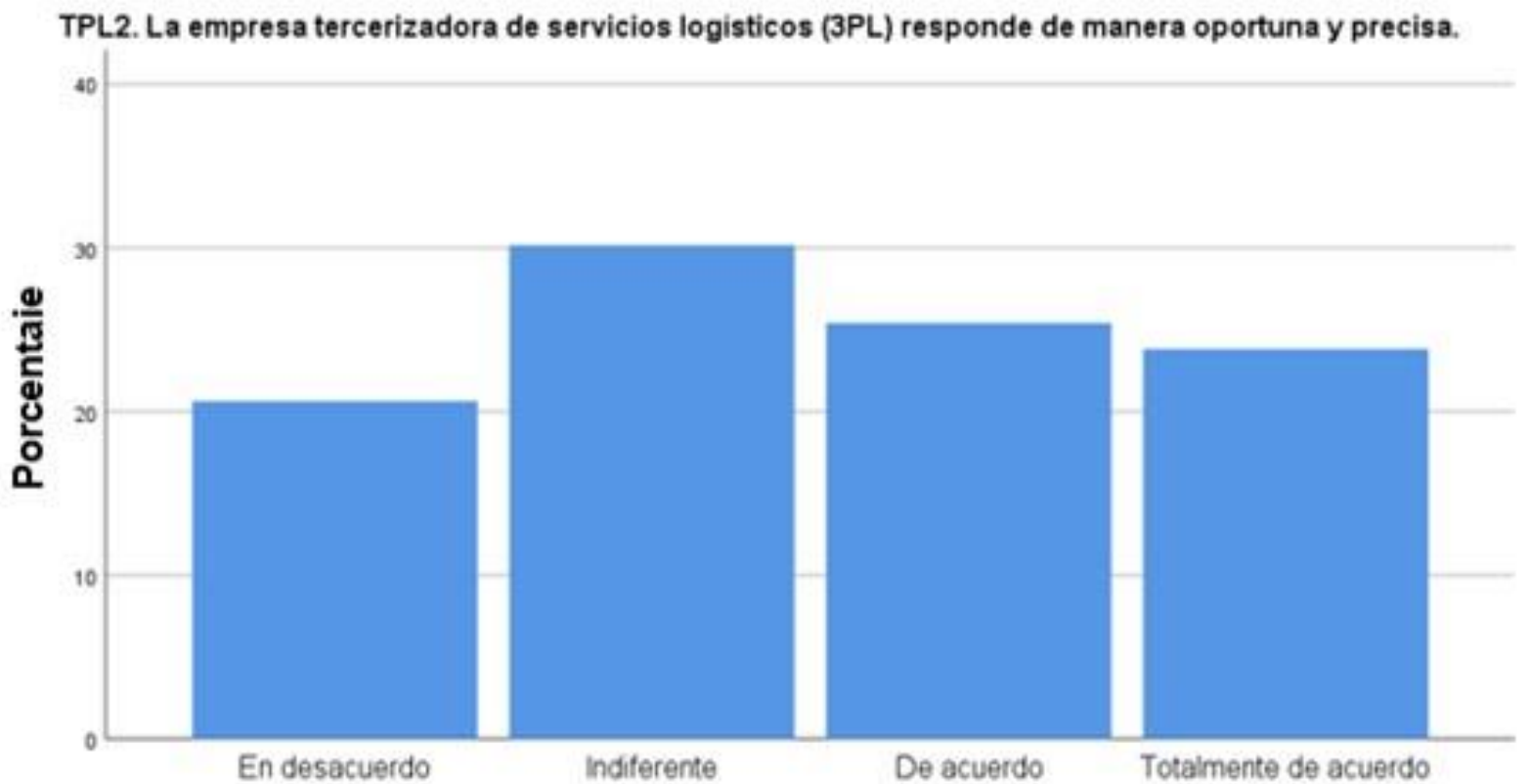

Interpretación: la tabla 11 muestra como del total de los apoderados de las empresas el $49.2 \%$ está de acuerdo y totalmente de acuerdo con el ítem "La empresa tercerizadora de servicios logísticos (3PL) responde de manera oportuna y precisa", el 30.2\% está ind iferente y el 20.6\% está en desacuerdo. Es por esto que se llega a la determinación que la gran mayoría afirma que la empresa tercerizadora de servicios logísticos (3PL) responde de manera oportuna y precisa. 
Tabla 12:

Servicios oportunos

\begin{tabular}{llrrr}
\hline \multicolumn{5}{c}{ TPL3. La empresa tercerizadora de servicios logisticos (3PL) brinda servicios oportunos para } \\
satisfacer necesidades particulares.
\end{tabular}

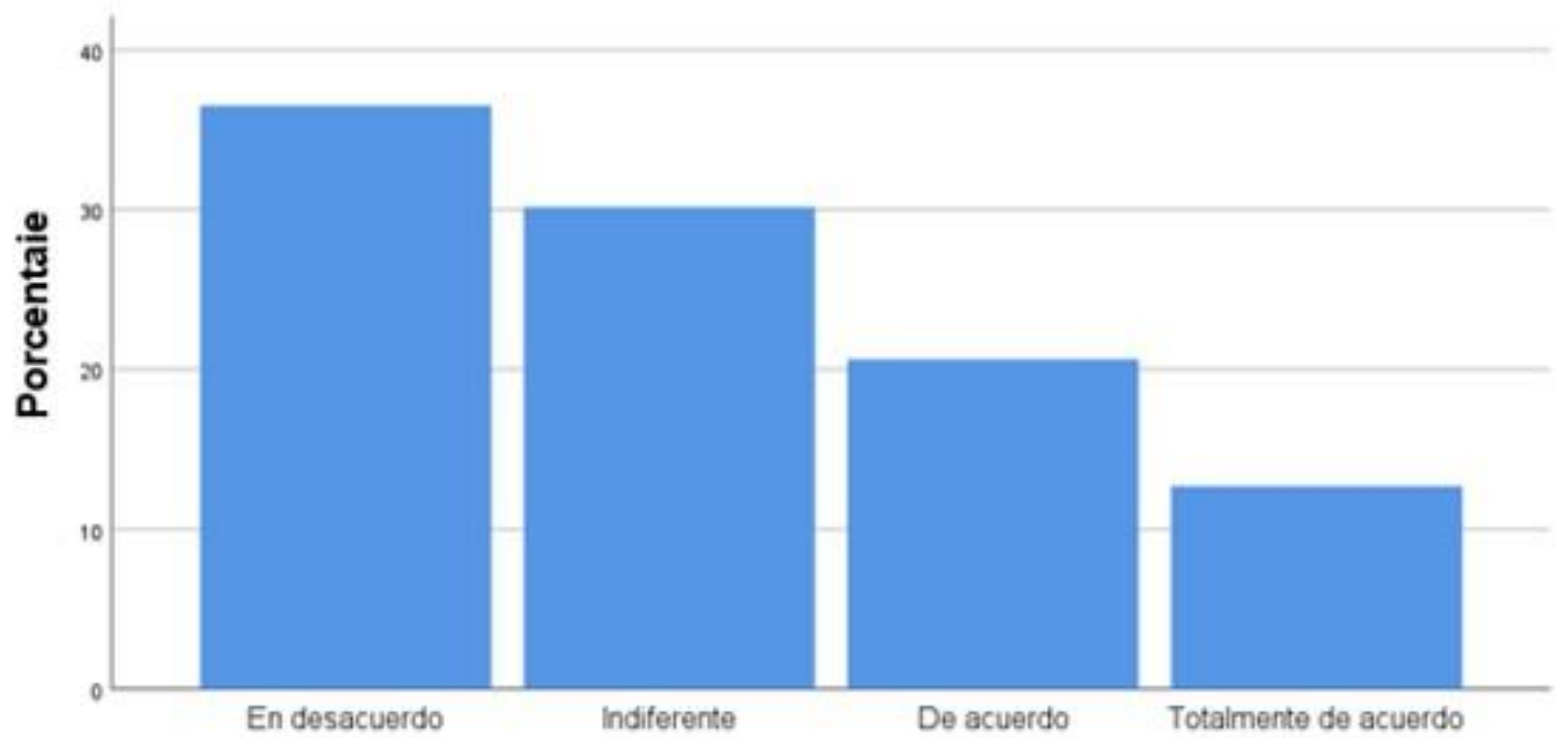

Figura 3. Servicios oportunos

Interpretación: la tabla 12 muestra como del total de los apoderados de las empresas el $33.3 \%$ está de acuerdo y totalmente de acuerdo con el ítem "La empresa tercerizadora de servicios logísticos (3PL) brinda servicios oportunos para satisfacer necesidades particulares”, el 30.2\% está indiferente y el $36.5 \%$ está en desacuerdo y totalmente en desacuerdo. Es por esto que se llega a la determinación que la gran mayoría afirma que la empresa tercerizadora de servicios logísticos (3PL) no brinda servicios oportunos para satisfacer necesidades particulares. 
Tabla 13:

Entregas

\begin{tabular}{llrrr}
\hline TPL4. La empresa tercerizadora de servicios logisticos (3PL) proporciona entregas a tiempo y \\
confiables.
\end{tabular}

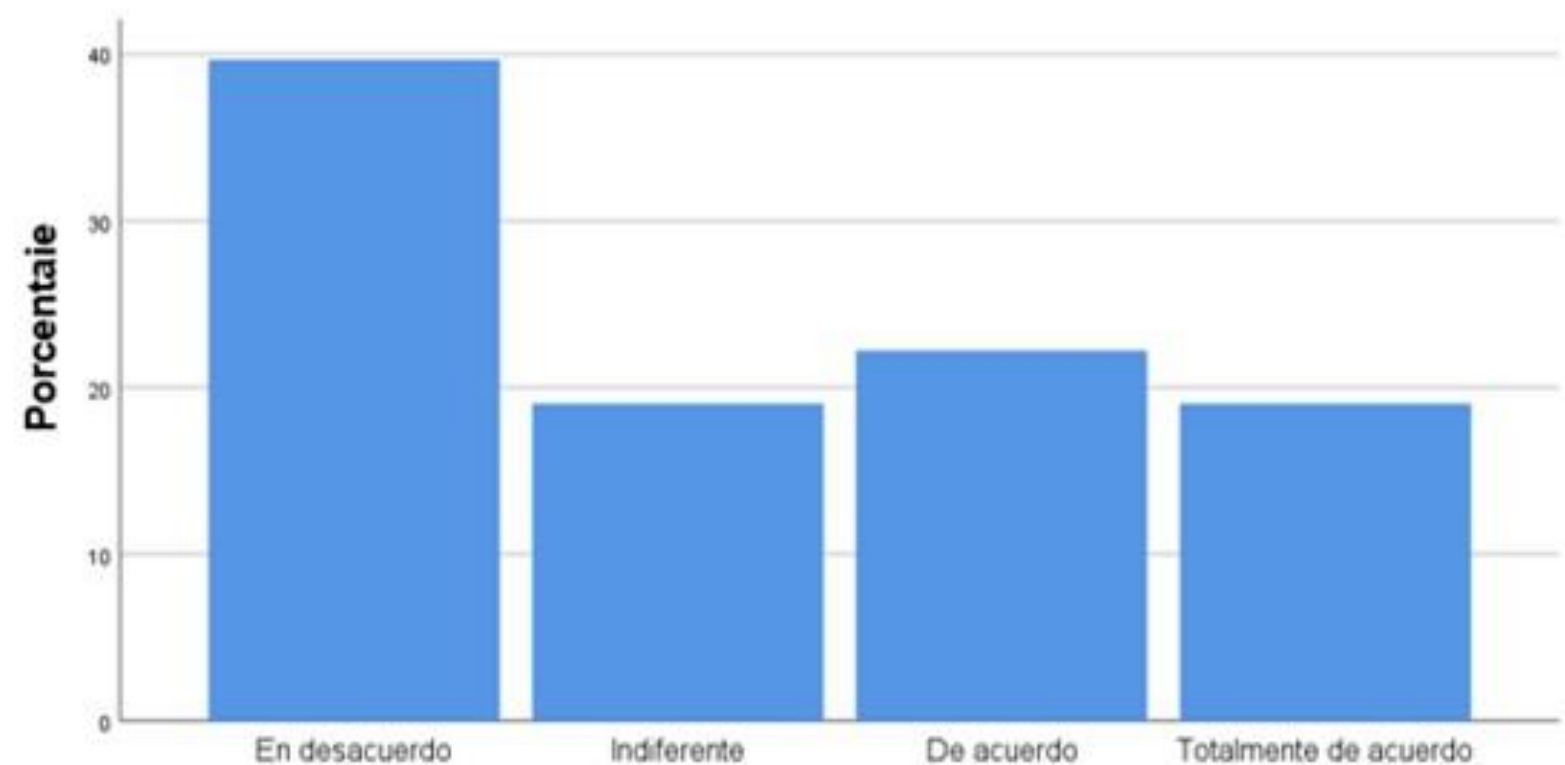

Figura 4. Entregas

Interpretación: la tabla 13 muestra como del total de los apoderados de las empresas, el $41.2 \%$ está de acuerdo y totalmente de acuerdo con el ítem "La empresa tercerizadora de servicios logísticos (3PL) proporciona entregas a tiempo y confiables”, el 19\% está indiferente y el 39.7\% está en desacuerdo. Es por esto que se llega a la determinación que la gran mayoría afirma que la empresa tercerizadora de servicios logísticos (3PL) proporciona entregas a tiempo y confiables. 
Tabla 14:

Problemas de servicio

\begin{tabular}{llrrr}
\hline TPL5. La empresa tercerizadora de servicios logisticos (3PL) lleva los problemas de servicio a un \\
final satisfactorio.
\end{tabular}

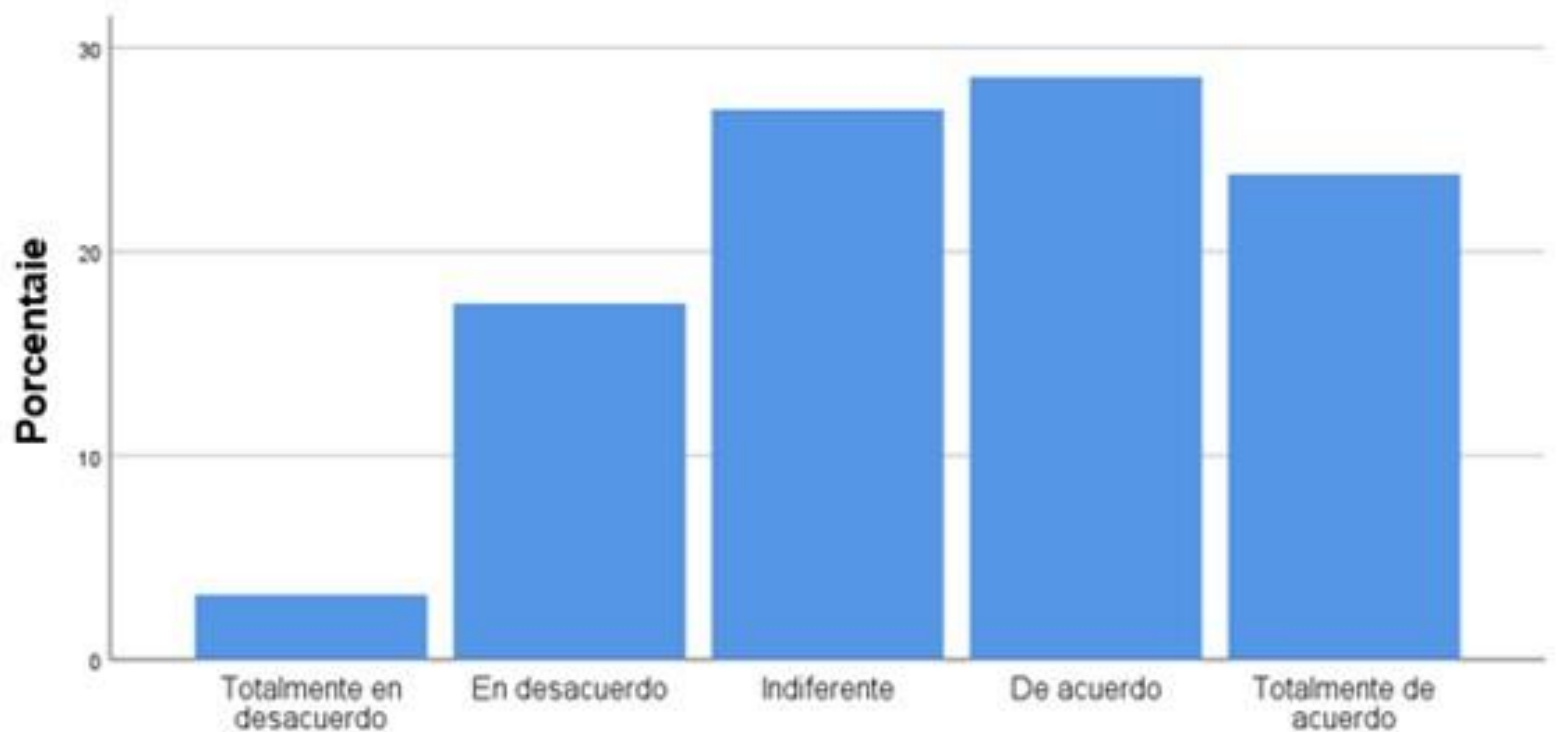

Figura 5. Problemas de servicio

Interpretación: la tabla 14 muestra como del total de los apoderados de las empresas, el 52.4\% está de acuerdo y totalmente de acuerdo con el ítem "La empresa tercerizadora de servicios logísticos (3PL) lleva los problemas de servicio a un final satisfactorio”, el 27\% está indiferente y el $20.6 \%$ está en desacuerd o y totalmente en desacuerdo. Es por esto que se llega a la determinación que la gran mayoría afirma que la empresa tercerizadora de servicios logísticos (3PL) lleva los problemas de servicio a un final satisfactorio. 
Tabla 15:

Requisitos

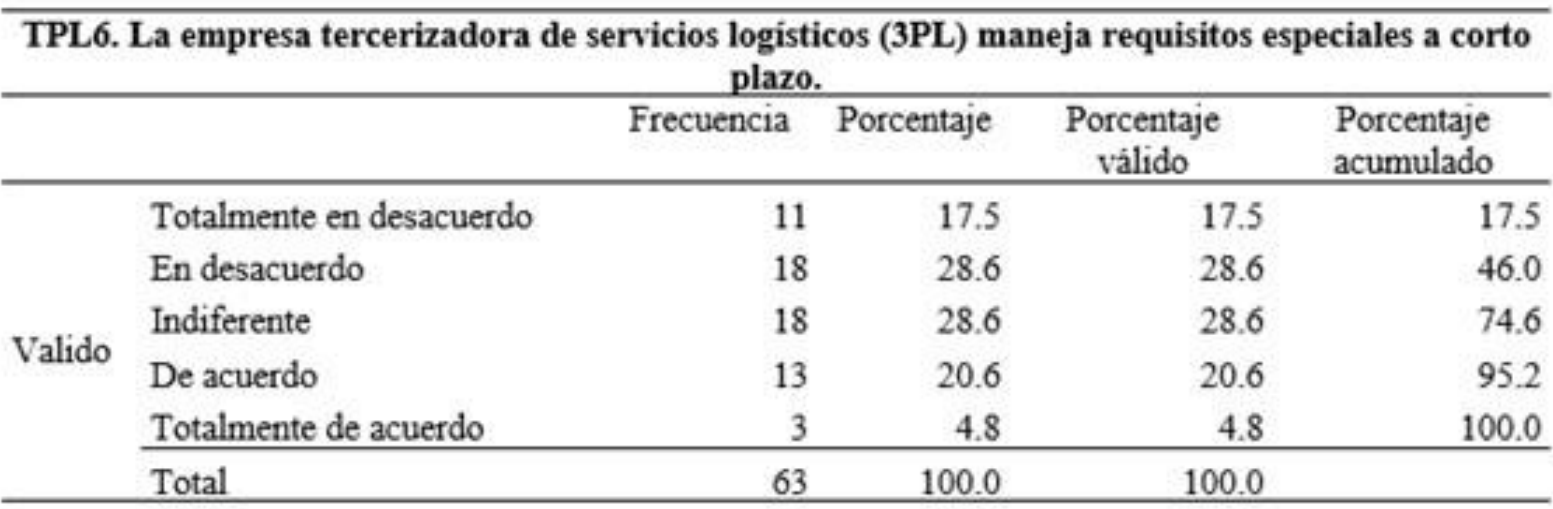

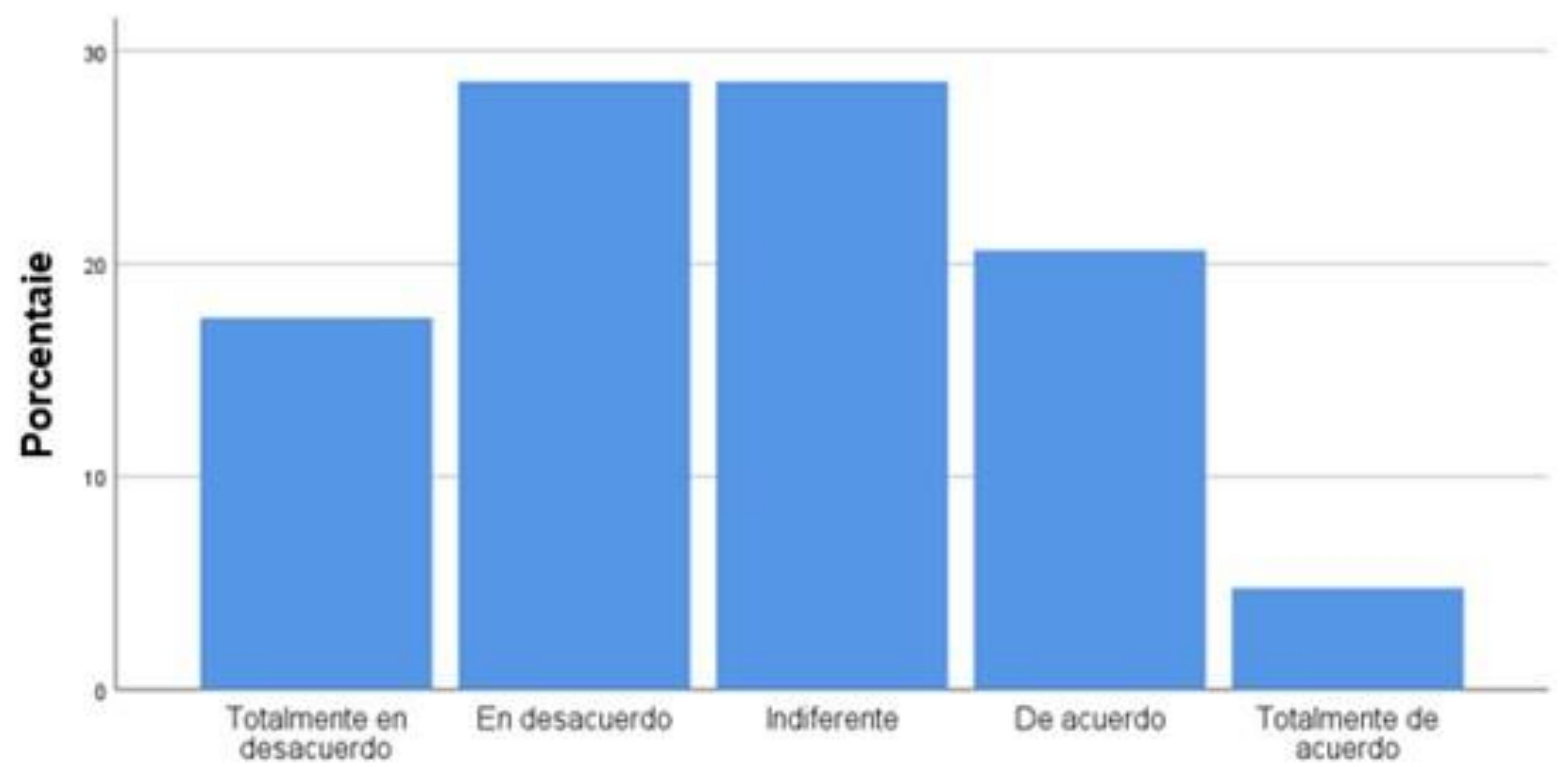

Figura 6. Requisitos

Interpretación: la tabla 15 muestra como del total de los apoderados de las empresas, el $25.4 \%$ está de acuerdo y totalmente de acuerdo con el ítem "La empresa tercerizadora de servicios logísticos (3PL) maneja requisitos especiales a corto plazo”, el 28.6\% está indiferente y el $46 \%$ está en desacuerdo y totalmente en desacuerdo. Es por esto que se llega a la determinación que la gran mayoría afirma que la empresa tercerizadora de servicios logísticos (3PL) no maneja requisitos especiales a corto plazo. 
Tabla 16:

Solicitudes de servicio

\begin{tabular}{|c|c|c|c|c|c|}
\hline \multicolumn{6}{|c|}{$\begin{array}{l}\text { TPL7. La empresa tercerizadora de servicios logísticos (3PL) acomoda } \\
\text { solicitudes de servicio personalizado de manera oportuna. }\end{array}$} \\
\hline & & Frecuencia & Porcentaje & $\begin{array}{l}\text { Porcentaje } \\
\text { válido }\end{array}$ & $\begin{array}{l}\text { Porcentaje } \\
\text { acumulado }\end{array}$ \\
\hline \multirow{6}{*}{ Valido } & Totalmente en desacuerdo & 12 & 19.0 & 19.0 & 19.0 \\
\hline & En desacuerdo & 21 & 33.3 & 33.3 & 52.4 \\
\hline & Indiferente & 14 & 22.2 & 22.2 & 74.6 \\
\hline & De acuerdo & 15 & 23.8 & 23.8 & 98.4 \\
\hline & Totalmente de acuerdo & 1 & 1.6 & 1.6 & 100.0 \\
\hline & Total & 63 & 100.0 & 100.0 & \\
\hline
\end{tabular}

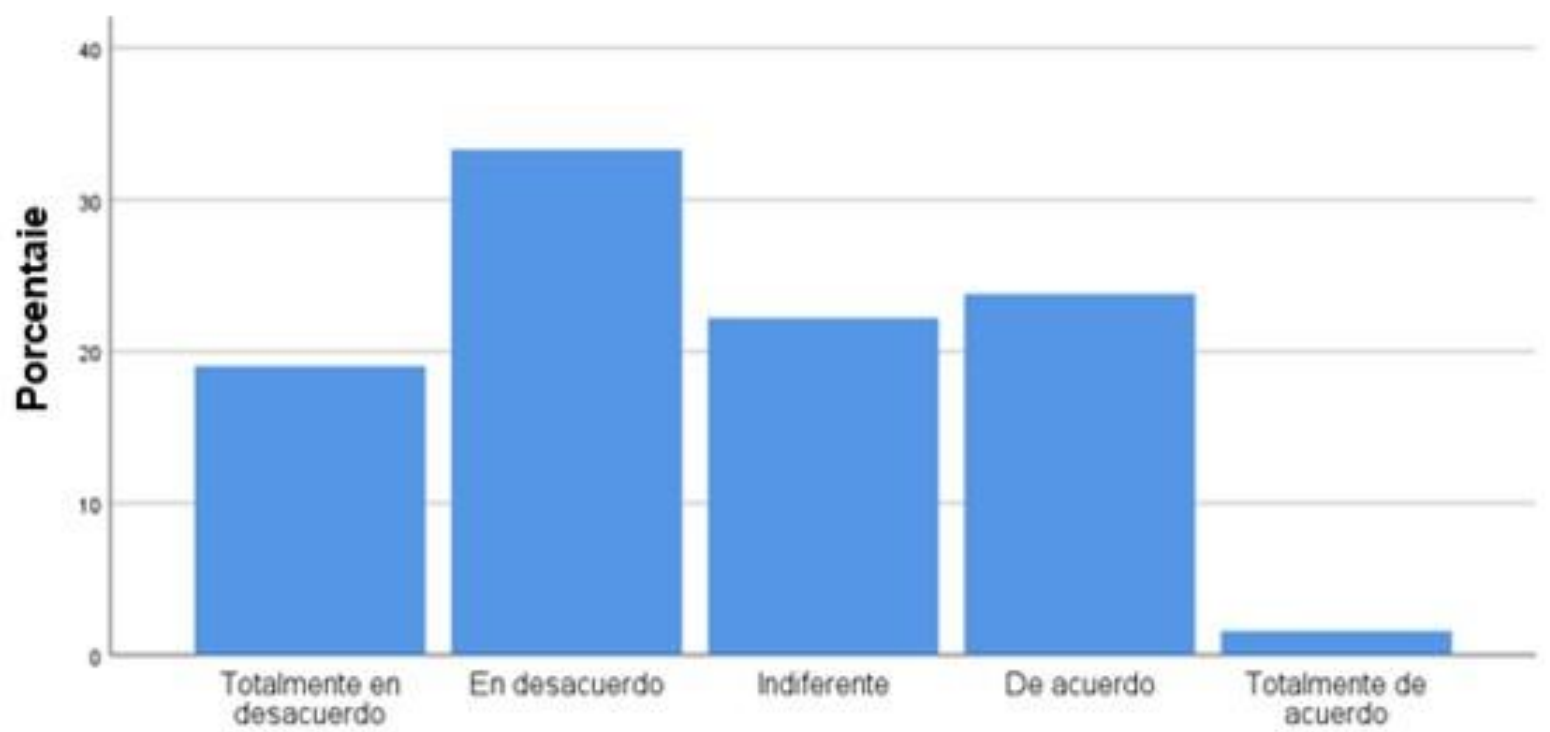

Figura 7. Solicitudes de servicio

Interpretación: la tabla 16 muestra como del total de los apoderados de las empresas, el 25.4\% está de acuerdo y totalmente de acuerdo con el ítem "La empresa tercerizadora de servicios logísticos (3PL) acomoda solicitudes de servicio personalizado de manera oportuna”, el 22.2\% está indiferente y el $52.4 \%$ está en desacuerdo y totalmente en desacuerdo. Es por esto que se llega a la determinación que la gran mayoría afirma que la empresa tercerizadora de servicios logísticos (3PL) no acomoda solicitudes de servicio personalizado de manera oportuna. 
Tabla 17:

Entregas oportunas

\begin{tabular}{llrrrr}
\hline TPLS. La empresa tercerizadora de servicios logisticos (3PL) realiza entregas urgentes de manera \\
oportuna.
\end{tabular}

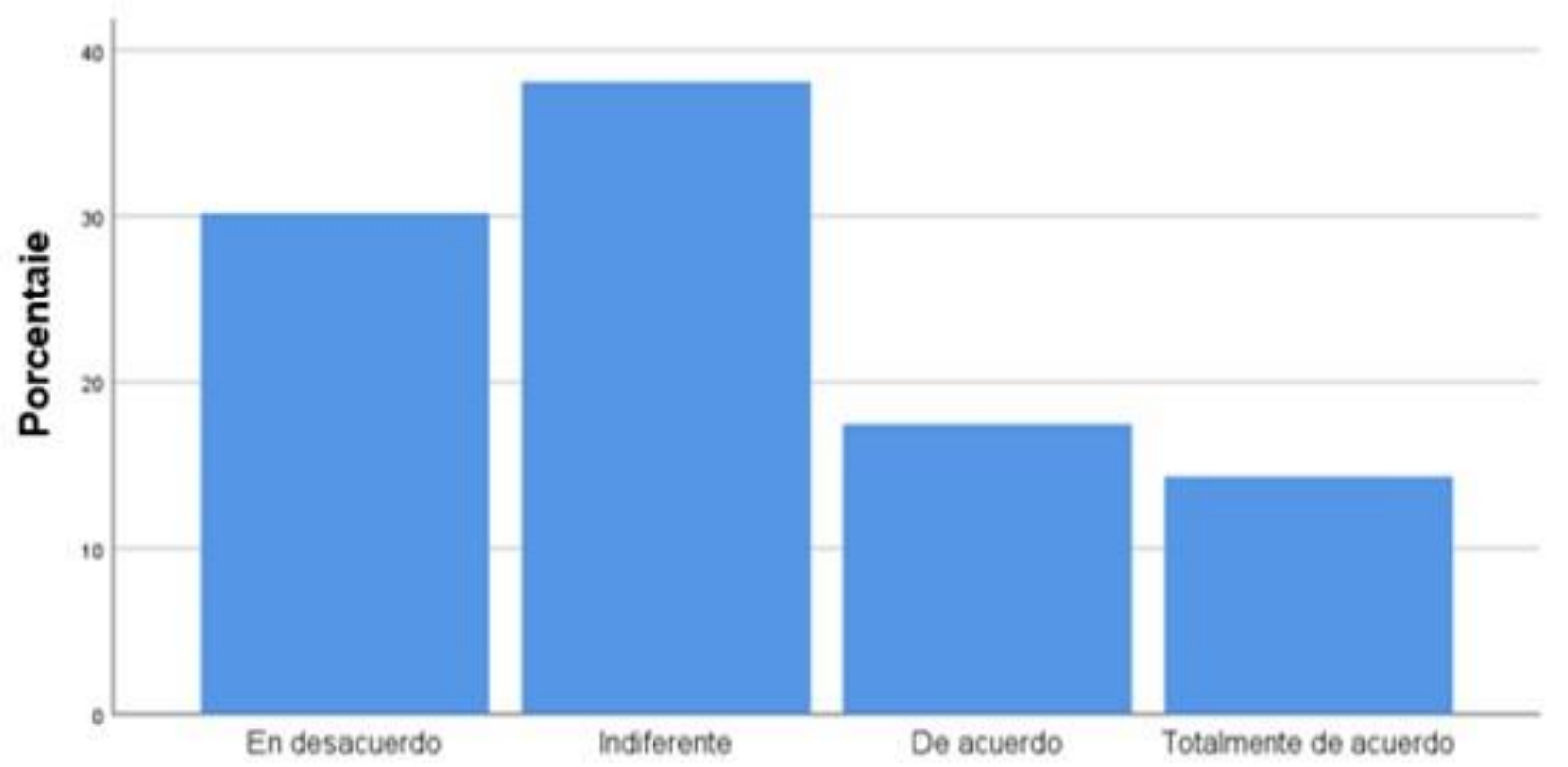

Figura 8. Entregas oportunas

Interpretación: la tabla 17 muestra como del total de los apoderados de las empresas, el 31.8\% está de acuerdo y totalmente de acuerdo con el ítem "La empresa tercerizadora de servicios logísticos (3PL) realiza entregas urgentes de manera oportuna”, el 38.1\% está indiferente y el $30.2 \%$ está en desacuerdo. Es por esto que se llega a la determinación que la gran mayoría afirma no saber si la empresa tercerizadora de servicios logísticos (3PL) realiza entregas urgentes de manera oportuna. 


\section{Servicios complementarios a medida}

Tabla 18:

Mejora de operatividad

\begin{tabular}{|c|c|c|c|c|c|}
\hline \multicolumn{6}{|c|}{$\begin{array}{l}\text { TPL9. La empresa tercerizadora de servicios logísticos (3PL) ayuda a mejorar la eficiencia } \\
\text { operativa. }\end{array}$} \\
\hline & & Frecuencia & Porcentaje & $\begin{array}{l}\text { Porcentaje } \\
\text { válido }\end{array}$ & $\begin{array}{l}\text { Porcentaje } \\
\text { acumulado }\end{array}$ \\
\hline \multirow{5}{*}{ Valido } & En desacuerdo & 2 & 3.2 & 3.2 & 3.2 \\
\hline & Indiferente & 13 & 20.6 & 20.6 & 23.8 \\
\hline & De acuerdo & 5 & 7.9 & 7.9 & 31.7 \\
\hline & Totalmente de acuerdo & 43 & 68.3 & 68.3 & 100.0 \\
\hline & Total & 63 & 100.0 & 100.0 & \\
\hline
\end{tabular}

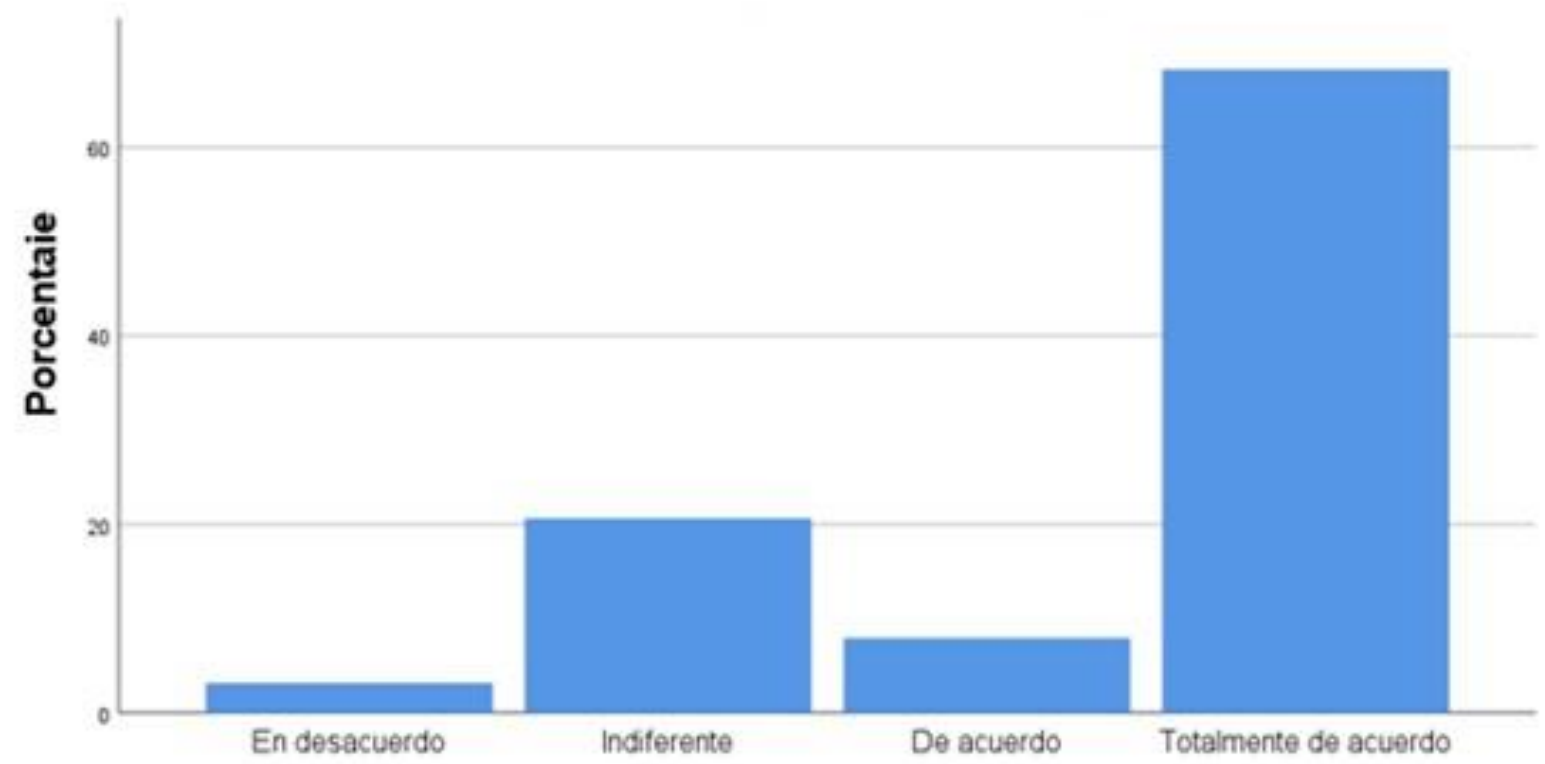

Figura 9. Mejora de operatividad

Interpretación: la tabla 18 muestra como del total de los apoderados de las empresas, el 76.2\% está de acuerdo y totalmente de acuerdo con el ítem "La empresa tercerizadora de servicios logísticos (3PL) realiza el servicio prometido satisfactoriamente", el $20.6 \%$ está indiferente y el $3.2 \%$ está en desacuerdo. Es por esto que se llega a la determinación que la gran mayoría afirma que la empresa tercerizadora de servicios logísticos (3PL) ayuda a mejorar la eficiencia operativa. 
Tabla 19:

Soluciones creativas

\begin{tabular}{|c|c|c|c|c|c|}
\hline \multicolumn{6}{|c|}{$\begin{array}{l}\text { TPL10. La empresa tercerizadora de servicios logisticos (3PL) explora y brinda soluciones } \\
\text { creativas. }\end{array}$} \\
\hline & & Frecuencia & Porcentaje & $\begin{array}{l}\text { Porcentaje } \\
\text { válido }\end{array}$ & $\begin{array}{l}\text { Porcentaje } \\
\text { acumulado }\end{array}$ \\
\hline \multirow{6}{*}{ Valido } & Totalmente en desacuerdo & 13 & 20.6 & 20.6 & 20.6 \\
\hline & En desacuerdo & 8 & 12.7 & 12.7 & 33.3 \\
\hline & Indiferente & 11 & 17.5 & 17.5 & 50.8 \\
\hline & De acuerdo & 28 & 44.4 & 44.4 & 95.2 \\
\hline & Totalmente de acuerdo & 3 & 4.8 & 4.8 & 100.0 \\
\hline & Total & 63 & 100.0 & 100.0 & \\
\hline
\end{tabular}

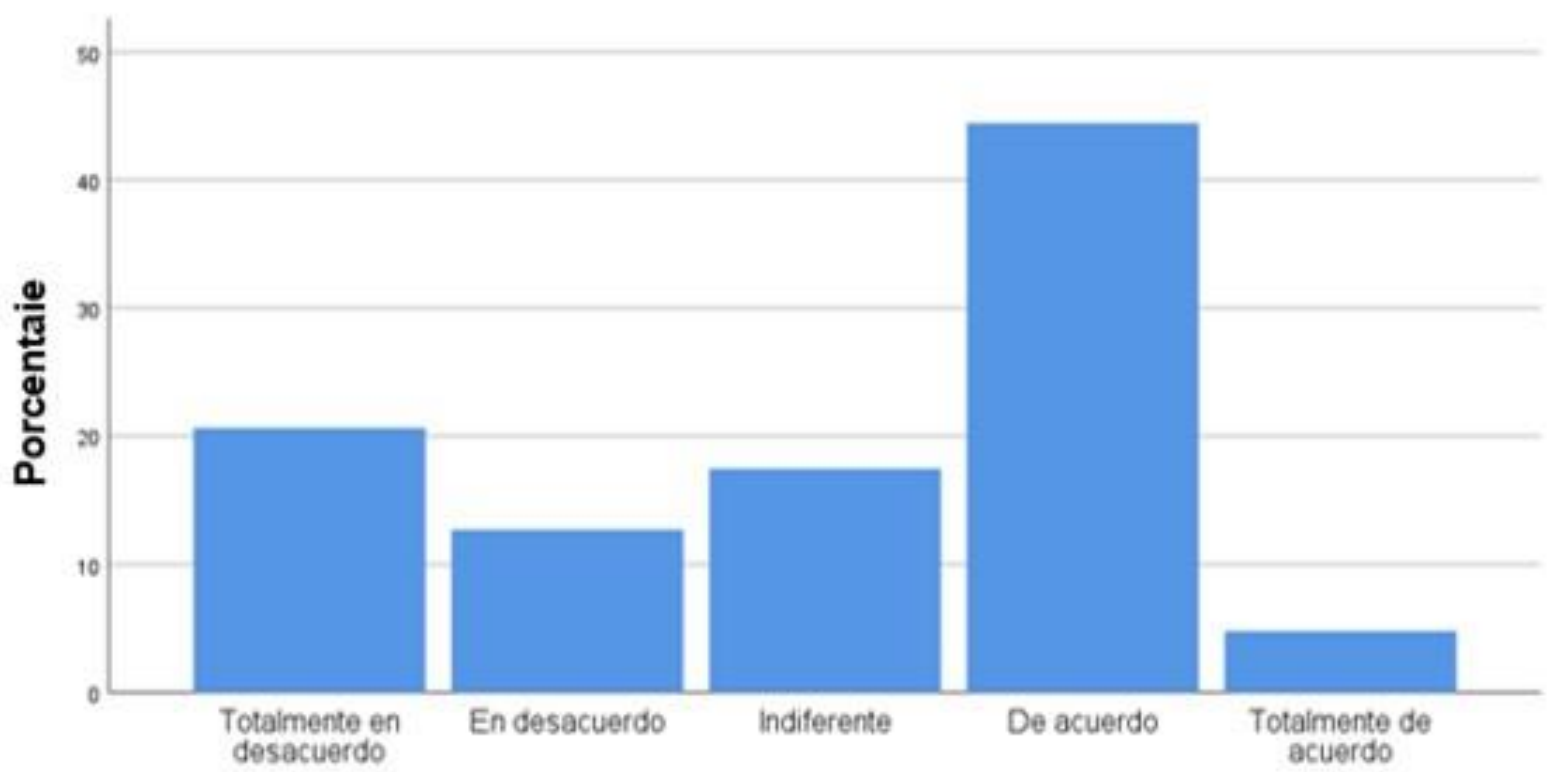

Figura 10. Soluciones creativas

Interpretación: la tabla 19 muestra como del total de los apoderados de las empresas, el 49.2\% está de acuerdo y totalmente de acuerdo con el ítem "La empresa tercerizadora de servicios logísticos (3PL) explora y brinda soluciones creativas", el 17.5\% está indiferente y el 33.3\% está en desacuerdo y totalmente en desacuerdo. Es por esto que se llega a la determinación que la gran mayoría afirma que la empresa tercerizadora de servicios logísticos (3PL) explora y brinda soluciones creativas. 
Tabla 20:

Personalización de servicios

\begin{tabular}{|c|c|c|c|c|c|}
\hline \multicolumn{6}{|c|}{$\begin{array}{l}\text { TPL11. La empresa tercerizadora de servicios logisticos (3PL) personaliza servicios para eventos } \\
\text { inesperados. }\end{array}$} \\
\hline & & Frecuencia & Porcentaje & $\begin{array}{l}\text { Porcentaje } \\
\text { válido }\end{array}$ & $\begin{array}{l}\text { Porcentaje } \\
\text { acumulado }\end{array}$ \\
\hline \multirow{6}{*}{ Valido } & Totalmente en desacuerdo & 2 & 3.2 & 3.2 & 3.2 \\
\hline & En desacuerdo & 13 & 20.6 & 20.6 & 23.8 \\
\hline & Indiferente & 5 & 7.9 & 7.9 & 31.7 \\
\hline & De acuerdo & 19 & 30.2 & 30.2 & 61.9 \\
\hline & Totalmente de acuerdo & 24 & 38.1 & 38.1 & 100.0 \\
\hline & Total & 63 & 100.0 & 100.0 & \\
\hline
\end{tabular}

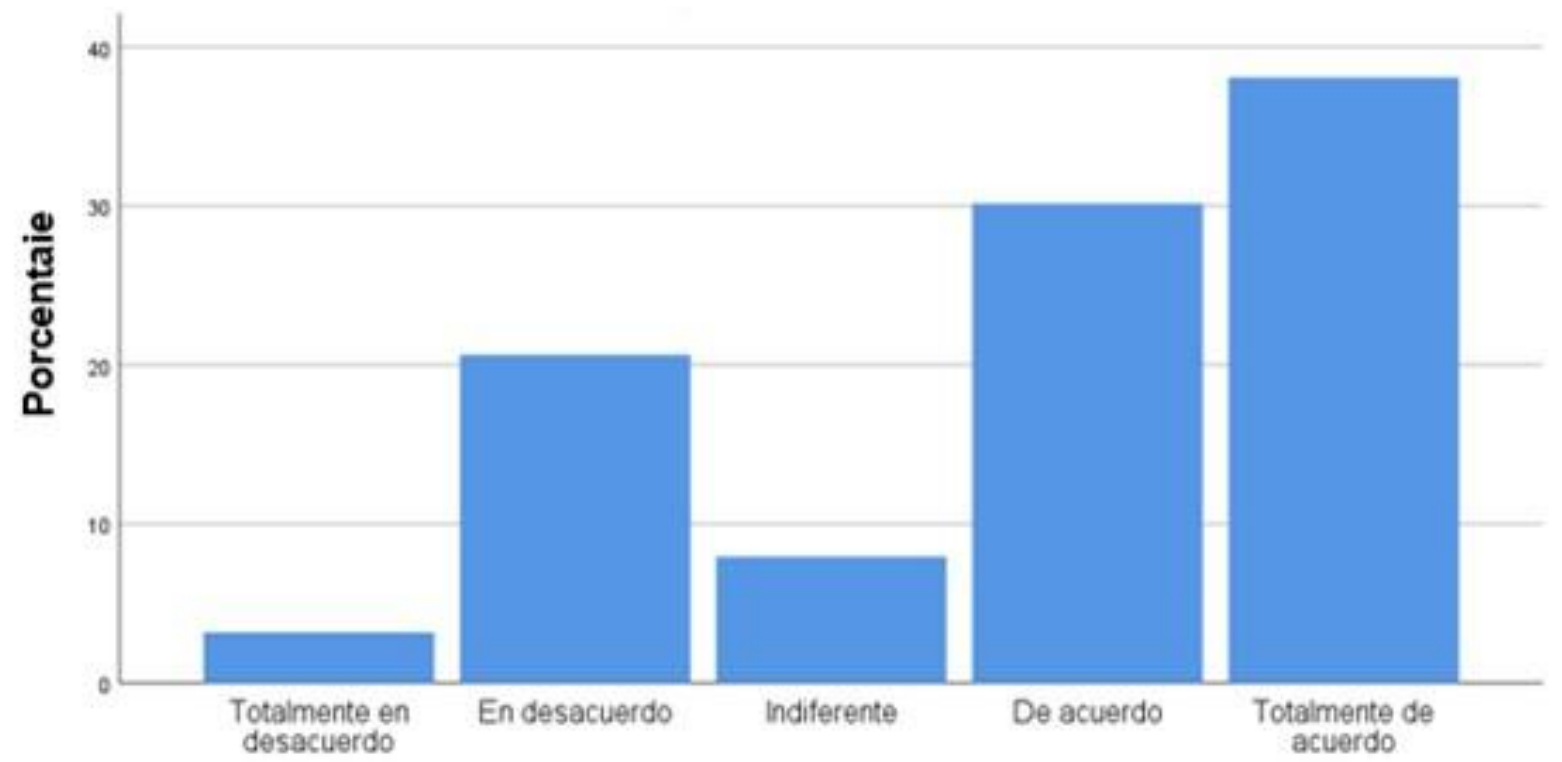

Figura 11. Personalización de servicios

Interpretación: la tabla 20 muestra como del total de los apoderados de las empresas, el 68.3\% está de acuerdo y totalmente de acuerdo con el ítem "La empresa tercerizadora de servicios logísticos (3PL) personaliza servicios para eventos inesperados”, el $7.9 \%$ está indiferente y el 23.8\% está en desacuerdo y totalmente en desacuerdo. Es por esto que se llega a la determinación que la gran mayoría afirma que la empresa tercerizad ora de servicios logísticos (3PL) personaliza servicios para eventos inesperados. 
Tabla 21:

Conocimiento profesional

\begin{tabular}{|c|c|c|c|c|c|}
\hline & & Frecuencia & Porcentaje & $\begin{array}{l}\text { Porcentaje } \\
\text { válido }\end{array}$ & $\begin{array}{l}\text { Porcentaje } \\
\text { acumulado }\end{array}$ \\
\hline \multirow{6}{*}{ Valido } & Totalmente en desacuerdo & 7 & 11.1 & 11.1 & 11.1 \\
\hline & En desacuerdo & 9 & 14.3 & 14.3 & 25.4 \\
\hline & Indiferente & 19 & 30.2 & 30.2 & 55.6 \\
\hline & De acuerdo & 23 & 36.5 & 36.5 & 92.1 \\
\hline & Totalmente de acuerdo & $\underline{5}$ & 7.9 & 7.9 & 100.0 \\
\hline & Total & 63 & 100.0 & 100.0 & \\
\hline
\end{tabular}

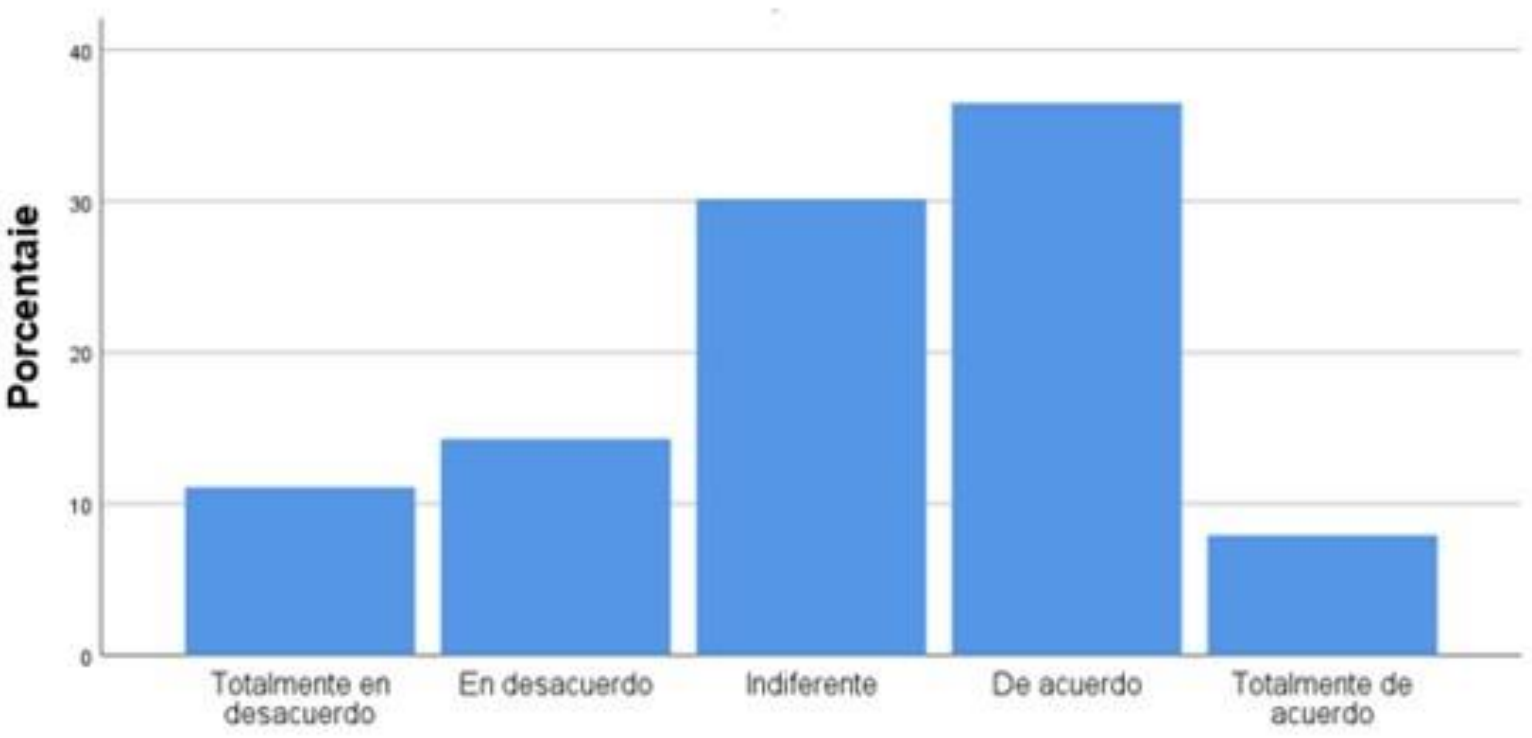

Figura 12. Conocimiento profesional

Interpretación: la tabla 21 muestra como del total de los apoderados de las empresas, el $44.4 \%$ está de acuerdo y totalmente de acuerdo con el ítem "La empresa tercerizadora de servicios logísticos (3PL) posee conocimiento profesional y experiencia en sus empleados”, el 30.2\% está indiferente y el $25.4 \%$ está en desacuerdo y totalmente en desacuerdo. Es por esto que se llega a la determinación que la gran mayoría afirma que la empresa tercerizadora de servicios logísticos (3PL) posee conocimiento profesional y experiencia en sus empleados. 
Tabla 22:

Automatización personalizada

TPL13. La empresa tercerizadora de servicios logísticos (3PL) proporciona automatización personalizada y servicio de II avanzado.

\begin{tabular}{llrrrr}
\hline & Frecuencia & Porcentaje & $\begin{array}{c}\text { Porcentaje } \\
\text { válido }\end{array}$ & $\begin{array}{c}\text { Porcentaje } \\
\text { acumulado }\end{array}$ \\
\hline \multirow{6}{*}{ Valido } & & & 17.5 & 17.5 & 17.5 \\
& Totalmente en desacuerdo & 11 & 11.1 & 11.1 & 28.6 \\
& En desacuerdo & 7 & 11.5 & 50.8 \\
& Indiferente & 14 & 22.2 & 22.2 & 95.2 \\
& De acuerdo & 28 & 44.4 & 44.4 & 100.0 \\
\cline { 2 - 6 } & Totalmente de acuerdo & 3 & 4.8 & 4.8 & \\
\cline { 2 - 6 } & Total & 63 & 100.0 & 100.0 & \\
\hline
\end{tabular}

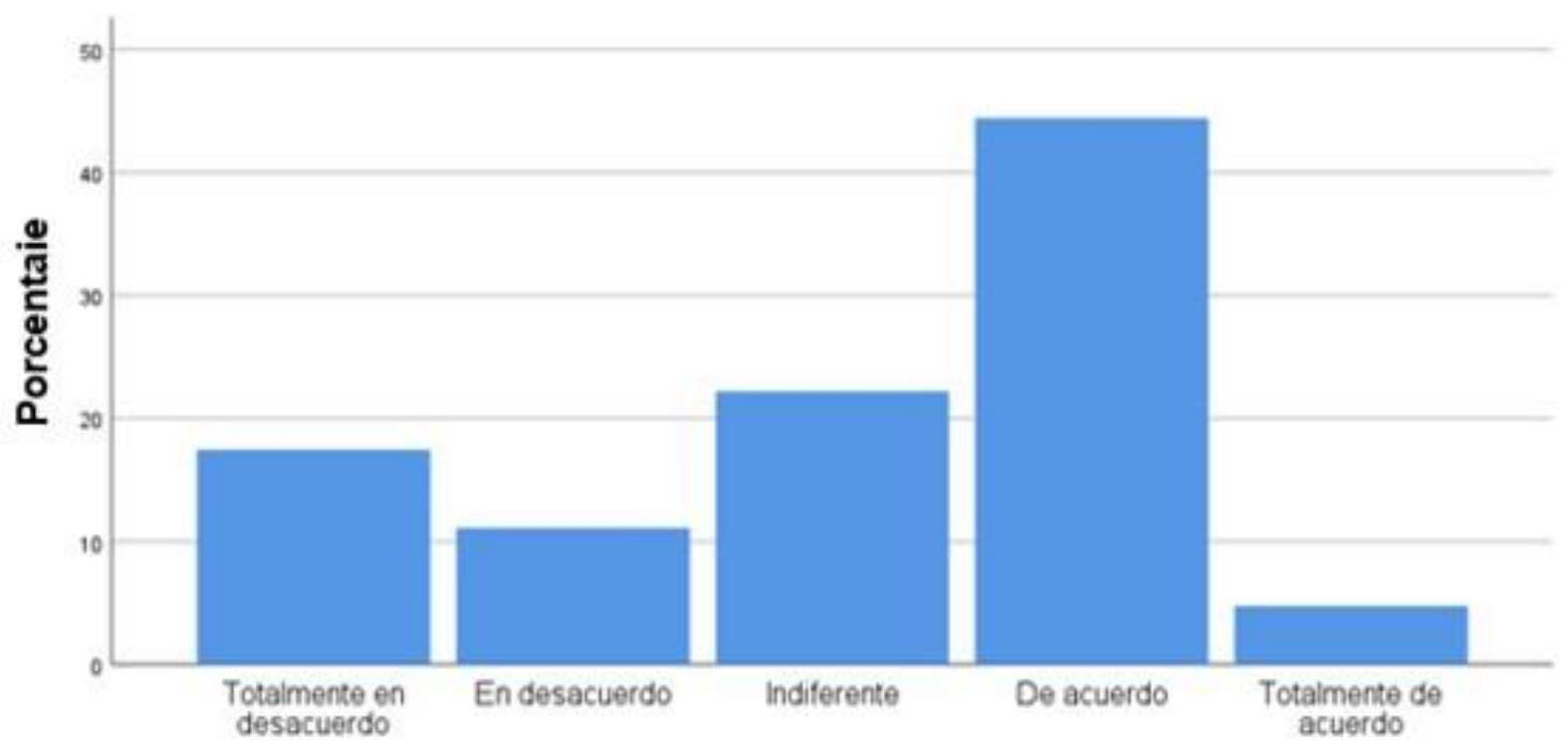

Figura 13. Automatización personalizada

Interpretación: la tabla 22 muestra como del total de los apoderados de las empresas, el 49.2\% está de acuerdo y totalmente de acuerdo con el ítem "La empresa tercerizadora de servicios logísticos (3PL) proporciona automatización personalizada y servicio de TI avanzado", el 22.2\% está indiferente y el $28.6 \%$ está en desacuerdo y totalmente en desacuerdo. Es por esto que se llega a la determinación que la gran mayoría afirma que la empresa tercerizadora de servicios logísticos (3PL) proporciona automatización personalizada y servicio de TI avanzado. 
Tabla 23:

Respuesta a quejas

\begin{tabular}{|c|c|c|c|c|c|}
\hline \multicolumn{6}{|c|}{ TPL14. La empresa tercerizadora de servicios logísticos (3PL) responde a las quejas. } \\
\hline & & Frecuencia & Porcentaje & $\begin{array}{c}\text { Porcentaje } \\
\text { válido }\end{array}$ & $\begin{array}{l}\text { Porcentaje } \\
\text { acumulado }\end{array}$ \\
\hline \multirow{6}{*}{ Valido } & Totalmente en desacuerdo & 8 & 12.7 & 12.7 & 12.7 \\
\hline & En desacuerdo & 8 & 12.7 & 12.7 & 25.4 \\
\hline & Indiferente & 14 & 22.2 & 22.2 & 47.6 \\
\hline & De acuerdo & 29 & 46.0 & 46.0 & 93.7 \\
\hline & Totalmente de acuerdo & 4 & 6.3 & 6.3 & 100.0 \\
\hline & Total & 63 & 100.0 & 100.0 & \\
\hline
\end{tabular}

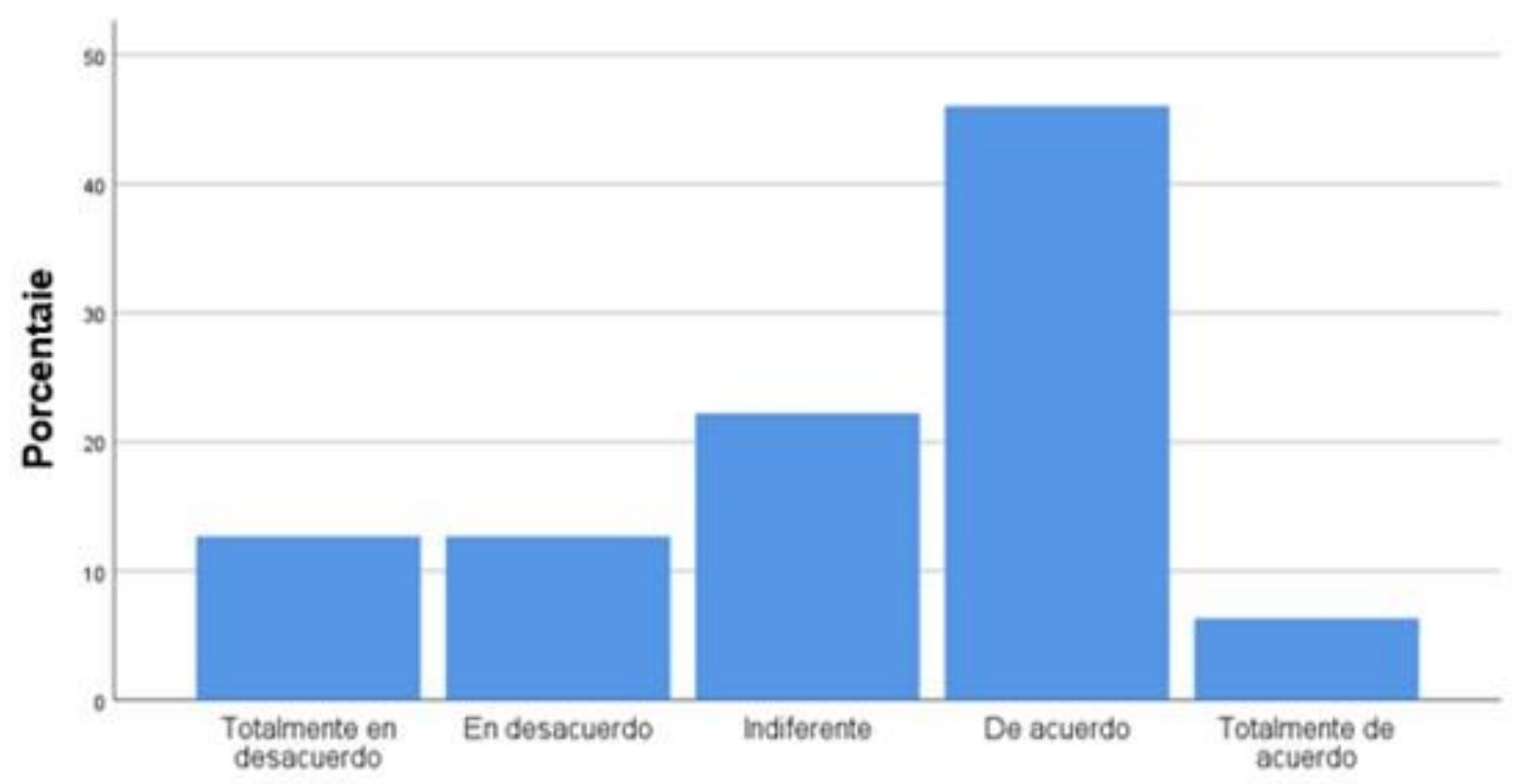

Figura 14. Respuesta a quejas

Interpretación: la tabla 23 muestra como del total de los apoderados de las empresas, el 52.3\% está de acuerdo y totalmente de acuerdo con el ítem "La empresa tercerizadora de servicios logísticos (3PL) responde a las quejas”, el 22.2\% está indiferente y el 25.4\% está en desacuerdo y totalmente en desacuerdo. Es por esto que se llega a la determinación que la gran mayoría afirma que la empresa tercerizadora de servicios logísticos (3PL) responde a las quejas. 
Tabla 24:

Servicio integral

\begin{tabular}{llrrr}
\hline TPL15. La empresa tercerizadora de servicios logisticos (3PL) proporciona un paquete completo \\
de servicio integral.
\end{tabular}

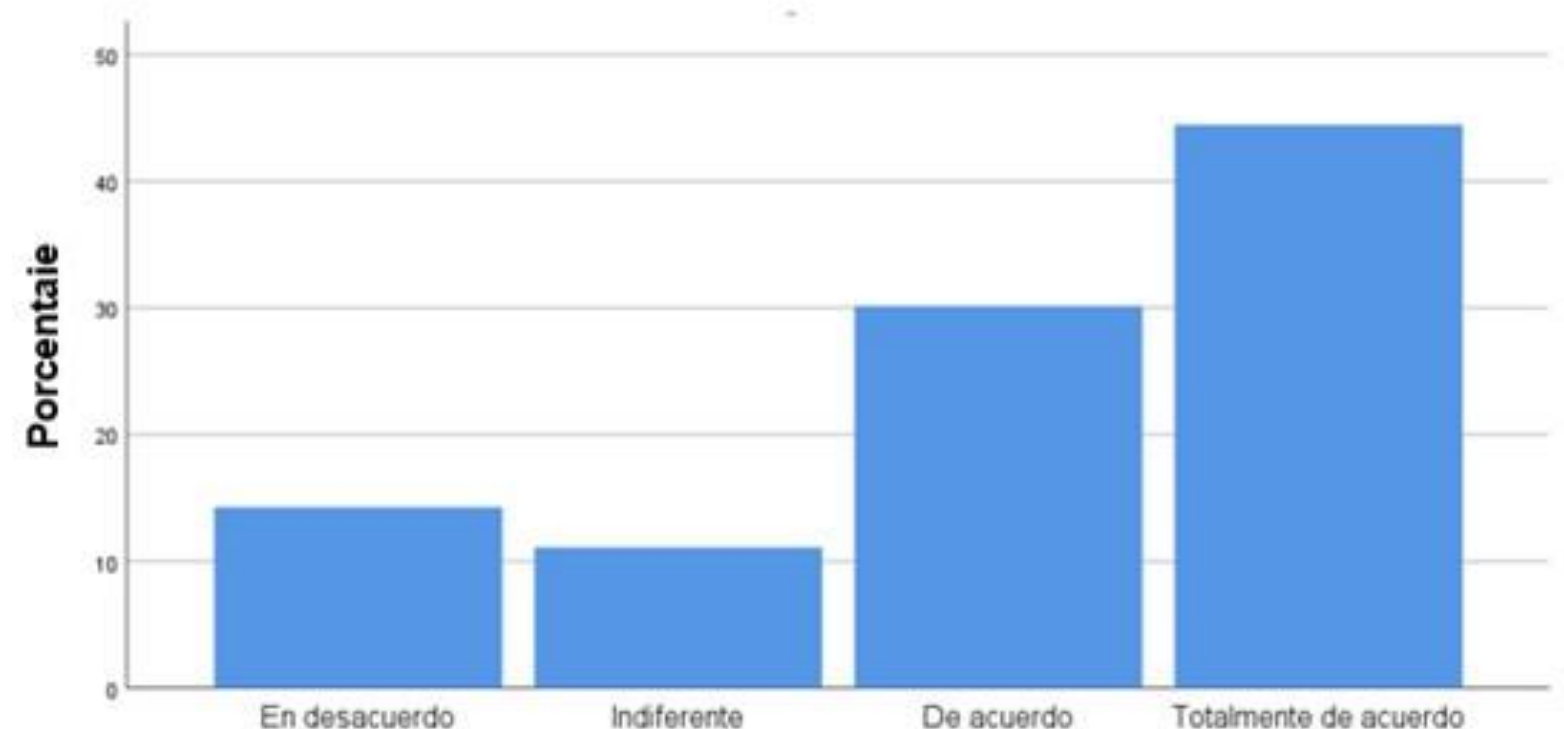

Figura 15. Servicio integral

Interpretación: la tabla 24 muestra como del total de los apoderados de las empresas, el 74.6\% está de acuerdo y totalmente de acuerdo con el ítem "La empresa tercerizadora de servicios logísticos (3PL) proporciona un paquete completo de servicio integral”, el 11.1\% está indiferente y el $14.3 \%$ está en desacuerdo. Es por esto que se llega a la determinación que la gran mayoría afirma que la empresa tercerizadora de servicios logísticos (3PL) proporciona un paquete completo de servicio integral. 


\section{Factor de fijación de precios}

Tabla 25:

Precios de servicios

\begin{tabular}{llrrr}
\hline \multicolumn{5}{c}{ TPL16. La empresa tercerizadora de servicios logisticos (3PL) posee precios razonables según la } \\
calidad de los servicios prestados.
\end{tabular}

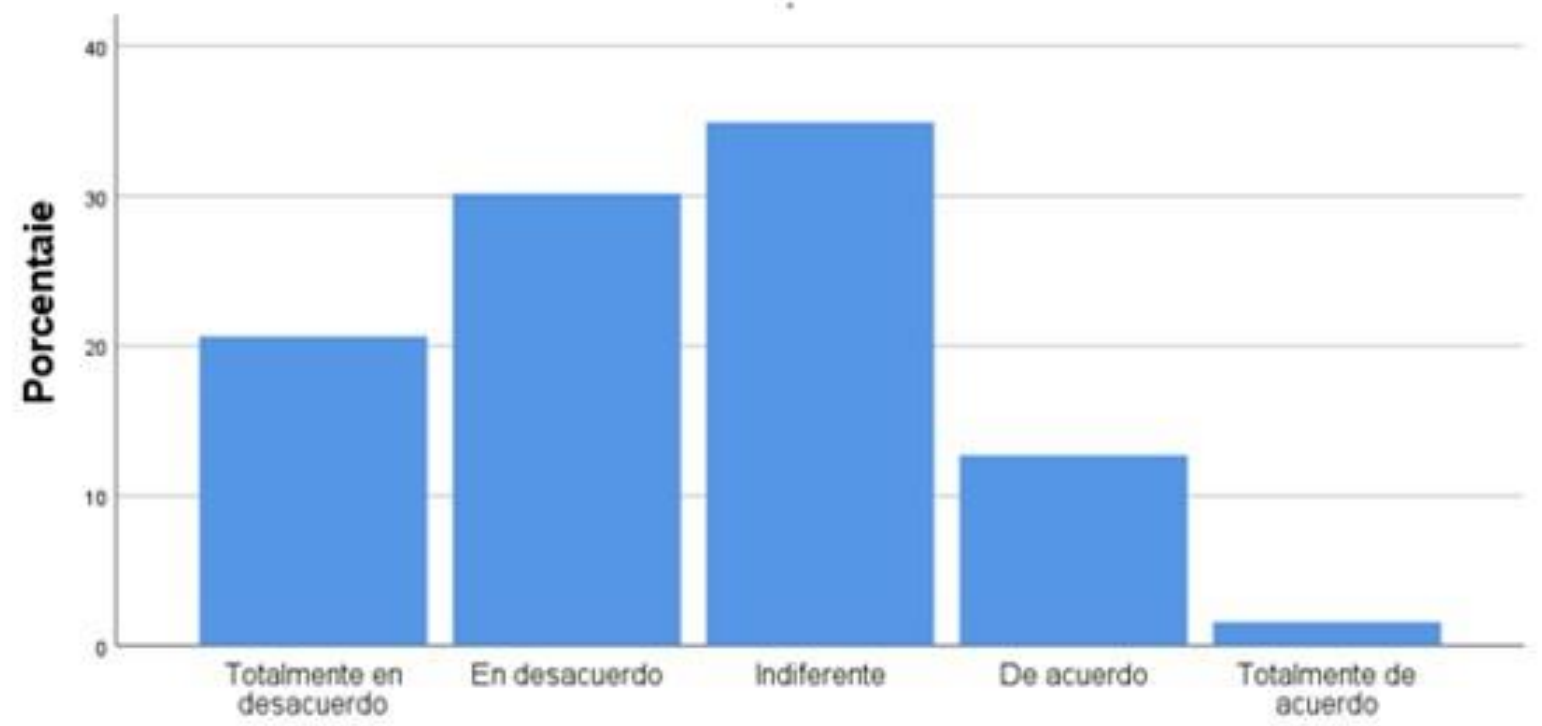

Figura 16. Precios de servicios

Interpretación: la tabla 25 muestra como del total de los apoderados de las empresas, el 14.3\% está de acuerdo y totalmente de acuerdo con el ítem "La empresa tercerizadora de servicios logísticos (3PL) posee precios razonables según la calidad de los servicios prestados”, el 34.9\% está indiferente, y el $50.8 \%$ está en desacuerdo y totalmente en desacuerdo. Es por esto que se llega a la determinación que la gran mayoría afirma que la empresa tercerizadora de servicios logísticos (3PL) no posee precios razonables según la calidad de los servicios prestados. 
Tabla 26:

Comparación de precios

TPL17. La empresa tercerizadora de servicios logisticos (3PL) posee mejores precios en comparación con servicios similares de competidores.

\begin{tabular}{llrrrr}
\hline & Frecuencia & Porcentaje & $\begin{array}{c}\text { Porcentaje } \\
\text { válido }\end{array}$ & $\begin{array}{c}\text { Porcentaje } \\
\text { acumulado }\end{array}$ \\
\hline \multirow{6}{*}{ Valido } & & & 3.2 & 3.2 \\
& Totalmente en desacuerdo & 2 & 3.2 & 23.8 & 27.0 \\
& En desacuerdo & 15 & 23.8 & 20.6 & 47.6 \\
& Indiferente & 13 & 20.6 & 42.9 & 90.5 \\
& De acuerdo & 27 & 42.9 & 9.5 & 100.0 \\
\cline { 2 - 6 } & Totalmente de acuerdo & 6 & 9.5 & 100.0 & \\
\hline
\end{tabular}

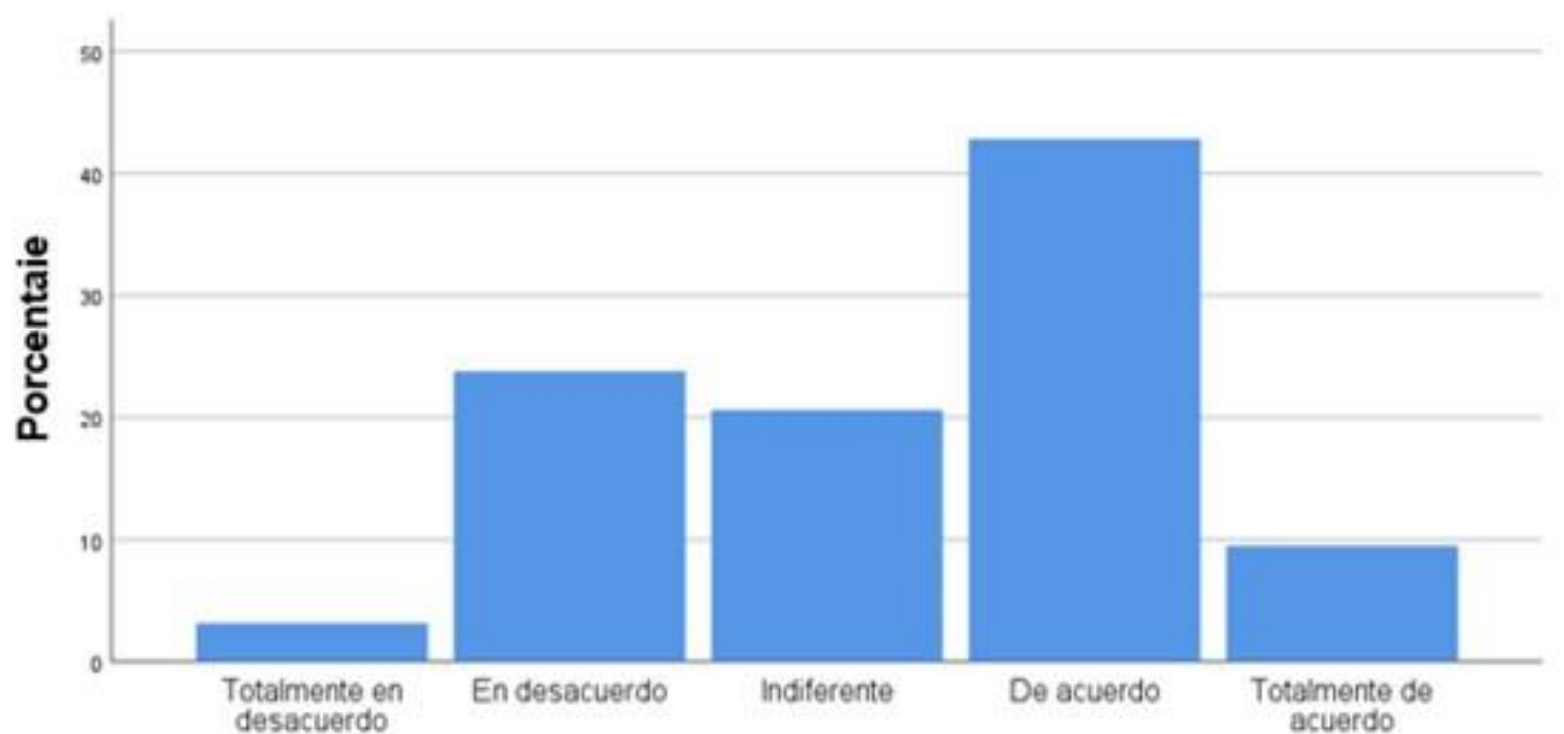

Figura 17. Comparación de precios

Interpretación: la tabla 26 muestra como del total de los apoderados de las empresas, el 52.4\% está de acuerdo y totalmente de acuerdo con el ítem "La empresa tercerizadora de servicios logísticos (3PL) posee mejores precios en comparación con servicios similares de competidores", el 20.6\% está indiferente, y el 27\% está en desacuerdo y totalmente en desacuerdo. Es por esto que se llega a la determinación que la gran mayoría afirma que la empresa tercerizadora de servicios logísticos (3PL) posee mejores precios en comparación con servicios similares de competidores. 


\section{Calidad de entrega}

Tabla 27:

Calidad de embalaje

\begin{tabular}{|c|c|c|c|c|c|}
\hline & & Frecuencia & Porcentaje & $\begin{array}{c}\text { Porcentaje } \\
\text { válido }\end{array}$ & $\begin{array}{l}\text { Porcentaje } \\
\text { acumulado }\end{array}$ \\
\hline \multirow{5}{*}{ Valido } & En desacuerdo & 2 & 3.2 & 3.2 & 3.2 \\
\hline & Indiferente & 10 & 15.9 & 15.9 & 19.0 \\
\hline & De acuerdo & 15 & 23.8 & 23.8 & 42.9 \\
\hline & Totalmente de acuerdo & 36 & 57.1 & 57.1 & 100.0 \\
\hline & Total & 63 & 100.0 & 100.0 & \\
\hline
\end{tabular}

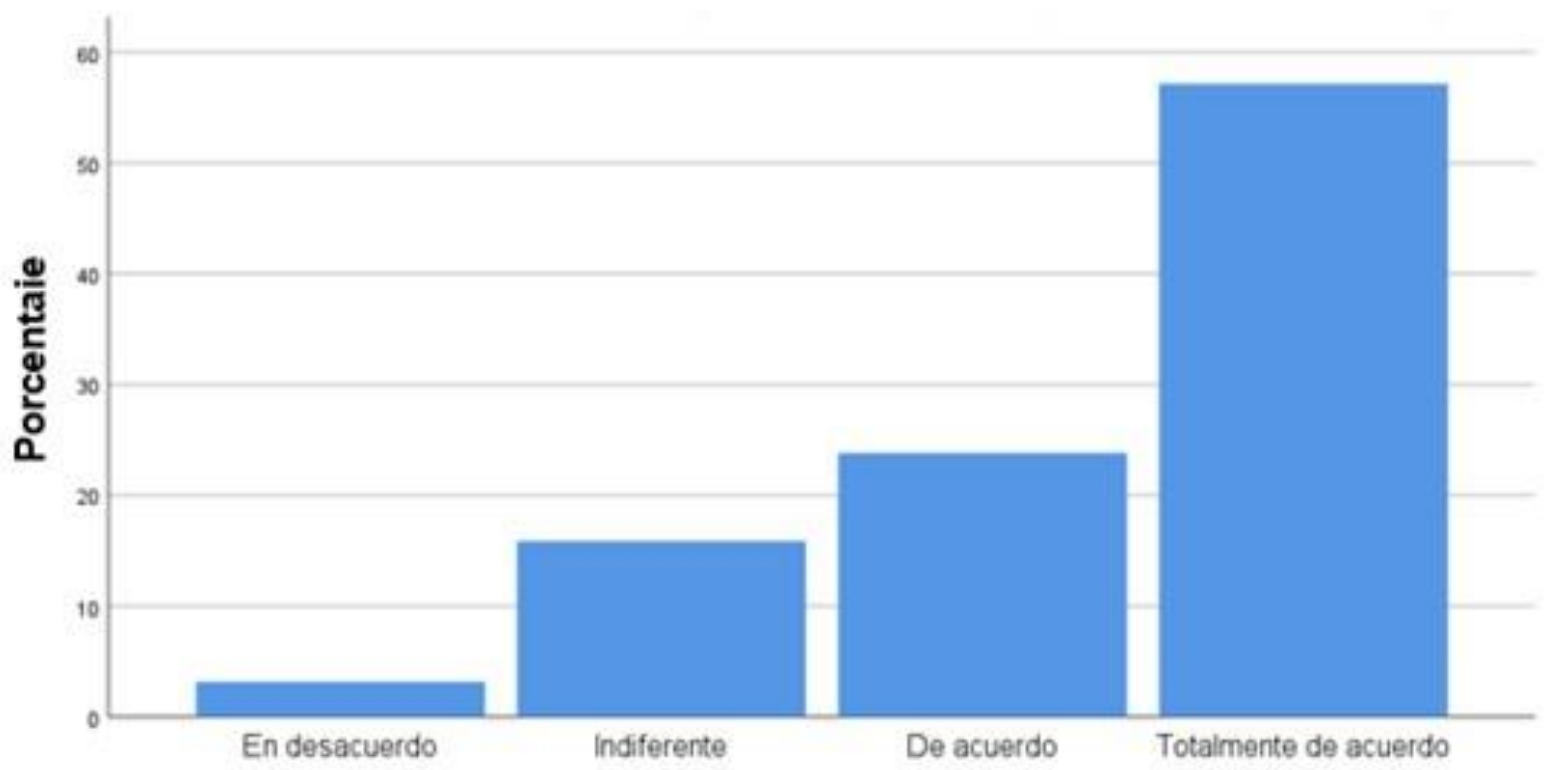

Figura 18. Calidad de embalaje

Interpretación: la tabla 27 muestra como del total de los apoderados de las empresas, el 80.9\% está de acuerdo y totalmente de acuerdo con el ítem "La empresa tercerizadora de servicios logísticos (3PL) posee mejor calidad de embalaje entregado", el 15.9\% está indiferente y el 3.2\% está en desacuerdo. Es por esto que se llega a la determinación que la gran mayoría afirma que la empresa tercerizadora de servicios logísticos (3PL) posee mejor calidad de embalaje entregado. 
Tabla 28:

Manipulación de mercancías

\begin{tabular}{|c|c|c|c|c|c|}
\hline \multicolumn{6}{|c|}{$\begin{array}{l}\text { TPL19. La empresa tercerizadora de servicios logísticos (3PL) posee mejor calidad de la } \\
\text { manipulación de mercancias. }\end{array}$} \\
\hline & & Frecuencia & Porcentaje & Porcentaje válido & $\begin{array}{l}\text { Porcentaje } \\
\text { acumulado }\end{array}$ \\
\hline \multirow{4}{*}{ Valido } & En desacuerdo & 8 & 12.7 & 12.7 & 12.7 \\
\hline & Indiferente & 46 & 73.0 & 73.0 & 85.7 \\
\hline & De acuerdo & 9 & 14.3 & 14.3 & 100.0 \\
\hline & Total & 63 & 100.0 & 100.0 & \\
\hline
\end{tabular}

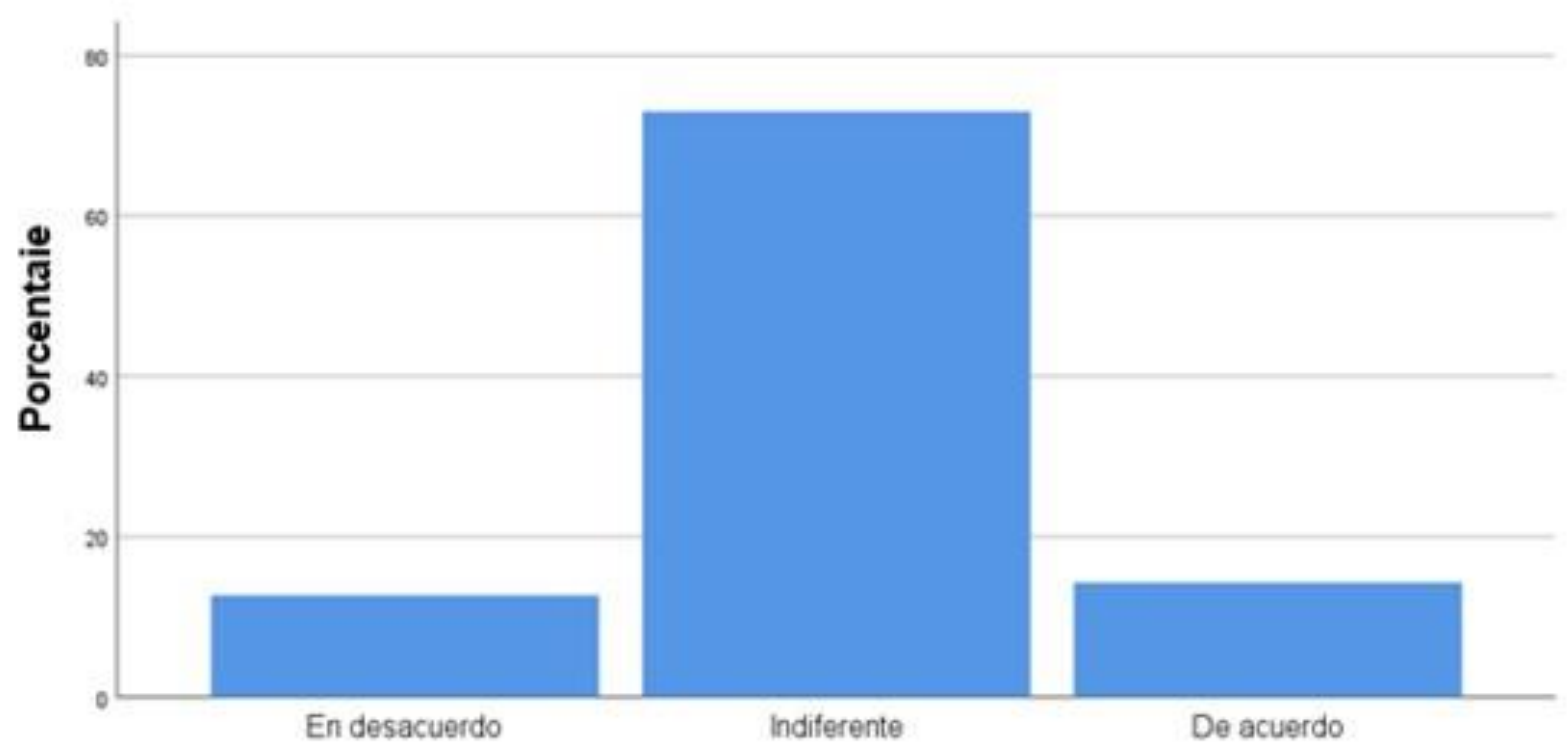

Figura 19. Manipulación de mercancías

Interpretación: la tabla 28 muestra como del total de los apoderados de las empresas, el 14.3\% está de acuerdo con el ítem "La empresa tercerizadora de servicios logísticos (3PL) posee mejor calidad de la manipulación de mercancías”, el 73\% está ind iferente, y el 12.7\% está en desacuerdo. Es por esto que se llega a la determinación que la gran mayoría afirma no saber si la empresa tercerizad ora de servicios logísticos (3PL) posee mejor calidad de la manipulación de mercancías. 


\subsubsection{Análisis de resultados de desempeño exportador}

\section{Desempeño de exportación del usuario}

Tabla 29:

Percepción de rentabilidad

\begin{tabular}{lrrrr}
\hline \multicolumn{5}{c}{ DEXPl. La percepción de la rentabilidad de las exportaciones se encuentra. } \\
\hline & Frecuencia & Porcentaje & $\begin{array}{c}\text { Porcentaje } \\
\text { valido }\end{array}$ & $\begin{array}{c}\text { Porcentaje } \\
\text { acumulado }\end{array}$ \\
\hline Muy por debajo de las expectativas & 3 & 4.8 & 4.8 & 4.8 \\
Debajo de las expectativas & 10 & 15.9 & 15.9 & 20.6 \\
Valido Ni debajo ni encima de las expectativas & 20 & 31.7 & 31.7 & 52.4 \\
Encima de las expectativas & 15 & 23.8 & 23.8 & 76.2 \\
Muy por encima de las expectativas & 15 & 23.8 & 23.8 & 100.0 \\
\hline Total & 63 & 100.0 & 100.0 & \\
\hline
\end{tabular}

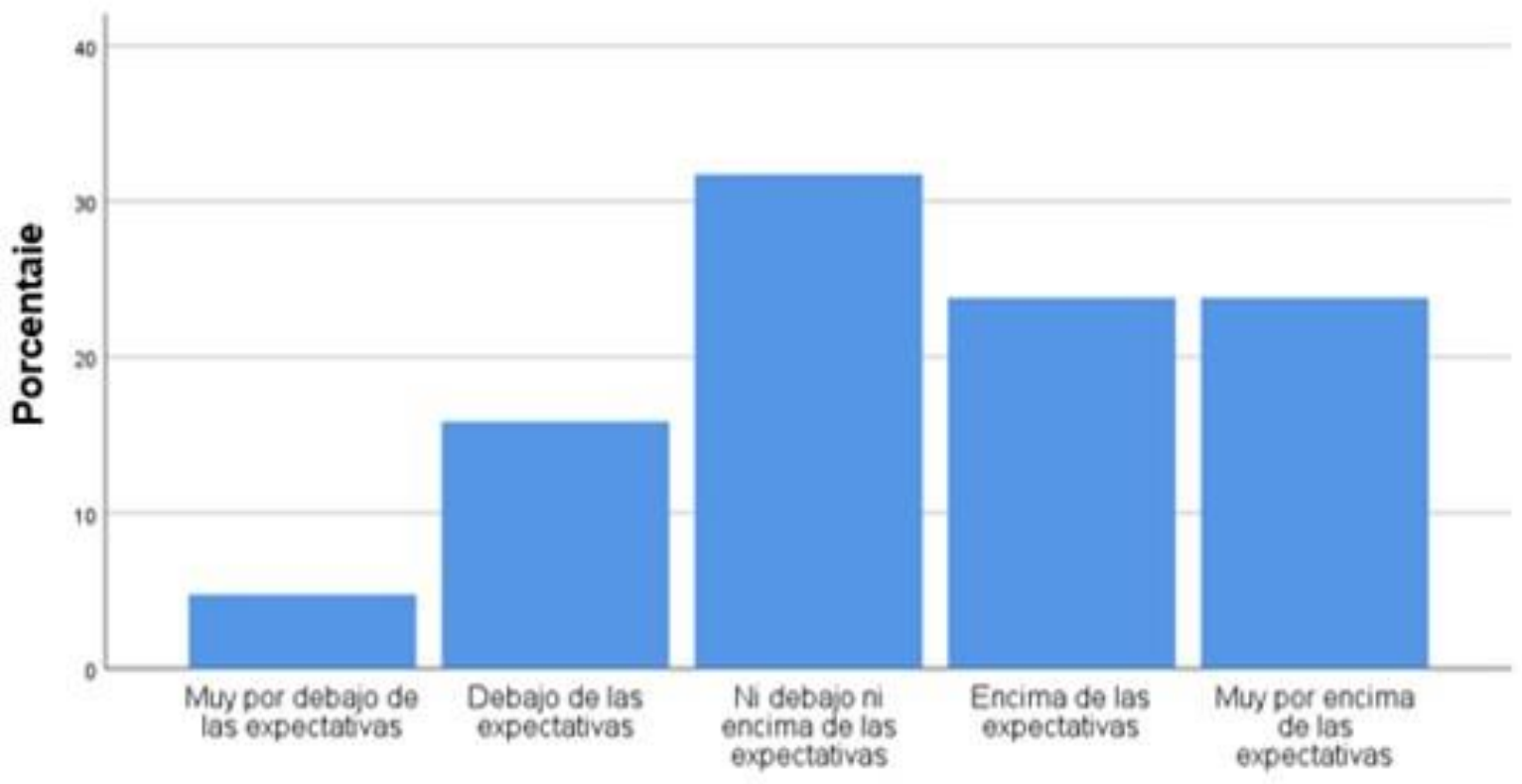

Figura 20. Percepción de rentabilidad

Interpretación: la tabla 29 muestra como del total de los apoderados de las empresas, el 47.6\% respondió ante el ítem "La percepción de la rentabilidad de las exportaciones se encuentra" muy por encima de las expectativas y encima de las expectativas, el 31.7\% ni debajo ni encima de las expectativas, y el $20.7 \%$ debajo de las expectativas y muy por debajo de las expectativas. Es por esto que se llega a la determinación que la gran mayoría afirma que la percepción dela rentabilidad de las exportaciones se encuentra encima de las expectativas. 
Tabla 30:

Cuota de mercado

\begin{tabular}{|c|c|c|c|c|c|}
\hline \multicolumn{6}{|c|}{ DEXP2. La cuota de mercado en los mercados objetivo se encuentra. } \\
\hline & & Frecuencia & Porcentaje & $\begin{array}{c}\text { Porcentaje } \\
\text { válido }\end{array}$ & $\begin{array}{l}\text { Porcentaje } \\
\text { acumulado }\end{array}$ \\
\hline \multirow{6}{*}{ Valido } & Muy por debajo de las expectativas & 3 & 4.8 & 4.8 & 4.8 \\
\hline & Debajo de las expectativas & 9 & 14.3 & 14.3 & 19.0 \\
\hline & $\mathrm{Ni}$ debajo ni encima de las expectativas & 15 & 23.8 & 23.8 & 42.9 \\
\hline & Encima de las expectativas & 19 & 30.2 & 30.2 & 73.0 \\
\hline & Muy por encima de las expectativas & 17 & 27.0 & 27.0 & 100.0 \\
\hline & Total & 63 & 100.0 & 100.0 & \\
\hline
\end{tabular}

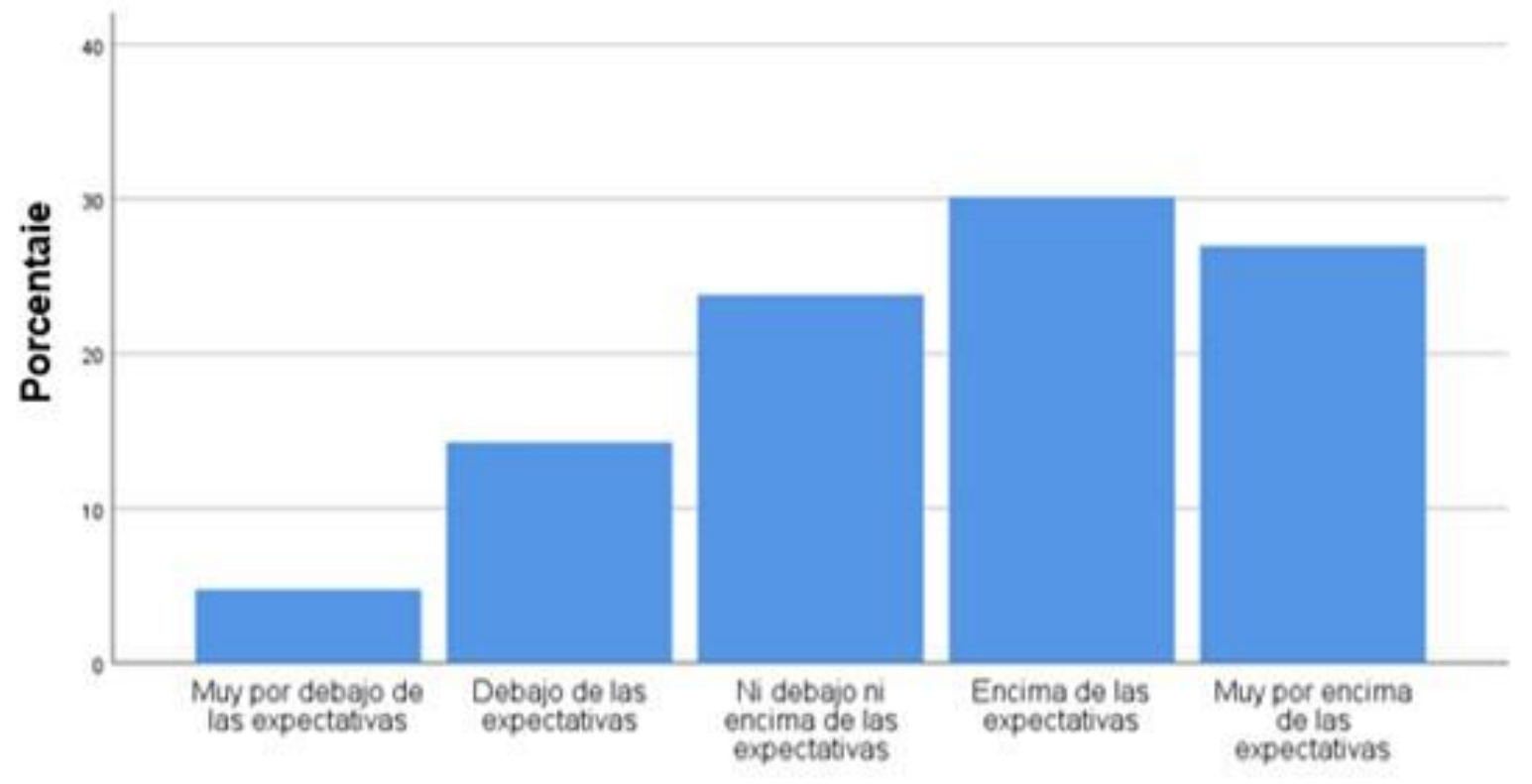

Figura 21. Cuota de mercado

Interpretación: la tabla 30 muestra como del total de los apoderados de las empresas, el 57.2\% respondió ante el ítem "La cuota de mercado en los mercados objetivo se encuentra" muy por encima de las expectativas y encima de las expectativas, el $23.8 \%$ ni debajo ni encima de las expectativas, y el 19\% debajo de las expectativas y muy por debajo de las expectativas. Es por esto que se llega a la determinación que la gran mayoría afirma que la cuota de mercado en los mercados objetivo se encuentra encima de las expectativas. 
Tabla 31:

Desempeño de ventas

\begin{tabular}{llrrr}
\hline \multicolumn{6}{c}{ DEXP3. El desempeño en las ventas y crecimiento exportador se encuentra. } \\
\hline & Frecuencia & Porcentaje & $\begin{array}{c}\text { Porcentaje } \\
\text { válido }\end{array}$ & $\begin{array}{r}\text { Porcentaje } \\
\text { acumulado }\end{array}$ \\
\hline Muy por debajo de las expectativas & 4 & 6.3 & 6.3 & 6.3 \\
Debajo de las expectativas & 7 & 11.1 & 11.1 & 17.5 \\
Valido & 18 & 28.6 & 28.6 & 46.0 \\
Ni debajo ni encima de las expectativas & 18 & 28.6 & 28.6 & 74.6 \\
Encima de las expectativas & 16 & 25.4 & 25.4 & 100.0 \\
Muy por encima de las expectativas & 63 & 100.0 & 100.0 & \\
\cline { 2 - 6 } & Total & & &
\end{tabular}

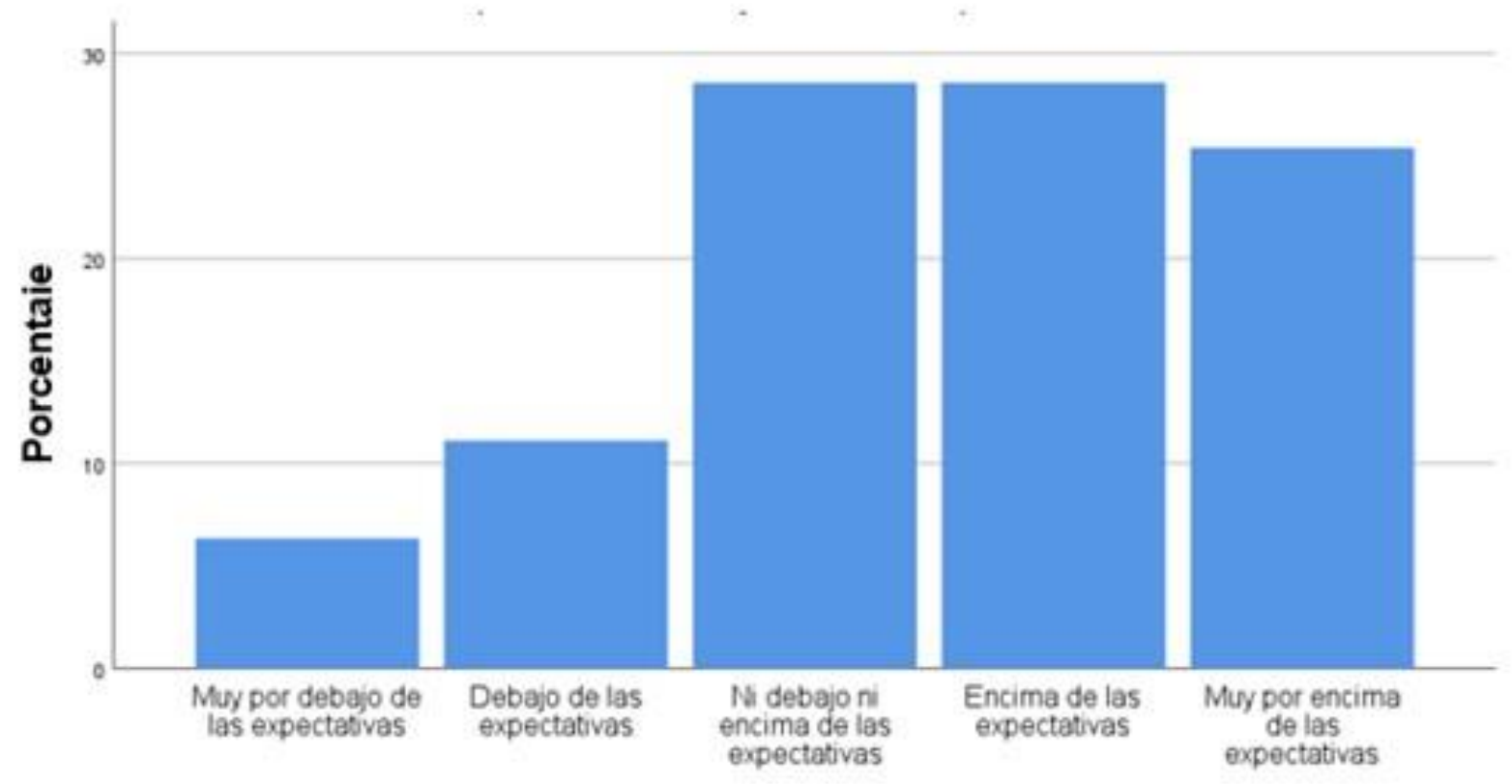

Figura 22. Desempeño de ventas

Interpretación: la tabla 31 muestra como del total de los apoderados de las empresas, el 54\% respondió ante el ítem "El desempeño en las ventas y crecimiento exportador se encuentra" muy por encima de las expectativas y encima de las expectativas, el $28.6 \%$ ni debajo ni encima de las expectativas, y el $17.4 \%$ debajo de las expectativas y muy por debajo de las expectativas. Es por esto que se llega a la determinación que la gran mayoría afirma que el desempeño en las ventas y crecimiento exportador se encuentra encima de las expectativas. 


\section{Logro de metas y objetivos de exportación}

Tabla 32:

Logro de metas y objetivos

\begin{tabular}{llrrrr}
\hline \multicolumn{6}{c}{ DEXP4. El logro de metas y objetivos de exportación se encuentra. } \\
\hline & Frecuencia & Porcentaje & $\begin{array}{c}\text { Porcentaje } \\
\text { válido }\end{array}$ & $\begin{array}{r}\text { Porcentaje } \\
\text { acumulado }\end{array}$ \\
\hline Muy por debajo de las expectativas & 3 & 4.8 & 4.8 & 4.8 \\
Debajo de las expectativas & 11 & 17.5 & 17.5 & 22.2 \\
Valido & 29 & 46.0 & 46.0 & 68.3 \\
Ni debajo ni encima de las expectativas & 13 & 20.6 & 20.6 & 88.9 \\
\cline { 2 - 6 } Encima de las expectativas & 7 & 11.1 & 11.1 & 100.0 \\
\cline { 2 - 6 } & Muy por encima de las expectativas & 100.0 & 100.0 & \\
\cline { 2 - 6 } & Total & & &
\end{tabular}

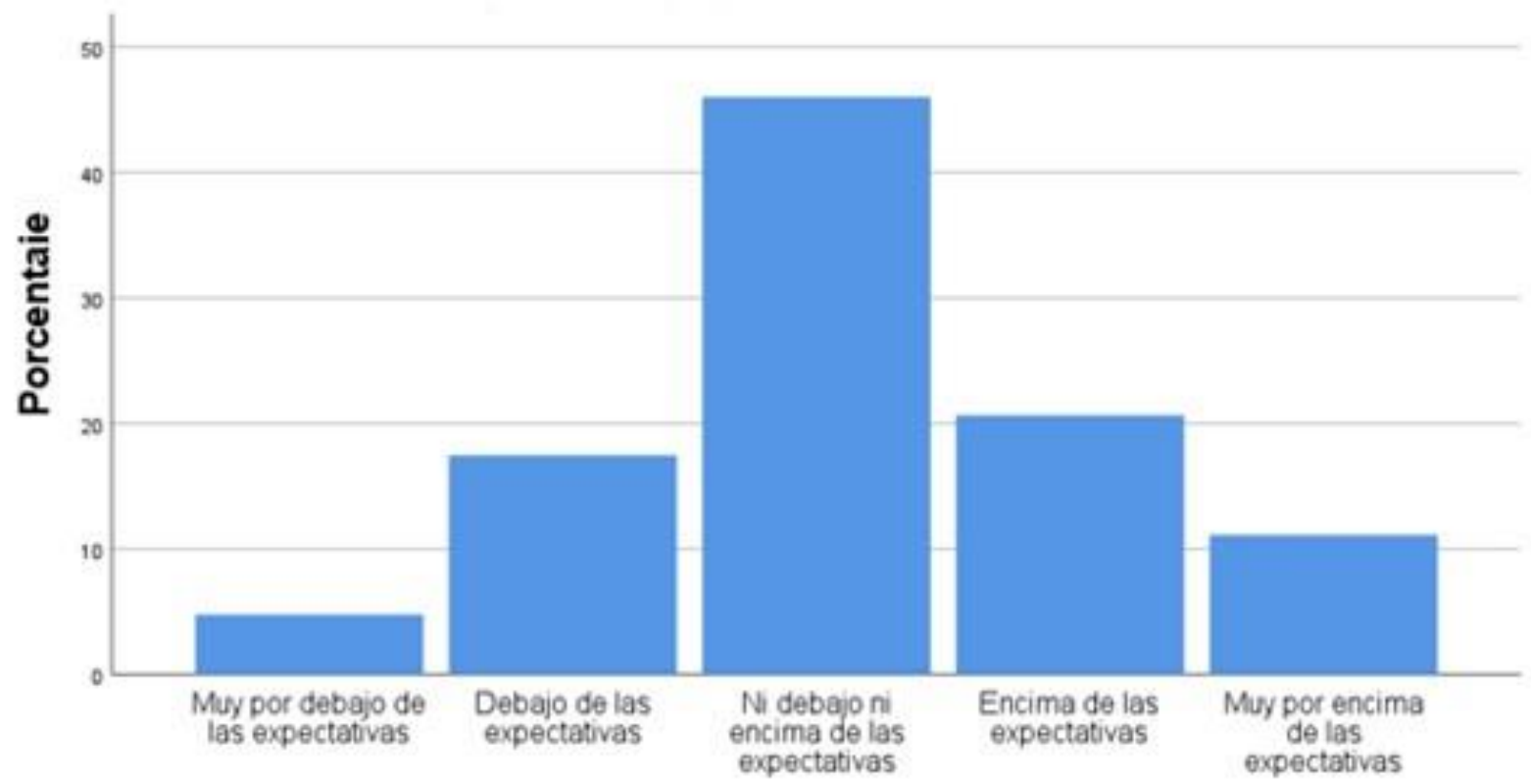

Figura 23. Logro de metas y objetivos

Interpretación: la tabla 32 muestra como del total de los apoderados de las empresas, el $33.7 \%$ respondió ante el ítem "El logro de metas y objetivos de exportación se encuentra" muy por encima de las expectativas y encima de las expectativas, el $46 \%$ ni debajo ni encima de las expectativas, y el $22.3 \%$ debajo de las expectativas y muy por debajo de las expectativas. Es por esto que se llega a la determinación que la gran mayoría afirma que el logro de metas y objetivos de exportación se encuentra ni debajo ni encima de las expectativas. 


\subsection{Contrastación de hipótesis}

\subsubsection{Prueba de normalidad Shapiro-Wilk}

Con el fin de saber si los datos reunidos poseen una distribución normal o no, se desarrolló la prueba de normalidad Shapiro-Wilk. Como se muestra en la Tabla 33 y la Tabla 34, el resultado de ambos cuestionarios tienen una distribución no normal, por lo que se realizó una prueba no paramétrica. Por lo tanto, el coeficiente de correlación Rho de Spearman se utiliza para probar la hipótesis propuesta.

Según Hernandez et al. (2014) El coeficiente de correlación Rho de Spearman se utiliza para medir la correlación de variables en el nivel de medida ordenad o con el fin de dar el orden al nivel de los elementos analizados. De manera similar, los coeficientes se usan para la relación de los niveles es del tipo Likert.

Tabla 33:

Prueba de normalidad Shapiro-Wilk - desempeño de la tercerización de los servicios logísticos (3PL)

\begin{tabular}{|c|c|c|c|c|c|c|}
\hline \multicolumn{7}{|c|}{ Pruebas de normalidad } \\
\hline & \multicolumn{3}{|c|}{$\begin{array}{l}\text { Kolmogeroy: } \\
\text { Smirnova }\end{array}$} & \multicolumn{3}{|c|}{ Shapiro-Wilk } \\
\hline & Estadistica & df & Sig. & Estadistica & df & Sig. \\
\hline $\begin{array}{l}\text { TPL1. La empresa tercerizadora de servicios logisticos (3PL) } \\
\text { realiza el servicio prometido satisfactoriamente. }\end{array}$ & .184 & 63 & .000 & .868 & 63 & .000 \\
\hline $\begin{array}{l}\text { TPL2. La empresa tercerizadora de servicios logísticos (3PL) } \\
\text { responde de manera oportuna y precisa. }\end{array}$ & .195 & 63 & .000 & 867 & 63 & .000 \\
\hline TPL3. La empresa tercerizadora de servicios logisticos (3PL) & & & & & & \\
\hline $\begin{array}{l}\text { brinda servicios oportunos para satisfacer necesidades } \\
\text { particulares. }\end{array}$ & .218 & 63 & .000 & .839 & 63 & .000 \\
\hline $\begin{array}{l}\text { TPL4. La empresa tercerizadora de servicios logisticos (3PL) } \\
\text { proporciona entregas a tiempo y confiables. }\end{array}$ & .246 & 63 & .000 & .819 & 63 & .000 \\
\hline $\begin{array}{l}\text { TPL5. La empresa tercerizadora de servicios logisticos (3PL) } \\
\text { lleva los problemas de servicio a un final satisfactorio. }\end{array}$ & .187 & 63 & .000 & .897 & 63 & .000 \\
\hline $\begin{array}{l}\text { TPL6. La empresa tercerizadora de servicios logisticos (3PL) } \\
\text { maneja requisitos especiales a corto plazo. }\end{array}$ & .182 & 63 & .000 & .909 & 63 & .000 \\
\hline TPL 7. La empresa tercerizadora de servicios logisticos (3PL) & & & & & & \\
\hline $\begin{array}{l}\text { acomoda solicitudes de servicio personalizado de manera } \\
\text { oportuna. }\end{array}$ & .216 & 63 & .000 & .887 & 63 & .000 \\
\hline
\end{tabular}


IPLS. La empresa tercerizadora de servicios logisticos (3PL)

realiza entregas urgentes de manera oportuna.

$.244 \quad 63 \quad .000 \quad .84763 .000$

TPL9. La empresa tercerizadora de servicios logisticos (3PL)

ayuda a mejorar la eficiencia operativa.

$.419 \quad 63.000 \quad .644 \quad 63.000$

TPL 10. La empresa tercerizadora de servicios logisticos (3PL)

explora y brinda soluciones creativas.

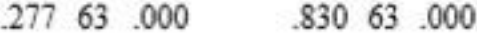

TPL11. La empresa tercerizadora de servicios logisticos (3PL)

personaliza servicios para eventos inesperados.

$248 \quad 63 \quad 000 \quad 819 \quad 63 \quad 000$

TPL12. La empresa tercerizadora de servicios logisticos (3PL)

posee conocimiento profesional y experiencia en sus empleados.

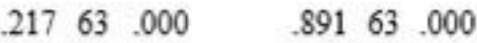

TPL 13. La empresa tercerizadora de servicios logisticos (3PL)

proporciona automatización personalizada y servicio de TI

$\begin{array}{lllll}.269 & 63 & .000 & .835 \quad 63 & .000\end{array}$

avanzado.

TPL14. La empresa tercerizadora de servicios logisticos (3PL)

responde a las quejas.

$\begin{array}{lllll}.278 \quad 63 & .000 \quad .847 \quad 63 \quad .000\end{array}$

TPL15. La empresa tercerizadora de servicios logisticos (3PL)

proporciona un paquete completo de servicio integral.

$\begin{array}{lllll}.258 \quad 63 & .000 \quad .788 \quad 63 & .000\end{array}$

TPL16. La empresa tercerizadora de servicios logisticos (3PL)

posee precios razonables según la calidad de los servicios

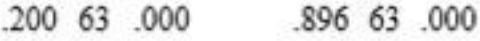

prestados.

TPL17. La empresa tercerizadora de servicios logisticos (3PL)

posee mejores precios en comparación con servicios similares de

$\begin{array}{lllll}.267 \quad 63 \quad .000 \quad & 877 \quad 63 \quad .000\end{array}$ competidores.

TPL 18. La empresa tercerizadora de servicios logisticos (3PL)

posee mejor calidad de embalaje entregado.

$\begin{array}{llll}.346 \quad 63 \quad .000 \quad .738 \quad 63 & .000\end{array}$

TPL 19. La empresa tercerizadora de servicios logisticos (3PL)

posee mejor calidad de la manipulación de mercancias.

$\begin{array}{llllll}.369 & 63 & .000 \quad .699 \quad 63 \quad .000\end{array}$

Elaboración: Cadenillas y Farge (2020) - Extraido del SPSS

Tabla 34:

Prueba de normalidad Shapiro-Wilk - desempeño exportador

\begin{tabular}{|c|c|c|c|c|c|c|}
\hline \multicolumn{7}{|c|}{ Pruebas de normalidad } \\
\hline & \multicolumn{3}{|c|}{$\begin{array}{l}\text { Kolmogoroy: } \\
\text { Smirnox" }\end{array}$} & \multicolumn{3}{|c|}{ Shapiro-Wilk } \\
\hline & Estadistica & df & Sig. & Estadistica & df & Sig. \\
\hline $\begin{array}{l}\text { DEXP1. La percepción de la rentabilidad de las exportaciones se } \\
\text { encuentra. }\end{array}$ & .178 & 63 & .000 & .899 & 63 & .000 \\
\hline $\begin{array}{l}\text { DEXP2. La cuota de mercado en los mercados objetivo se } \\
\text { encuentra. }\end{array}$ & .204 & 63 & .000 & .887 & 63 & .000 \\
\hline $\begin{array}{l}\text { DEXP3. E1 desempeño en las ventas y crecimiento exportador se } \\
\text { encuentra. }\end{array}$ & .187 & 63 & .000 & .891 & 63 & .000 \\
\hline $\begin{array}{l}\text { DEXP4. E1 logro de metas y objetivos de exportación se } \\
\text { encuentra. }\end{array}$ & .245 & 63 & .000 & .899 & 63 & .000 \\
\hline
\end{tabular}

Elaboración: Cadenillas y Farge (2020) - Extraido del SPSS 


\subsubsection{Análisis factorial exploratorio}

Para verificar la dimensionalidad de las variables y su método de agrupación, se realizó un análisis factorial exploratorio, en el que se utilizó el método de componentes principales (utilizado para la extracción de los ítems) y el método Varimax (utilizado para la rotación de los ítems).

A continuación, se muestran los resultados alcanzados para la variable desempeño de 3PL: 0.847 en la medida Kaiser-Meyer-Olkin (KMO), 1846.587 en el aproximado Chi-cuadradoy 0.000 en la significancia. Según los resultados mostrados y basados en la capacidad de la aplicación del estadístico KMO (0.847) se observa que se posee un buen ajuste factorial. Después de haber realizado el análisis apropiado, se consiguen cuatro dimensiones que logran explicar el $86.180 \%$ en la varianza total.

Tabla 35:

"Prueba de KMO, Bartlett y Método de extracción"- desempeño de la tercerización de los servicios logísticos $(3 P L)$

\begin{tabular}{lrr}
\hline \multicolumn{2}{c}{ Prueba de KMO y Bartlett } \\
\hline Medida Kaiser-Meyer-Olkin de adecuación de muestreo. & .847 \\
Prueba de esfericidad de Bartlett & Aprox. Chi-cuadrado & 1846.587 \\
& Df & 171 \\
& Sig. & .000 \\
\hline
\end{tabular}

Elaboración: Cadenillas y Farge (2020) - Extraido del SPSS

La dimensión "puntualidad de los servicios" es el factor uno y tiene una varianza de 50.477\%, la dimensión "servicios complementarios a medida" es el factor dos y tiene un varianza de 20.338\%, la dimensión "factor de fijación de precios" es el factor tres y tiene un varianza de 9.029\% y la dimensión "calidad de entrega" es el factor cuatro y tiene un varianza de $6.337 \%$. 
Tabla 36:

"Varianza Total Explicada”- desempeño de la tercerización de los servicios logísticos (3PL)

\begin{tabular}{|c|c|c|c|c|c|c|c|c|c|}
\hline \multicolumn{10}{|c|}{ Varianza Total Explicada } \\
\hline \multirow[t]{2}{*}{ Factor } & \multicolumn{3}{|c|}{ Valores propios Iniciales } & \multicolumn{3}{|c|}{$\begin{array}{l}\text { Suma de rotación de cargas al } \\
\text { cuadrado }\end{array}$} & \multicolumn{3}{|c|}{$\begin{array}{c}\text { Sumas de rotación de cargas } \\
\text { al cuadrado }\end{array}$} \\
\hline & Total & $\begin{array}{c}\% \text { de } \\
\text { varianza }\end{array}$ & $\begin{array}{c}\text { acumulado } \\
\% \\
\end{array}$ & Total & $\begin{array}{c}\% \text { de } \\
\text { varianza }\end{array}$ & $\begin{array}{c}\text { acumulado } \\
\% \\
\end{array}$ & Total & $\begin{array}{c}\% \text { de } \\
\text { varianza }\end{array}$ & $\begin{array}{c}\text { acumulado } \\
\% \\
\end{array}$ \\
\hline 1 & 9.591 & 50.477 & 50.477 & 9.591 & 50.477 & 50.477 & 6.515 & 34.292 & 34.292 \\
\hline 2 & 3.864 & 20.338 & 70.815 & 3.864 & 20.338 & 70.815 & 6.173 & 32.491 & 66.783 \\
\hline 3 & 1.716 & 9.029 & 79.844 & 1.716 & 9.029 & 79.844 & 2.057 & 10.826 & 77.610 \\
\hline 4 & 1.204 & 6.337 & 86.180 & 1.204 & 6.337 & 86.180 & 1.628 & 8.571 & 86.180 \\
\hline 5 & .762 & 4.013 & 90.193 & & & & & & \\
\hline 6 & .518 & 2.726 & 92.920 & & & & & & \\
\hline 7 & .393 & 2.067 & 94.986 & & & & & & \\
\hline 8 & .252 & 1.324 & 96.311 & & & & & & \\
\hline 9 & .209 & 1.102 & 97.412 & & & & & & \\
\hline 10 & .121 & .635 & 98.048 & & & & & & \\
\hline 11 & .088 & .462 & 98.510 & & & & & & \\
\hline 12 & .085 & .450 & 98.960 & & & & & & \\
\hline 13 & .058 & .304 & 99.264 & & & & & & \\
\hline 14 & .038 & .200 & 99.464 & & & & & & \\
\hline 15 & .032 & .170 & 99.634 & & & & & & \\
\hline 16 & .024 & .128 & 99.762 & & & & & & \\
\hline 17 & .022 & .114 & 99.876 & & & & & & \\
\hline 18 & .017 & .089 & 99.965 & & & & & & \\
\hline 19 & .007 & .035 & 100.000 & & & & & & \\
\hline
\end{tabular}

Elaboración: Cadenillas y Earge (2020) - Extraido del SPSS

Según el método Varimax, este método se utiliza para simplificar expresiones de subgrupos específicos con menos elementos principales, con normalización Kaiser, en la matriz de componente rotado el factor uno la dimensión "puntualidad de los servicios" se localiza entre los ítems 1 y 8 , el factor dos la dimensión "servicios complementarios a medida" se localiza entre los ítems 9 y 15, el factor tres la dimensión "factor de fijación de precios" se localiza entre los ítems 16 y 17 y el factor cuatro la dimensión "calidad de entrega" se localiza entre los ítems 18 y 19. 
Tabla 37:

"Método de rotación: Varimax con normalización Kaiser"- desempeño de la tercerización de los servicios logísticos (3PL)

\begin{tabular}{|c|c|c|c|c|}
\hline \multicolumn{5}{|l|}{ Matriz de componente rotado" } \\
\hline & \multicolumn{4}{|c|}{ Componente } \\
\hline & 1 & 2 & 3 & 4 \\
\hline $\begin{array}{l}\text { TPL4. La empresa tercerizadora de servicios logisticos (3PL) proporciona } \\
\text { entrezas a tiempo y confiables. }\end{array}$ & .924 & & & \\
\hline $\begin{array}{l}\text { TPL7. La empresa tercerizadora de servicios logisticos (3PL) acomoda } \\
\text { solicitudes de servicio personalizado de manera oportuna. }\end{array}$ & 915 & & & \\
\hline $\begin{array}{l}\text { TPL2. La empresa tercerizadora de servicios logísticos (3PL) responde de } \\
\text { manera oportuna y precisa. }\end{array}$ & .901 & & & \\
\hline $\begin{array}{l}\text { TPL1. La empresa tercerizadora de servicios logisticos (3PL) realiza el } \\
\text { servicio prometido satisfactoriamente. }\end{array}$ & .897 & & & \\
\hline $\begin{array}{l}\text { TPL5. La empresa tercerizadora de servicios logisticos (3PL) lleva los } \\
\text { problemas de servicio a un final satisfactorio. }\end{array}$ & .872 & & & \\
\hline $\begin{array}{l}\text { TPL6. La empresa tercerizadora de servicios logisticos (3PL) maneja } \\
\text { requisitos especiales a corto plazo. }\end{array}$ & .866 & & & \\
\hline $\begin{array}{l}\text { TPL8. La empresa tercerizadora de servicios logisticos (3PL) realiza entregas } \\
\text { urgentes de manera oportuna. }\end{array}$ & .847 & & & \\
\hline $\begin{array}{l}\text { TPL3. La empresa tercerizadora de servicios logisticos (3PL) brinda servicios } \\
\text { oportunos para satisfacer necesidades particulares. }\end{array}$ & .742 & & & \\
\hline $\begin{array}{l}\text { TPL15. La empresa tercerizadora de servicios logisticos (3PL) proporciona } \\
\text { un paquete completo de servicio integral. }\end{array}$ & & .940 & & \\
\hline $\begin{array}{l}\text { TPL14. La empresa tercerizadora de servicios logisticos (3PL) responde a las } \\
\text { quejas. }\end{array}$ & & 923 & & \\
\hline $\begin{array}{l}\text { TPL9. La empresa tercerizadora de servicios logisticos (3PL) ayuda a mejorar } \\
\text { la eficiencia operativa. }\end{array}$ & & .903 & & \\
\hline $\begin{array}{l}\text { TPL11. La empresa tercerizadora de servicios logisticos (3PL) personaliza } \\
\text { servicios para eventos inesperados. }\end{array}$ & & .902 & & \\
\hline $\begin{array}{l}\text { TPL12. La empresa tercerizadora de servicios logisticos (3PL) posee } \\
\text { conocimiento profesional y experiencia en sus empleados. }\end{array}$ & & .902 & & \\
\hline $\begin{array}{l}\text { TPL10. La empresa tercerizadora de servicios logisticos (3PL) explora y } \\
\text { brinda soluciones creativas. }\end{array}$ & & .884 & & \\
\hline $\begin{array}{l}\text { TPL13. La empresa tercerizadora de servicios logisticos (3PL) proporciona } \\
\text { automatización personalizada y servicio de } T I \text { avanzado. }\end{array}$ & & .859 & & \\
\hline $\begin{array}{l}\text { TPL16. La empresa tercerizadora de servicios logisticos (3PL) posee precios } \\
\text { razonables según la calidad de los servicios prestados. }\end{array}$ & & & .947 & \\
\hline $\begin{array}{l}\text { TPL17. La empresa tercerizadora de servicios logisticos (3PL) posee mejores } \\
\text { precios en comparación con servicios similares de competidores. }\end{array}$ & & & .927 & \\
\hline
\end{tabular}


TPL19. La empresa tercerizadora de servicios logisticos (3PL) posee mejor

calidad de la manipulación de mercancias.

TPL18. La empresa tercerizadora de servicios logisticos (3PL) posee mejor

calidad de embalaje entregado.

Elaboracion: Cadenillas y Farge (2020) - Extraido del SPSS

Mientras que se logró obtener los siguientes resultados para la variable desempeño exportador son: 0.652 en la medida Kaiser-Meyer-Olkin (KMO), 82.104 en el aproximado Chi-cuadrado y 0.000 en la significancia. Según los resultados mostrados y basados en la capacidad de la aplicación del estadístico KMO (0.652) se observa que se posee un buen ajuste factorial. Después de un análisis apropiado, se consiguen dos dimensiones que logran explicar el $81.317 \%$ en la varianza total.

Tabla 38:

"Prueba de KMO, Bartlett y Método de extracción"- desempeño exportador

\begin{tabular}{lrr}
\hline & \multicolumn{2}{c}{ Prueba de KMO y Bartlett } \\
\hline Medida Kaiser-Meyer-Olkin de adecuación de muestreo. & .652 \\
Prueba de esfericidad de Bartlett & Aprox. Chi-cuadrado & 82.104 \\
& Df & 6 \\
& Sig. & .000 \\
\hline
\end{tabular}

Elaboración: Cadenillas y Farge (2020) - Extraido del SPSS

La dimensión “desempeño de exportación del usuario" es el factor uno y tiene un varianza de $58.483 \%$, la dimensión "logro de metas y objetivos de exportación" es el factor dos y tiene un varianza de $22.834 \%$.

Tabla 39:

“Varianza Total Explicada”- desempeño exportador

\begin{tabular}{|c|c|c|c|c|c|c|c|c|c|}
\hline \multicolumn{10}{|c|}{ Varianza Total Explicada } \\
\hline \multirow[t]{2}{*}{ Factor } & \multicolumn{3}{|c|}{ Valores propios Iniciales } & \multicolumn{3}{|c|}{$\begin{array}{c}\text { Suma de rotación de cargas al } \\
\text { cuadrado }\end{array}$} & \multicolumn{3}{|c|}{$\begin{array}{c}\text { Sumas de rotación de cargas } \\
\text { al cuadrado }\end{array}$} \\
\hline & Total & $\begin{array}{c}\% \text { de } \\
\text { varianza }\end{array}$ & $\begin{array}{c}\text { acumulado } \\
\%\end{array}$ & Total & $\begin{array}{l}\% \text { de } \\
\text { varianza }\end{array}$ & $\begin{array}{c}\text { acumulado } \\
\%\end{array}$ & Total & $\begin{array}{c}\% \text { de } \\
\text { varianza }\end{array}$ & $\begin{array}{c}\text { acumulado } \\
\%\end{array}$ \\
\hline 1 & 2.339 & 58.483 & 58.483 & 2.339 & 58.483 & 58.483 & 2.155 & 53.872 & 53.872 \\
\hline 2 & 1.013 & 22.834 & 81.317 & 1.013 & 22.834 & 81.317 & 1.098 & 27.445 & 81.317 \\
\hline 3 & .518 & 12.961 & 94.278 & & & & & & \\
\hline 4 & .229 & 5.722 & 100.000 & & & & & & \\
\hline
\end{tabular}

Elaboración: Cadenillas y Earge (2020) - Extraido del SPSS 
Según el método Varimax, este método se utiliza para simplificar expresiones de subgrupos específicos con menos elementos principales, con normalización Kaiser, en la matriz de componente rotado el factor uno la dimensión “desempeño de exportación del usuario" se localiza entre los ítems 1 y 3, el factor dos la dimensión "logro de metas y objetivos de exportación" se localiza entre los ítems 4.

Tabla 40:

"Método de rotación: Varimax con normalización Kaiser"- desempeño exportador

\begin{tabular}{lc}
\hline \multicolumn{2}{c}{ Matriz de componente rotado } \\
\hline & \multicolumn{2}{c}{ Componente } \\
\cline { 2 - 2 } & \multicolumn{2}{c}{2} \\
\hline DEXP2. La cuota de mercado en los mercados objetivo se encuentra. & .901 \\
DEXP3. El desempeño en las ventas y crecimiento exportador se encuentra. & .825 \\
DEXP1. La percepción de la rentabilidad de las exportaciones se encuentra. & .806 \\
DEXP4. El logro de metas y objetivos de exportación se encuentra. & .983 \\
\hline
\end{tabular}

Elaboración: Cadenillas y Farge (2020) - Extraido del SPSS

\subsubsection{Correlaciones Rho de Spearman}

Con base en los resultados obtenidos de los dos cuestionarios, se utiliza el programa estadístico SPSS 22 para tabular la información recolectada, con lo que se llegó a reunir mediante la suma de puntajes las variables y cada una de sus dimensiones, puntualidad delos servicios TPL1 a la TPL8, servicios complementarios a medida TPL9 a la TPL15, factor de fijación de precios TPL16 a la TPL17, calidad de entrega TPL18 a la TPL19, desempeño de exportación del usuario DEXP1 a la DEXP3 y logro de metas y objetivos de exportación DEXP4. Finalmente, los resultados se obtienen mediante el coeficiente de correlación Rho de Spearman, que se usa para variables con escala Likert. A continuación se presentan las relaciones encontradas entre el desempeño de 3PL y el desempeño exportador basados en los cuestionarios aplicados a cada gerente o administrador de las empresas MYPES exportadoras de uvas frescas del Perú a Estados Unidos (tabla 41). 
Tabla 41:

Correlación Rho Spearman

\begin{tabular}{|c|c|c|c|c|c|c|c|}
\hline \multicolumn{8}{|c|}{ Correlaciones } \\
\hline & & & Pun-ser & Ser-com & Fa-fi-pre & Cali-en & Dese-ex \\
\hline \multirow{15}{*}{ Spearman's rho } & \multirow{2}{*}{ Pun-ser } & $\begin{array}{l}\text { Coeficiente de } \\
\text { correlación }\end{array}$ & 1.000 & $.350^{\circ *}$ & $322^{\circ}$ & $.429 *$ & $.392^{* *}$ \\
\hline & & Sig. (bilateral) & 63 & .005 & $\begin{array}{r}.010 \\
63\end{array}$ & $\begin{array}{r}.000 \\
63\end{array}$ & $\begin{array}{r}.001 \\
63\end{array}$ \\
\hline & \multirow{4}{*}{ Ser-som } & Coeficiente de & & & & & \\
\hline & & correlación & $350^{\circ}$ & 1.000 & .200 & $.360^{\circ}$ & $.459^{\circ}$ \\
\hline & & Sig (bilateral) & .005 & & 117 & .004 & .000 \\
\hline & & $\mathrm{N}$ & 63 & 63 & 63 & 63 & 63 \\
\hline & \multirow{3}{*}{ Fa-fi-pre } & $\begin{array}{l}\text { Coeficiente de } \\
\text { correlación }\end{array}$ & $322^{\circ}$ & .200 & 1.000 & $.272^{\circ}$ & $353^{* *}$ \\
\hline & & Sig (bilateral) & .010 & .117 & & .031 & .005 \\
\hline & & $\mathrm{N}$ & 63 & 63 & 63 & 63 & 63 \\
\hline & \multirow{3}{*}{ Cali-en } & $\begin{array}{l}\text { Coeficiente de } \\
\text { correlación }\end{array}$ & $429^{\circ *}$ & $360^{* *}$ & $272^{\circ}$ & 1.000 & $531^{* *}$ \\
\hline & & Sig (bilateral) & .000 & .004 & .031 & & .000 \\
\hline & & $\mathrm{N}$ & 63 & 63 & 63 & 63 & 63 \\
\hline & \multirow{3}{*}{ Dese-ex } & $\begin{array}{l}\text { Coeficiente de } \\
\text { correlación }\end{array}$ & $392^{* *}$ & $.459^{* *}$ & $353^{* *}$ & $531^{* *}$ & 1.000 \\
\hline & & Sig (bilateral) & .001 & .000 & .005 & .000 & \\
\hline & & $\mathrm{N}$ & 63 & 63 & 63 & 63 & 63 \\
\hline
\end{tabular}

*. La correlación es significativa en el nivel 0.01 (bilateral); *. La correlación es significativa en el nivel 0,05 (bilateral)

Elaboracion: Cadenillas y Farze $(2020)$ - Extraido de SPSS 


\subsubsection{Contrastación de las hipótesis}

El coeficiente de correlación Rho de Spearman se desarrolló para poder verificar las hipótesis propuestas y confirmar los resultados obtenidos.

\subsubsection{Hipótesis general.}

El desempeño de 3PL se relaciona con el desempeño de las empresas MYPES exportadoras de uvas a Estados Unidos 2020.

\section{i. Planteamiento de las hipótesis}

Ho: $\rho=0$, (El desempeño de 3PL NO se relaciona con el desempeño de las empresas MYPES exportadoras de uvas a Estados Unidos 2020)

H1: $\rho \neq 0$, (El desempeño de 3PL SI se relaciona con el desempeño de las empresas MYPES exportadoras de uvas a Estados Unidos 2020)

\section{ii. Nivel de significancia $(\alpha)$}

Se considera el nivel de significancia $\alpha=0.05$

\section{iii. Cálculo del estadístico de prueba:}

Tabla 42:

Hipótesis general - Resultado de Rho de Spearman

\begin{tabular}{|c|c|c|c|}
\hline & & & Dese-ex \\
\hline & & Coeficiente de correlación & $.520^{*}$ \\
\hline \multirow{2}{*}{ Spearman's rho } & D3PL & Sig. (bilateral) & .000 \\
\hline & & $\mathrm{N}$ & 63 \\
\hline
\end{tabular}

\section{iv. Toma de decisiones}

El nivel de significancia es $0.05, r=0.520 ;$ p_valor $=0.000<0.05$, existe suficiente evidencia estadística para RH0, por lo que se puede decir que el desempeño de 3PL si se relaciona con el desempeño de las empresas MYPES exportadoras de uvas a Estados Unidos 2020. 


\subsubsection{Primera hipótesis específica.}

La puntualidad de los servicios se relaciona con el desempeño de las empresas MYPES exportadoras de uvas a Estados Unidos 2020.

\section{i. Planteamiento de las hipótesis}

Ho: $\rho=0$, (La puntualidad de los servicios NO se relaciona con el desempeño de las empresas MYPES exportadoras de uvas a Estados Unidos 2020)

H1: $\rho \neq 0$, (La puntualidad de los servicios SI se relaciona con el desempeño de las empresas MYPES exportadoras de uvas a Estados Unidos 2020)

\section{ii. $\quad$ Nivel de significancia $(\alpha)$}

Se considera el nivel de significancia $\alpha=0.05$

\section{iii. Cálculo del estadístico de prueba:}

Tabla 43:

Primera hipótesis específica - Resultado de Rho de Spearman

\begin{tabular}{|c|c|c|c|}
\hline & & & Dese-ex \\
\hline \multirow{3}{*}{ Spearman's rho } & \multirow{3}{*}{ Pun-ser } & Coeficiente de correlación & $.392^{*}$ \\
\hline & & Sig. (bilateral) & .001 \\
\hline & & $\mathrm{N}$ & 115 \\
\hline
\end{tabular}

\section{iv. Toma de decisiones}

El nivel de significancia es $0.05, r=0.392 ; p_{-}$valor $=0.001<0.05$, existe suficiente evidencia estadística para RH0, por lo que se puede decir que la puntualidad de los servicios si se relaciona con el desempeño de las empresas MYPES exportadoras de uvas a Estados Unidos 2020. 


\subsubsection{Segunda hipótesis específica.}

Los servicios complementarios a medida se relaciona con el desempeño de las empresas MYPES exportadoras de uvas a Estados Unidos 2020.

\section{i. Planteamiento de las hipótesis}

Ho: $\rho=0$, (Los servicios complementarios a medida NO se relaciona con el desempeño de las empresas MYPES exportadoras de uvas a Estados Unidos 2020)

H1: $\rho \neq 0$, (Los servicios complementarios a medida SI se relaciona con el desempeño de las empresas MYPES exportadoras de uvas a Estados Unidos 2020)

\section{ii. $\quad$ Nivel de significancia $(\alpha)$}

Se considera el nivel de significancia $\alpha=0.05$

\section{iii. Cálculo del estadístico de prueba:}

Tabla 44:

Segunda hipótesis especifica - Resultado de Rho de Spearman

\begin{tabular}{lllc}
\hline & & Dese-ex \\
\hline \multirow{2}{*}{ Spearman's, rho } & & Coeficiente de correlación & $.459^{* *}$ \\
& Ser-com & Sig. (bilateral) & .000 \\
& & $\mathrm{~N}$ & 115 \\
\hline
\end{tabular}

\section{iv. Toma de decisiones}

El nivel de significancia es $0.05, r=0.459$; $p_{-}$valor $=0.000<0.05$, existe suficiente evidencia estadística para RH0, por lo que se afirma que los servicios complementarios a medida si se relaciona con el desempeño de las empresas MYPES exportadoras de uvas a Estados Unidos 2020. 


\subsubsection{Tercera hipótesis específica.}

El factor de precios se relaciona con el desempeño de las empresas MYPES exportadoras de uvas a Estados Unidos 2020.

\section{i. $\quad$ Planteamiento de las hipótesis}

Ho: $\rho=0$, (El factor de precios NO se relaciona con el desempeño de las empresas MYPES exportadoras de uvas a Estados Unidos 2020)

H1: $\rho \neq 0$, (El factor de precios SI se relaciona con el desempeño de las empresas MYPES exportadoras de uvas a Estados Unidos 2020)

\section{ii. Nivel de significancia $(\alpha)$}

Se considera el nivel de significancia $\alpha=0.05$

\section{iii. Cálculo del estadístico de prueba:}

Tabla 45:

Tercera hipótesis específica - Resultado de Rho de Spearman

\begin{tabular}{|c|c|c|c|}
\hline & & & Dese-ex \\
\hline & & Coeficiente de correlación & $.353^{* *}$ \\
\hline \multirow{2}{*}{ Spearman's rho } & Fa-fi-pre & Sig. (bilateral) & .005 \\
\hline & & $\mathrm{N}$ & 115 \\
\hline
\end{tabular}

\section{iv. Toma de decisiones}

El nivel de significancia es $0.05, r=0.353 ; p_{-}$valor $=0.005<0.05$, existe suficiente evidencia estadística para RH0, por lo que se puede decir que el factor de precios si se relaciona con el desempeño de las empresas MYPES exportadoras de uvas a Estados Unidos 2020. 


\subsubsection{Cuarta hipótesis específica.}

La calidad de entrega se relaciona con el desempeño de las empresas MYPES exportadoras de uvas a Estados Unidos 2020.

\section{i. Planteamiento de las hipótesis}

Ho: $\rho=0$, (La calidad de entrega NO se relaciona con el desempeño de las empresas MYPES exportadoras de uvas a Estados Unidos 2020)

H1: $\rho \neq 0$, (La calidad de entrega SI se relaciona con el desempeño de las empresas MYPES exportadoras de uvas a Estados Unidos 2020)

\section{ii. Nivel de significancia $(\alpha)$}

Se considera el nivel de significancia $\alpha=0.05$

\section{iii. Cálculo del estadístico de prueba:}

Tabla 46:

Cuarta hipótesis específica - Resultado de Rho de Spearman

\begin{tabular}{|c|c|c|c|}
\hline & & & Dese-ex \\
\hline \multirow{3}{*}{ Spearman's rho } & & Coefíciente de correlación & $.531^{*}$ \\
\hline & Cali-en & Sig. (bilateral) & .000 \\
\hline & & $\mathrm{N}$ & 115 \\
\hline
\end{tabular}

\section{iv. Toma de decisiones}

El nivel de significancia es $0.05, r=0.531 ; p_{-}$valor $=0.000<0.05$, existe suficiente evidencia estadística para RH0, por lo que se puede decir que la calidad de entrega si se relaciona con el desempeño de las empresas MYPES exportadoras de uvas a Estados Unidos 2020. 


\subsection{Discusiones}

En esta investigación denominada "Relación del desempeño de la tercerización de servicios logísticos con el desempeño de las MYPES exportadoras de uvas a EUA, 2020" fueron aplicados dos cuestionarios, los mismos que se dirigieron a cada gerente o administrador de las empresas MYPES exportadoras de uvas frescas del Perú a Estados Unidos, en cuanto a la relación entre las variables tomadas en cuenta: el cuestionario de desempeño de tercerización de los servicios logísticos y el cuestionario de desempeño exportador en ambos casos del investigador Yeung (2006). Los dos cuestionarios se usaron con la finalidad de analizar la relación entre el desempeño de 3PL y el desempeño exportador de las mismas empresas MYPES. Los resultados alcanzados muestran semejanza con los resultados alcanzados por otros investigadores como se demuestra a continuación.

\section{Hipótesis general}

Según los resultados alcanzados en la presente investigación, se aprueba la hipótesis general "El desempeño de proveedores logísticos de terceros impacta en el desempeño de las empresas MYPES exportadoras de uvas a Estados Unidos 2020” es decir, a raíz que el desempeño de 3PL posee un coeficiente de correlación Rho de Spearman de $r=0.520$; p_valor $=0.000<0.05$, por lo que el desempeño de 3PL si se relaciona con el desempeño de las empresas MYPES exportadoras de uvas a Estados Unidos. En seguida, se realiza la comparación con diversas investigaciones que alcanzaron el mismo resultado, como en la investigación de Yeung (2006) donde se obtuvo que el desempeño de 3PL si se relaciona con el desempeño exportador.

\section{Primera hipótesis específica}

Según los resultados alcanzados en la presente investigación, se aprueba la primera hipótesis específica "La puntualidad de los servicios impacta en el desempeño de las empresas MYPES 
exportadoras de uvas a Estados Unidos 2020” es decir, a raíz que la puntualidad de los servicios tiene un coeficiente de correlación Rho de Spearman de $r=0.392 ;$ p_valor $=0.001<0.05$, por lo que la puntualidad de los servicios si se relaciona con el desempeño de las empresas MYPES exportadoras de uvas a Estados Unidos. En seguida, se realiza la comparación con diversas investigaciones que alcanzaron el mismo resultado, como en la investigación de Hausman, Lee y Subramanian (2013) donde se obtuvo que la puntualizando que la puntualidad de los servicios si se relaciona con el desempeño exportador.

\section{Segunda hipótesis específica}

Según los resultados alcanzados en la presente investigación, se aprueba la segunda hipótesis específica "Los servicios complementarios a medida impacta en el desempeño de las empresas MYPES exportadoras de uvas a Estados Unidos 2020" es decir, a raíz que los servicios complementarios a medida tiene un coeficiente de correlación Rho de Spearman de $\mathrm{r}=0.459$; p_valor $=0.000<0.05$, por lo que los servicios complementarios a medida si se relaciona con el desempeño de las empresas MYPES exportadoras de uvas a Estados Unidos. En seguida, se realiza la comparación con diversas investigaciones que alcanzaron el mismo resultado, como en la investigación de Nuhanović (2016) donde se obtuvo que los servicios complementarios a medida si se relaciona con el desempeño exportador.

\section{Tercera hipótesis específica}

Según los resultados alcanzados en la presente investigación, se aprueba la tercera hipótesis específica "El factor de precios impacta en el desempeño de las empresas MYPES exportadoras de uvas a Estados Unidos 2020” es decir, a raíz que el factor de precios tiene un coeficiente de correlación Rho de Spearman de $r=0.353$; p_valor $=0.005<0.05$, por lo que el factor de precios si se relaciona con el desempeño de las empresas MYPES exportadoras de uvas a Estados Unidos. 
En seguida, se realiza la comparación con diversas investigaciones que alcanzaron el mismo resultado, como en la investigación de Barakat, Haikal, Ali y Eid (2018) donde se obtuvo que el factor de precios si se relaciona con el desempeño exportador.

\section{Cuarta hipótesis específica}

Según los resultados alcanzados en la presente investigación, se aprueba la cuarta hipótesis específica "La calidad de entrega impacta en el desempeño de las empresas MYPES exportadoras de uvas a Estados Unidos 2020" es decirpalabras, a raíz que la calidad de entrega tiene un coeficiente de correlación Rho de Spearman de $\mathrm{r}=0.531$; $\mathrm{p}_{\text {_valor }}=0.000<0.05$, por lo que la calidad de entrega si se relaciona con el desempeño de las empresas MYPES exportadoras de uvas a Estados Unidos. En seguida, se realiza la comparación con diversas investigaciones que alcanzaron el mismo resultado, como en la investigación de Skender, Host y Nuhanovic (2016) donde se obtuvo que la calidad de entrega si se relaciona con el desempeño exportador.

\subsection{Conclusiones}

Con base en los resultados de esta investigación y los dos cuestionarios acerca del desempeño de 3PL y el desempeño de las exportaciones, se llega a las siguientes conclusiones.

1) El desempeño de 3PL es un elemento importante para las empresas MYPES exportadoras de uvas frescas del Perú a Estados Unidos aumenten su desempeño exportador. Por tal en la presente investigación se afirma que el desempeño de tercerización de los servicios logísticos si se relaciona con el desempeño exportador, con lo que se puede confirmar que si las mismas empresas MYPES exportadoras de uvas frescas midieran adecuadamente las actividades del outsourcing que ofrecen las empresas encargadas de los procesos logísticos de otras empresas, el desempeño exportador aumentaría de igual manera. Basados en los datos reunidos de los dos 
cuestionarios, y consiguiendo los resultados mediante el Rho de Spearman, se corrobora que el desempeño de tercerización de los servicios logísticos y el desempeño de las empresas MYPES exportadoras de uvas frescas del Perú a Estados Unidos si existe, por lo que se ratifica la hipótesis planteada.

2) La puntualidad de los servicios es significativo para las empresas MYPES exportadoras de uvas frescas del Perú a Estados Unidos aumenten su desempeño exportador. Por tal en la presente investigación se afirma que la puntualidad de los servicios si se relaciona con el desempeño exportador, con lo que se puede confirmar que si las mismas empresas MYPES exportadoras de uvas frescas midieran el tiempo de entrega de las empresas encargadas de los procesos logísticos de otras empresas, el desempeño exportador aumentaría de igual manera. Basados en los datos reunidos de los dos cuestionarios, y consiguiendo los resultados mediante el Rho de Spearman, se corrobora que la puntualidad de los servicios y el desempeño de las empresas MYPES exportadoras de uvas frescas del Perú a Estados Unidos si existe, por lo que se ratifica la hipótesis planteada.

3) Los servicios complementarios a medida es un elemento importante para las empresas MYPES exportadoras de uvas frescas del Perú a Estados Unidos aumenten su desempeño exportador. Por tal en la presente investigación se afirma que los servicios complementarios a medida si se relaciona con el desempeño exportador, con lo que se puede confirmar que si las mismas empresas MYPES exportadoras de uvas frescas midieran el conocimiento profesional y la experiencia de las empresas encargadas de los procesos logísticos de otras empresas, el desempeño exportador aumentaría de igual manera. Basados en los datos reunidos de los dos cuestionarios, y consiguiendo los 
resultados mediante el Rho de Spearman, se corrobora que los servicios complementarios a medida y el desempeño de las empresas MYPES exportadoras de uvas frescas del Perú a Estados Unidos si existe, por lo que se ratifica la hipótesis planteada.

4) El factor de precios es un elemento importante para las empresas MYPES exportadoras de uvas frescas del Perú a Estados Unidos aumenten su desempeño exportador. Por tal en la presente investigación se afirma que el factor de precios si se relaciona con el desempeño exportador, con lo que se puede confirmar que si las mismas empresas MYPES exportadoras de uvas frescas midieran el servicio ofrecido en cuanto a los precios según la calidad de dichos servicios, el desempeño exportador aumentaría de igual manera. Basados en los datos reunidos de los dos cuestionarios, y consiguiendo los resultados mediante el Rho de Spearman, se corrobora que el factor de precios y el desempeño de las empresas MYPES exportadoras de uvas frescas del Perú a Estados Unidos si existe, por lo que se ratifica la hipótesis planteada.

5) La calidad de entrega es un elemento importante para las empresas MYPES exportadoras de uvas frescas del Perú a Estados Unidos aumenten su desempeño exportador. Por tal en la presente investigación se afirma que la calidad de entrega si se relaciona con el desempeño exportador, con lo que se puedeconfirmar que si las mismas empresas MYPES exportadoras de uvas frescas midieran el servicio ofrecido en cuanto a cómo los productos son manejados y al embalaje de estos al ser entregados, el desempeño exportador aumentaría de igual manera. Basados en los datos reunidos de los dos cuestionarios, y consiguiendo los resultados mediante el Rho de Spearman, se corrobora que la calidad de entrega y el desempeño de las empresas MYPES 
exportadoras de uvas frescas del Perú a Estados Unidos si existe, por lo que se ratifica la hipótesis planteada.

\subsection{Recomendaciones}

1) A las empresas MYPES exportadoras de uvas frescas del Perú a Estados Unidos se les recomienda que antes de contratar una empresa de tercerización de los servicios logísticos identificar cuáles son los criterios más importantes en base a sus objetivos, ya sean estratégicos, tácticos u operacionales, para que después puedan definir los indicadores que utilizaran para medir el desempeño de dichas empresas, y así puedan contratar una empresa tercerizadora de servicios logísticos adecuada a sus necesidades.

2) A las empresas MYPES exportadoras de uvas frescas del Perú a Estados Unidos se les recomienda contratar una empresa de tercerización de los servicios logísticos basados en la puntualidad de sus servicios, para esto deberán de medir el desempeño del servicio ofrecido de estas empresas en relación a el tiempo de entregas bajo un indicador de entregas a tiempo, el cual mide cuan agiles son las empresas de tercerización de los servicios logísticos en la última milla o kilometro en forma de porcentaje.

3) A las empresas MYPES exportadoras de uvas frescas del Perú a Estados Unidos se les recomienda contratar una empresa de tercerización de los servicios logísticos basados en los servicios complementarios, para esto deberán de seleccionar a una empresa de tercerización de los servicios logísticos 3pl que tenga como estrategia la valoración del profesionalismo, la experiencia, la transparencia y la flexibilidad de los terceros y que brinden un valor agregado a sus servicios impulsando a que sus clientes se inclinen por ellos. 
4) A las empresas MYPES exportadoras de uvas frescas del Perú a Estados Unidos se les recomienda contratar una empresa de tercerización de los servicios logísticos basados en los factores de precios, dado que este factor es importante y ayudara a que la empresa exportadora pueda reducir sus costos logísticos y a que se cumplan los objetivos trazados.

5) A las empresas MYPES exportadoras de uvas frescas del Perú a Estados Unidos se les recomienda contratar una empresa de tercerización de los servicios logísticos basados en la calidad de entrega, para esto deberán de medir el desempeño del servicio ofrecido de estas empresas en relación al porcentaje de entregas certificadas, las cuales son las entregas completas, a tiempo, con mercancías en perfectas condiciones y la documentación exacta para así obtener un parámetro de calidad al que siempre se debe de aspirar. 


\section{Referencias bibliográficas}

Aaby, N. E., \& Slater, S. F. (1989). Management influences on export performance: a review of the empirical literature 1978-88. International marketing review, 6(4), 7-26.

Africk, J. M., \& Calkins, C. (1994). Does asset ownership mean better service?. Transportation \& Distribution.

Aitken, B., Hanson, G. H., \& Harrison, A. E. (1997). Spillovers, foreign investment, and export behavior. Journal of International economics, 43(1-2), 103-132.

Akooric, M., \& Enderwick, P. (1992). The international operations of New Zealand companies. Asia Pacific Journal of Management, 9(1), 51-69.

Aktas, E., Agaran, B., Ulengin, F., \& Onsel, S. (2011). The use of outsourcing logistics activities: The case of turkey. Transportation Research Part C: Emerging Technologies, 19(5), 833852.

Amit, R., \& Schoemaker, P. J. (1993). Strategic assets and organizational rent. Strategic management journal, 14(1), 33-46.

Autio, E., Sapienza, H. J., \& Almeida, J. G. (2000). Effects of age at entry, knowled ge intensity, and imitability on international growth. Academy of management journal, 43(5), 909-924.

Barakat, M., Haikal, G., Ali, A., \& Eid, A. (2018) Enhancing Exports through Managing Logistics Performance: Evidence from Middle East and African Countries.

Barney, J. (1991). Firm resources and sustained competitive advantage. Journal of management, 17(1), 99-120.

Barney, J. B. (2001). Resource-based theories of competitive advantage: A ten-year retrospective on the resource-based view. Journal of management, 27(6), 643-650.

Barney, J. B., \& Arikan, A. M. (2001). The resource-based view: Origins and implications. The Blackwell handbook of strategic management, 124-188. 
Barney, J. B., \& Clark, D. N. (2007). Resource-based theory: Creating and sustaining competitive advantage. Oxford University Press on Demand.

Berglund, M., Laarhoven, P. V., Sharman, G., \& Wandel, S. (1999). Third-party logistics: is there a future?. The international journal of logistics management, 10(1), 59-70.

Bettis, R. A., Bradley, S. P., \& Hamel, G. (1992). Outsourcing and industrial decline. Academy of Management Perspectives, 6(1), 7-22.

Bromiley, P., \& Rau, D. (2016). Operations management and the resource based view: Another view. Journal of Operations Management, 41, 95-106.

Cavusgil, S. T., \& Nevin, J. R. (1981). Internal determinants of export marketing behavior: An empirical investigation. Journal of marketing Research, 18(1), 114-119.

Cavusgil, S. T., \& Zou, S. (1994). Marketing strategy-performance relationship: an investigation of the empirical link in export market ventures. Journal of marketing, 58(1), 1-21.

Chang, S. J. (1995). International expansion strategy of Japanese firms: Capability building through sequential entry. Academy of Management journal, 38(2), 383-407.

Christopher, M., (2005). Logistics and Supply Chain Management - Strategies for Reducing Cost and Improving Service (3rd ed.). Financial Times/ Prentice Hall.

Cilloniz (2020). "La uva es la principal fruta de exportación del Perú". Recuperado de: https://www.peru-retail.com/uva-principal-fruta-de-exportacionperu/\#: :text=El\%20Per\%C3\%BA\%20ha\%20podido\%20posicionarse,los\%20900\%20mi llones\%20de\%20d\%C3\%B3lares.

Coates, T. T., \& McDermott, C. M. (2002). An exploratory analysis of new competencies: a resource based view perspective. Journal of Operations Management, 20(5), 435-450.

Daugherty, P. J., \& Pittman, P. H. (1995). Utilization of time-based strategies. International Journal of Operations \& Production Management. 
Davis, P. S., Desai, A. B., \& Francis, J. D. (2000). Mode of international entry: An isomorphism perspective. Journal of International Business Studies, 31(2), 239-258.

De Clercq, D., Hessels, J., \& Van Stel, A. (2008). Knowledge spillovers and new ventures' export orientation. Small Business Economics, 31(3), 283-303.

Diamantopoulos, A. (1998). "From the Guest Editor". Journal of International Marketing, 6(3), 36.

DiMaggio, P. J., \& Powell, W. W. (1983). The iron cage revisited: Institutional isomorphism and collective rationality in organizational fields. American sociological review, 147-160.

Domingues, M. L., Reis, V., \& Macário, R. (2015). A comprehensive framework for measuring performance in a third-party logistics provider. Transportation Research Procedia, 10, 662672.

Feng, B., Fan, Z. P., \& Li, Y. (2011). A decision method for supplier selection in multi-service outsourcing. International journal of production economics, 132(2), 240-250.

Fill, C., \& Visser, E. (2000). The outsourcing dilemma: a composite approach to the make or buy decision. Management decision.

Gadde, L. E., \& Hulthén, K. (2009). Improving logistics outsourcing through increasing buyerprovider interaction. Industrial Marketing Management, 38(6), 633-640.

Gani, A. (2017). The logistics performance effect in international trade. The Asian Journal of Shipping and Logistics, 33(4), 279-288.

Gao, S. (2013). A study of value creation through the use of 3PL and 4PL partners within the white goods manufacturing industry of China's domestic market: a thesis presented in partial fulfillment of the requirements for the degree of Master in Logistics and Supply Chain Management at Massey University, Auckland, New Zealand (Doctoral dissertation, Massey University). 
García-León, A., \& Bermeo-Andrade, H. (2011). About regional logistics operator in Tolima under SCOR model approach. In 61st Annual Conference and Expo of the Institute of Industrial Engineers.

Gimeno, J., Hoskisson, R. E., Beal, B. D., \& Wan, W. P. (2005). Explaining the clustering of international expansion moves: A critical test in the US telecommunications industry. Academy of Management Journal, 48(2), 297-319.

Greenaway, D., Sousa, N., \& Wakelin, K. (2004). Do domestic firms learn to export from multinationals?. European Journal of Political Economy, 20(4), 1027-1043.

Greenwood, R., \& Hinings, C. R. (1988). Organizational design types, tracks and the dynamics of strategic change. Organization studies, 9(3), 293-316.

Guan, J., \& Ma, N. (2003). Innovative capability and export performance of Chinese firms. Technovation, 23(9), 737-747.

Hafeez, K., Zhang, Y., \& Malak, N. (2002). Core competence for sustainable competitive advantage: a structured methodology for identifying core competence. IEEE transactions on engineering management, 49(1), 28-35.

Harding, F. E. (1998). Logistics service provider quality private measurement, evaluation, and improvement. Journal of Business Logistics, 19(1), 103.

Hausman, W. H., Lee, H. L., \& Subramanian, U. (2013). The impact of logistics performance on trade. Production and Operations Management, 22(2), 236-252.

Hernández, R., Fernández, C., \& Baptista, P. (2014). Metodología de la investigación. México: Editorial Mc Graw Hill.

Hilletofth, P., \& Hilmola, O. P. (2010). Role of logistics outsourcing on supply chain strategy and management. Strategic Outsourcing: An International Journal. 
Honorato, M. (2016). Mide el impacto de tus proveedores de transporte o $3 \mathrm{pl}$ en tu empresa. Recuperado de: https://www.beetrack.com/es/blog/mide-el-impacto-de-tus-proveedoresde-transporte-o-3pl-en-tu-empresa

Hsiao, H. I., Kemp, R. G. M., Van der Vorst, J. G. A. J., \& Omta, S. O. (2010). A classification of logistic outsourcing levels and their impact on service performance: Evidence from the food processing industry. International journal of production economics, 124(1), 75-86.

Huang, D., \& Kadar, M. (2002). Third-party logistics in China: still a tough market. Mercer on Travel and Transport, 9(2), 3-10.

Hum, S. H. (2000). A Hayes-Wheelwright framework approach for strategic management of third party logistics services. Integrated Manufacturing Systems.

Jiang, B., Frazier, G. V., \& Prater, E. L. (2006). Outsourcing effects on firms' operational performance. International Journal of Operations \& Production Management.

Karia, N., \& Wong, C. Y. (2013). The impact of logistics resources on the performance of Malaysian logistics service providers. Production Planning \& Control, 24(7), 589-606.

Karia, N., Wong, C. Y., Asaari, M. H. A. H., \& Lai, K. H. (2015). The effects of resource bundling on third-party logistics providers' performance. International journal of engineering business management, 7(Godište 2015), 7-9.

Keeble, D., Lawson, C., Smith, H. L., Moore, B., \& Wilkinson, F. (1998). Internationalisation processes, networking and local embeddedness in technology-intensive small firms. Small Business Economics, 11(4), 327-342.

Kneller, R., \& Pisu, M. (2007). Industrial linkages and export spillovers from FDI. World Economy, 30(1), 105-134.

Knemeyer, A. M., \& Murphy, P. R. (2004). Evaluating the performance of third-party logistics arrangements: a relationship marketing perspective. Journal of supply chain management, 40(4), 35-51. 
Kotabe, M. (1992). Global sourcing strategy: R \& D, manufacturing, and marketing interfaces (p. 1992). New York: Quorum Books.

Lai, F., Li, D., Wang, Q., \& Zhao, X. (2008). The information technology capability of third-party logistics providers: a resource-based view and empirical evidence from China. Journal of supply chain management, 44(3), 22-38.

Lai, K. H. (2004). Service capability and performance of logistics service providers. Transportation Research Part E: Logistics and Transportation Review, 40(5), 385-399.

Leuschner, R., Carter, C. R., Goldsby, T. J., \& Rogers, Z. S. (2014). Third-party logistics: a metaanalytic review and investigation of its impact on performance. Journal of Supply Chain Management, 50(1), 21-43.

Maes, M. (2015). Contribution of third-party-logistics providers to export performance (Master's thesis, UHasselt).

McIvor, R. (2009). How the transaction cost and resource-based theories of the firm inform outsourcing evaluation. Journal of Operations management, 27(1), 45-63.

Mentzer, J. T., Min, S., \& Bobbitt, L. M. (2004). Toward a unified theory of logistics. International Journal of Physical Distribution \& Logistics Management.

Ministerio de Agricultura y Riego (2020). Recuperado de: https://www.gob.pe/minagri

Mitra, S., \& Bagchi, P. K. (2008). Key success factors, performance metrics, and globalization issues in the third-party logistics (3PL) industry: A survey of North American service providers. In Supply Chain Forum: An International Journal (Vol. 9, No. 1, pp. 42-54).

Murphy Jr, P. R., \& Wood, D. F. (2008). Contemporary Logistics.

Murphy, P. R., \& Daley, J. M. (2001). Profiling international freight forwarders: an update. International Journal of Physical Distribution \& Logistics Management.

Mwangangi, P. W. (2016). Influence of logistics management on performance of manufacturing firms in Kenya (Doctoral dissertation, SUpply chain management, COHRED, Jkaut). 
Myers, M. B., Fawcett, S. E., \& Smith, S. R. (1996). Operating in the Caribbean: a logistics perspective. International Journal of Physical Distribution \& Logistics Management.

Nielsen, L. B., Mitchell, F., \& Nørreklit, H. (2015). Management accounting and decision making: Two case studies of outsourcing. In Accounting Forum (V ol. 39, No. 1, pp. 66-82).

Nuhanović, M. (2016). The role of logistics service providers in international business (Doctoral dissertation, University of Rijeka. Faculty of Economics.).

Olavarrieta, S., \& Ellinger, A. E. (1997). Resource-based theory and strategic logistics research. International Journal of Physical Distribution \& Logistics Management.

Oliver, C. (1997). Sustainable competitive advantage: combining institutional and resource-based views. Strategic management journal, 18(9), 697-713.

Panayides, P. M. (2007). Effects of organizational learning in third-party logistics. Journal of Business Logistics, 28(2), 133-158.

Parashkevova, L. (2007). Logistics outsourcing-A means of assuring the competitive advantage for an organization. Vadyba/management, 2(15), 29-38.

Penrose, E. T. (2009). The Theory of the Growth of the Firm. Oxford university press.

Pfeffer, J., \& Salancik, G. R. (2003). The external control of organizations: A resource dependence perspective. Stanford University Press.

Puertas, R., Martí, L., \& García, L. (2014). Logistics performance and export competitiveness: European experience. Empirica, 41(3), 467-480.

Quinn, J. B. (1999). Strategic outsourcing: leveraging knowledge capabilities. MIT Sloan Management Review, 40(4), 9.

Ray, G., Barney, J. B., \& Muhanna, W. A. (2004). Capabilities, business processes, and competitive advantage: choosing the dependent variable in empirical tests of the resource based view. Strategic management journal, 25(1), 23-37. 
Razzaque, M. A., \& Sheng, C. C. (1998). Outsourcing of logistics functions: a literature survey. International Journal of Physical Distribution \& Logistics Management.

Roxo, M. (2014). Export Performance The case of the exports of cork stoppers from Portugal to emergent economies (Doctoral dissertation, Dissertation. Universidade Católica Portuguesa. $\quad$ Retrieved https://repositorio. ucp. pt/bitstream/10400.14/16988/1/TFM_mafalda_roxo.pdf).

Sahay, B. S., \& Mohan, R. (2006). 3PL practices: an Indian perspective. International Journal of Physical Distribution \& Logistics Management.

Sánchez, H., \& Reyes, C. (2000). Diseños de investigación. Alvitres, V. Métodos científicos, Planificación de la Investigación. Perú: Edit. Ciencia.

Sangam, V. K. (2007). Logistics outsourcing: an innovative strategy or a logistical nightmare?: a thesis submitted in partial fulfilment of the requirements for the degree of Master of Applied Science at Massey University (Doctoral dissertation, Massey University).

Scheaffer, R. L., Mendenhall, W., \& Ott, L. (2006). Elementos de muestreo. Editorial Paraninfo.

Scott, W, R. (1995). Institutions and Organizations: Thousand Oaks.

Selnes, F., \& Sallis, J. (2003). Promoting relationship learning. Journal of marketing, 67(3), 8095.

Sheffi, Y. (1990). Third party logistics: present and future prospects. Journal of Business Logistics, 11(2), 27.

Skender, H. P., Host, A., \& Nuhanović, M. (2016). The role of logistics service providers in international trade. Business Logistics in Modern Management.

Skjoett-Larsen, T. (1999). Supply chain management: a new challenge for researchers and managers in logistics. The International Journal of Logistics Management.

Skjoett-Larsen, T. (2000). Third party logistics-from an interorganizational point of view. International journal of physical distribution \& logistics management. 
Spencer, M. S., Rogers, D. S., \& Daugherty, P. J. (1994). JIT systems and external logistics suppliers. International Journal of Operations \& Production Management.

Stainer, A. (1997). Logistics-a productivity and performance perspective. Supply Chain Management: An International Journal.

Stock, J., \& Lambert, D. (1992). Becoming a world class company with logistics service. Strategy Planning in Logistics and Transportation, 35-52.

Teece, D. J., Pisano, G., \& Shuen, A. (1997). Dynamic capabilities and strategic management. Strategic management journal, 18(7), 509-533.

Tesfom, G., Lutz, C., \& Ghauri, P. (2004). Comparing export marketing channels: developed versus developing countries. International Marketing Review.

Van Witteloostuijn, A., \& Boone, C. (2006). A resource-based theory of market structure and organizational form. Academy of Management Review, 31(2), 409-426.

Virum, H. (1993) Third Party Logistics, Research report 1993/1, Norwegian School of Management, Sand vika, Norway.

Wang, I. C. (2010). The application of third party logistics to implement the Just-In-Time system with minimum cost under a global environment. Expert Systems with Applications, 37(3), 2117-2123.

Wang, Q., Zantow, K., Lai, F., \& Wang, X. (2006). Strategic postures of third-party logistics providers in mainland China. International Journal of Physical Distribution \& Logistics Management.

Wernerfelt, B. (1984). A resource-based view of the firm. Strategic management journal, 5(2), 171-180.

Westhead, P. (1995). Exporting and non-exporting small firms in Great Britain. International Journal of Entrepreneurial Behavior \& Research. 
Westney, D. E. (2001). Japanese enterprise faces the twenty-first century. The Twenty-FirstCentury Firm: Changing Economic Organization in International Perspective, 105-143.

Wong, C. Y., \& Karia, N. (2010). Explaining the competitive advantage of logistics service providers: A resource-based view approach. International Journal of Production Economics, 128(1), 51-67.

Wouters, J. (2010). Logistics Services Provider Opportunities: CTC Worldwide Logistics Case Study.

Yang, C. C., Marlow, P. B., \& Lu, C. S. (2009). Assessing resources, logistics service capabilities, innovation capabilities and the performance of container shipping services in Taiwan. International Journal of Production Economics, 122(1), 4-20.

Yeung, A. C. (2006). The impact of third-party logistics performance on the logistics and export performance of users: an empirical study. Maritime Economics \& Logistics, 8(2), 121-139.

Yeung, K., Zhou, H., Yeung, A. C., \& Cheng, T. C. E. (2012). The impact of third-party logistics providers' capabilities on exporters' performance. International Journal of Production Economics, 135(2), 741-753.

Young, K. R. (1994). Global Supply Chains: Factors Influencing Outsourcing of Logistics Functions. Management, 24(6), 11-19. 


\section{Anexos}

\section{Anexo 1. Matriz de Consistencia}

Tabla 47:

Matriz de consistencia

\begin{tabular}{|c|c|c|c|c|}
\hline PROBLEMA & OBJETIVOS & HIPOTESIS & VARIABLES & METODOLOGIA \\
\hline Problema general & Objetivo general & Hipótesis general & & Tipo de investigación: \\
\hline $\begin{array}{l}\text { ¿Cuál es la relación del } \\
\text { desempeño de proveedores } \\
\text { logisticos de terceros con el } \\
\text { desempeño de las empresas } \\
\text { MYPES exportadoras de } \\
\text { uvas a Estados Unidos } 2020 \text { ? } \\
\text { Problemas específicos } \\
\text { ¿Cuál es la relación de la } \\
\text { puntualidad de los servicios } \\
\text { con el desempeño de las } \\
\text { empresas MYPES } \\
\text { exportadoras de uvas a } \\
\text { Estados Unidos } 2020 \text { ? } \\
\text { ¿Cuál es la relación de los } \\
\text { servicios complementarios a } \\
\text { medida con el desempeño de } \\
\text { las empresas MYPES } \\
\text { exportadoras de uvas a } \\
\text { Estados Unidos } 2020 \text { ? } \\
\text { ¿Cuál es la relación del factor } \\
\text { de precios con el desempeño } \\
\text { de las empresas MYPES } \\
\text { exportadoras de uvas a } \\
\text { Estados Unidos } 2020 \text { ? } \\
\text { ¿Cuál es la relación de la } \\
\text { calidad de entrega con el } \\
\text { desempeño de las empresas } \\
\text { MYPES exportadoras de } \\
\text { uvas a Estados Unidos } 2020 \text { ? }\end{array}$ & $\begin{array}{l}\text { Analizar la relación del } \\
\text { desempeño de proveedores } \\
\text { logisticos de terceros con el } \\
\text { desempeño de las empresas } \\
\text { MYPES exportadoras de uvas } \\
\text { a Estados Unidos } 2020 \text {. } \\
\text { Objetivos especificos } \\
\text { Analizar la relación de la } \\
\text { puntualidad de los servicios } \\
\text { con el desempeño de las } \\
\text { empresas MYPES } \\
\text { exportadoras de uvas a Estados } \\
\text { Unidos } 2020 \text {. } \\
\text { Analizar la relación de los } \\
\text { servicios complementarios a } \\
\text { medida con el desempeño de } \\
\text { las empresas MYPES } \\
\text { exportadoras de uvas a Estados } \\
\text { Unidos } 2020 \text {. } \\
\text { Analizar la relación del factor } \\
\text { de precios con el desempeño de } \\
\text { las empresas MYPES } \\
\text { exportadoras de uvas a Estados } \\
\text { Unidos } 2020 \text {. } \\
\text { Analizar la relación de la } \\
\text { calidad de entrega con el } \\
\text { desempeño de las empresas } \\
\text { MYPES exportadoras de uvas } \\
\text { a Estados Unidos } 2020 \text {. }\end{array}$ & $\begin{array}{l}\text { El desempeño de } \\
\text { proveedores logisticos de } \\
\text { terceros se relaciona con el } \\
\text { desempeño de las empresas } \\
\text { MYPES exportadoras de } \\
\text { uvas a Estados Unidos } 2020 \text {. } \\
\text { Hipótesis especificas } \\
\text { La puntualidad de los } \\
\text { servicios se relaciona con el } \\
\text { desempeño de las empresas } \\
\text { MYPES exportadoras de } \\
\text { uvas a Estados Unidos } 2020 . \\
\text { Los servicios } \\
\text { complementarios a medida se } \\
\text { relaciona con el desempeño } \\
\text { de las empresas MYPES } \\
\text { exportadoras de uvas a } \\
\text { Estados Unidos } 2020 . \\
\text { El factor de precios se } \\
\text { relaciona con el desempeño } \\
\text { de las empresas MYPES } \\
\text { exportadoras de uvas a } \\
\text { Estados Unidos } 2020 \text {. } \\
\text { La calidad de entrega se } \\
\text { relaciona con el desempeño } \\
\text { de las empresas MYPES } \\
\text { exportadoras de uvas a } \\
\text { Estados Unidos } 2020 \text {. }\end{array}$ & $\begin{array}{l}\text { X1: Desempeño de } \\
\text { proveedores logísticos } \\
\text { de terceros } \\
\text { X1A: puntualidad de } \\
\text { los servicios. } \\
\text { X1B: servicios } \\
\text { complementarios a } \\
\text { medida. } \\
\text { X1C: factor de precios. } \\
\text { X1D: calidad de } \\
\text { entrega. }\end{array}$ & $\begin{array}{l}\text { Correlacional } \\
\text { cuantitativo) } \\
\text { Diseño de investigación: } \\
\text { No experimental transversal y } \\
\text { correlacional. } \\
\text { Muestra } \\
63 \text { gerentes o administradores de las } \\
\text { empresas MYPES exportadoras de } \\
\text { uvas a Estados Unidos } 2020 \text {. } \\
\text { Instrumentos de la investigación: } \\
\text { La encuesta está compuesta en la } \\
\text { primera parte está comprendida por } \\
\text { el cuestionario de desempeño de } \\
\text { proveedores logisticos de terceros } \\
\text { de } 19 \text { items y la segunda parte está } \\
\text { comprendida por el cuestionario de } \\
\text { desempeño exportador de } 4 \text { items, } \\
\text { en ambos casos del investigador } \\
\text { Yeung (2006). }\end{array}$ \\
\hline
\end{tabular}




\section{Anexo 2. Cuestionarios}

Tabla 48:

Cuestionario de desempeño de $3 P L$

Tema: “Impacto del desempeño de la tercerización de servicios logísticos en las MYPES exportadoras de uvas a EUA, 2020"

VARIABLE: desempeño de 3PL

Instrucción:

La siguiente es una serie de preguntas para responder. Lea cada oración con atención y marque una alternativa con una $\mathrm{X}$ en el cuadro correspondiente a la oración seleccionada. Su absoluta sinceridad en las respuestas es fundamental, porque de ellos depende el éxito de esta investigación.

NOTA: Para cada pregunta se considera la escala de 1 a 5 donde:

\begin{tabular}{|c|c|c|c|c|}
\hline 1 & 2 & 3 & 4 & 5 \\
\hline Muy pobre & Pobre & $\begin{array}{c}\text { Ni pobre ni } \\
\text { excelente }\end{array}$ & Excelente & $\begin{array}{c}\text { Muy } \\
\text { excelente }\end{array}$ \\
\hline
\end{tabular}

\begin{tabular}{|c|c|c|c|c|c|c|}
\hline Número & ITEM & 1 & 2 & 3 & 4 & 5 \\
\hline 1 & $\begin{array}{l}\text { La empresa tercerizadora de servicios logisticos } \\
\text { (3PL) realiza el servicio prometido } \\
\text { satisfactoriamente. }\end{array}$ & & & & & \\
\hline 2 & $\begin{array}{l}\text { La empresa tercerizadora de servicios logisticos } \\
\text { (3PL) responde de manera oportuna y precisa. }\end{array}$ & & & & & \\
\hline 3 & $\begin{array}{l}\text { La empresa tercerizadora de servicios logisticos } \\
\text { (3PL) brinda servicios oportunos para satisfacer } \\
\text { necesidades particulares. }\end{array}$ & & & & & \\
\hline 4 & $\begin{array}{l}\text { La empresa tercerizadora de servicios logisticos } \\
\text { (3PL) proporciona entregas a tiempo y confiables. }\end{array}$ & & & & & \\
\hline 5 & $\begin{array}{l}\text { La empresa tercerizadora de servicios logisticos } \\
\text { (3PL) lleva los problemas de servicio a un final } \\
\text { satisfactorio. }\end{array}$ & & & & & \\
\hline 6 & $\begin{array}{l}\text { La empresa tercerizadora de servicios logisticos } \\
\text { (3PL) maneja requisitos especiales a corto plazo. }\end{array}$ & & & & & \\
\hline 7 & $\begin{array}{l}\text { La empresa tercerizadora de servicios logísticos } \\
\text { (3PL) acomoda solicitudes de servicio } \\
\text { personalizado de manera oportuna. }\end{array}$ & & & & & \\
\hline
\end{tabular}




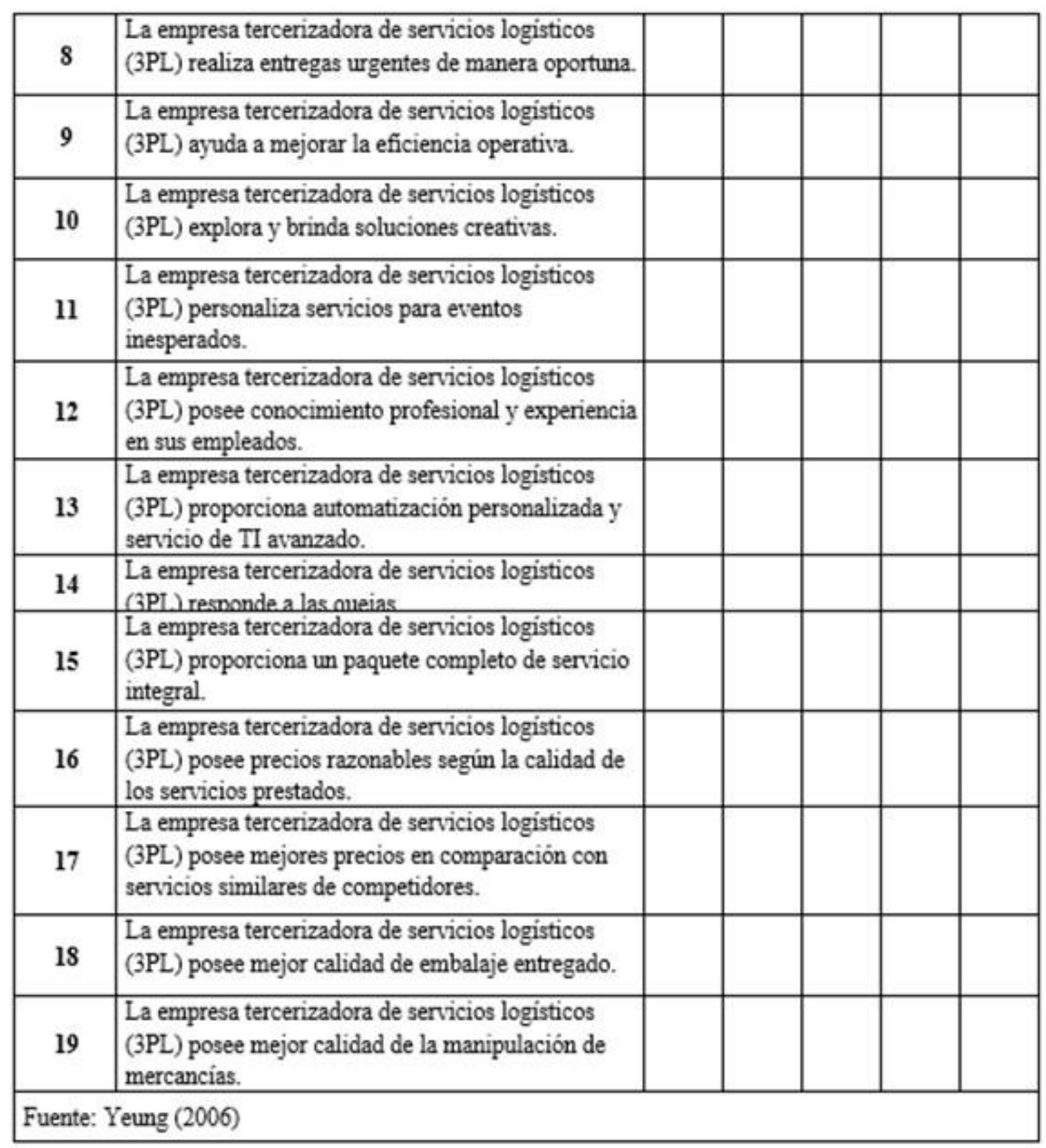


Tabla 49:

Cuestionario de desempeño exportador

Tema: "Impacto del desempeño de la tercerización de servicios logísticos en las MYPES exportadoras de uvas a EUA, 2020"

VARIABLE: desempeño exportador

\section{Instrucción:}

La siguiente es una serie de preguntas para responder. Lea cada oración con atención y marque una alternativa con una $\mathrm{X}$ en el cuadro correspondiente a la oración seleccionada. Su absoluta sinceridad en las respuestas es fundamental, porque de ellos depende el éxito de esta investigación.

NOTA: Para cada pregunta se considera la escala de 1 a 5 donde:

\begin{tabular}{|c|c|c|c|c|}
\hline 1 & 2 & 3 & 4 & 5 \\
\hline Muy pobre & pobre & $\begin{array}{c}\text { Ni pobre ni } \\
\text { excelente }\end{array}$ & Excelente & $\begin{array}{c}\text { Muy } \\
\text { excelente }\end{array}$ \\
\hline
\end{tabular}

\begin{tabular}{|c|l|r|r|r|r|r|}
\hline Nümero & \multicolumn{1}{|c|}{ ITEM } & 1 & $\mathbf{2}$ & $\mathbf{3}$ & $\mathbf{4}$ & $\mathbf{5}$ \\
\hline $\mathbf{1}$ & $\begin{array}{l}\text { La percepción de la rentabilidad de las } \\
\text { exportaciones de uva fresca se encuentra. }\end{array}$ & & & & & \\
\hline $\mathbf{2}$ & $\begin{array}{l}\text { La cuota de mercado en los mercados } \\
\text { objetivo de uva fresca se encuentra. }\end{array}$ & & & & & \\
\hline 3 & $\begin{array}{l}\text { El desempeño en las ventas y crecimiento } \\
\text { exportador de uva fresca se encuentra. }\end{array}$ & & & & & \\
\hline $\mathbf{4}$ & $\begin{array}{l}\text { El logro de metas y objetivos de } \\
\text { exportación de uva fresca se encuentra. }\end{array}$ & & & & & \\
\hline Fuente: Yeung (2006)
\end{tabular}




\section{Anexo 3. Prueba de Shapiro-Wilk}

Desempeño de tercerización de los servicios logísticos 3PL

\begin{tabular}{|c|c|c|c|c|c|c|}
\hline \multicolumn{7}{|l|}{ Tests of Normalit: } \\
\hline & \multicolumn{3}{|c|}{$\begin{array}{l}\text { Kolmosorer: } \\
\text { Smimexa }\end{array}$} & \multicolumn{3}{|c|}{ Shapiro-Wilk } \\
\hline & Statistic & df & Sig. & Statistic & df & Sig. \\
\hline TPL1. La empresa tercerizadora de servicios logisticos & .184 & 63 & .000 & .868 & 63 & .000 \\
\hline $\begin{array}{l}\text { (3PL) realiza el servicio prometido satisfactonamente. } \\
\text { TPL2. La empresa tercerizadora de servicios logisticos }\end{array}$ & & & & & & \\
\hline (3PL) responde de manera oportuna y precisa. & .195 & 63 & .000 & .867 & 63 & .000 \\
\hline TPL 3. La empresa tercerizadora de servicios logísticos & & & & & & \\
\hline $\begin{array}{l}\text { (3PL) brinda servicios oportunos para satisfacer necesidades } \\
\text { particulares. }\end{array}$ & .218 & 63 & .000 & .839 & 63 & .000 \\
\hline $\begin{array}{l}\text { TPL4. La empresa tercerizadora de servicios logisticos } \\
\text { (3PL) proporciona entregas a tiempo y confiables. }\end{array}$ & .246 & 63 & .000 & .819 & 63 & .000 \\
\hline TPL5. La empresa tercerizadora de servicios logisticos & & & & & & \\
\hline $\begin{array}{l}\text { (3PL) Lleva los problemas de servicio a un final } \\
\text { satisfactorio. }\end{array}$ & .187 & 63 & .000 & .897 & 63 & .000 \\
\hline $\begin{array}{l}\text { TPL6. La empresa tercerizadora de servicios logisticos } \\
\text { (3PL) maneja requisitos especiales a corto plazo. }\end{array}$ & .182 & 63 & .000 & .909 & 63 & .000 \\
\hline TPL 7. La empresa tercerizadora de servicios logisticos & & & & & & \\
\hline $\begin{array}{l}\text { (3PL) acomoda solicitudes de servicio personalizado de } \\
\text { manera oportuna. }\end{array}$ & .216 & 63 & .000 & .887 & 63 & .000 \\
\hline $\begin{array}{l}\text { TPL8. La empresa tercerizadora de servicios logísticos } \\
\text { (3PL) realiza entregas urgentes de manera oportuna. }\end{array}$ & .244 & 63 & .000 & .847 & 63 & .000 \\
\hline $\begin{array}{l}\text { TPL9. La empresa tercerizadora de servicios logisticos } \\
\text { (3PL) ayuda a mejorar la eficiencia operativa. }\end{array}$ & .419 & 63 & .000 & .644 & 63 & .000 \\
\hline $\begin{array}{l}\text { TPL10. La empresa tercerizadora de servicios logisticos } \\
\text { (3PL) explora y brinda soluciones creativas. }\end{array}$ & .277 & 63 & .000 & .830 & 63 & .000 \\
\hline TPL11. La empresa tercerizadora de servicios logisticos & .248 & 63 & .000 & .819 & 63 & .000 \\
\hline (3PL) personaliza servicios para eventos inesperados. & & & & & & \\
\hline TPL12. La empresa tercerizadora de servicios logisticos & & & & & & \\
\hline $\begin{array}{l}\text { (3PL) posee conocimiento profesional y experiencia en sus } \\
\text { empleados. }\end{array}$ & .217 & 63 & .000 & .891 & 63 & .000 \\
\hline TPL13. La empresa tercerizadora de servicios logisticos & & & & & & \\
\hline $\begin{array}{l}\text { (3PL) proporciona automatización personalizada y servicio } \\
\text { de } \pi \text { avanzado. }\end{array}$ & .269 & 63 & .000 & .835 & 63 & .000 \\
\hline $\begin{array}{l}\text { TPL14. La empresa tercerizadora de servicios logísticos } \\
\text { (3PL) responde a las quejas. }\end{array}$ & .278 & 63 & .000 & .847 & 63 & .000 \\
\hline
\end{tabular}


ITPL15. La empresa tercerizadora de servicios logisticos (3PL) proporciona un paquete completo de servicio integral. TPL16. La empresa tercerizadora de servicios logísticos (3PL) posee precios razonables segin la calidad de los gervicios prestados.

TPL17. La empresa tercerizadora de servicios logisticos (3PL) posee mejores precios en comparación con servicios similares de competidores.

TPL18. La empresa tercerizadora de servicios logisticos (3PL) posee mejor calidad de embalaje entregado.

TPL19. La empresa tercerizadora de servicios logisticos (3PL) posee mejor calidad de la manipulación de mercancias.

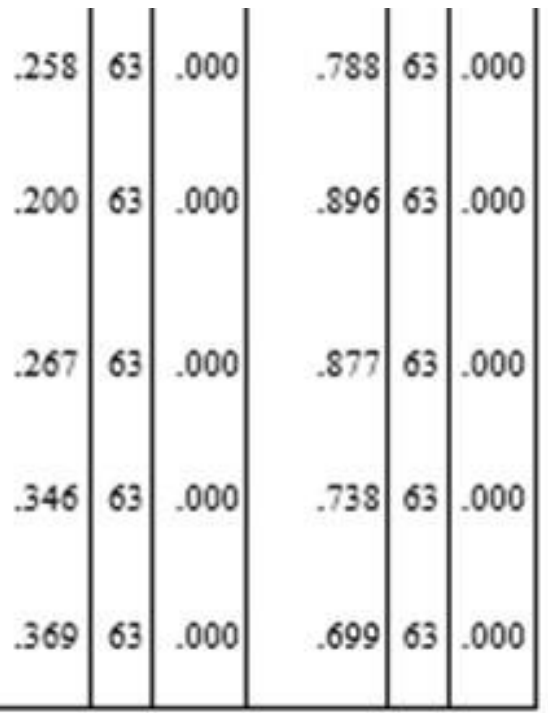

a. Lilliefors Siznificance Correction

\section{Desempeño exportador}

\begin{tabular}{|c|c|c|c|c|c|c|}
\hline \multicolumn{7}{|l|}{ Tests of Normality } \\
\hline & \multicolumn{3}{|c|}{$\begin{array}{l}\text { Kolmogorov- } \\
\text { Smirnoy: }\end{array}$} & \multicolumn{3}{|c|}{ Shapiro-Wilk } \\
\hline & Statistic & df & Sig. & Statistic & df & Sig. \\
\hline $\begin{array}{l}\text { DEXP1. La percepción de la rentabilidad de las exportaciones } \\
\text { se encuentra. }\end{array}$ & .178 & 63 & .000 & .899 & 63 & .000 \\
\hline $\begin{array}{l}\text { DEXP2. La cuota de mercado en los mercados objetivo se } \\
\text { encuentra. }\end{array}$ & .204 & 63 & .000 & .887 & 63 & .000 \\
\hline $\begin{array}{l}\text { DEXP3. El desempeño en las ventas y crecimiento } \\
\text { exportador se encuentra. }\end{array}$ & .187 & 63 & .000 & .891 & 63 & .000 \\
\hline $\begin{array}{l}\text { DEXP4. El logro de metas y objetivos de exportación se } \\
\text { encuentra. }\end{array}$ & .245 & 63 & .000 & .899 & 63 & .000 \\
\hline
\end{tabular}

a. Lilliefors. Significance Correction. 


\section{Anexo 4. Alfa de Cronbach}

Desempeño de tercerización de los servicios logísticos 3PL

\begin{tabular}{rlrr}
\multicolumn{3}{c}{ Case Processing Summary } \\
& \multicolumn{1}{c}{ N } & \multicolumn{1}{l}{$\%$} \\
\hline \multirow{3}{*}{ Cases } & Yalid & 63 & 100.0 \\
\cline { 2 - 4 } & Excluded & 0 & .0 \\
\cline { 2 - 4 } & Total & 63 & 100.0 \\
\hline
\end{tabular}

a. Listwise deletion based on all variables in the procedure.

\section{Reliability Statistics}

\begin{tabular}{r|r}
$\begin{array}{c}\text { Cronbach's. } \\
\text { Alpha }\end{array}$ & N of Items \\
\hline .943 & 19 \\
\hline
\end{tabular}

\section{Desempeño exportador}

\begin{tabular}{|c|c|c|c|}
\hline \multicolumn{4}{|c|}{ Case Processing Summary } \\
\hline & & $\mathrm{N}$ & $\%$ \\
\hline \multirow{3}{*}{ Cases } & Yalid & 63 & 100.0 \\
\hline & Excluded $z$ & 0 & .0 \\
\hline & Total & 63 & 100.0 \\
\hline
\end{tabular}

\begin{tabular}{c|c}
\multicolumn{2}{c}{ Reliability Statistics } \\
$\begin{array}{c}\text { Cronbach's } \\
\text { Alpha }\end{array}$ & N of Items \\
\hline .752 & 4 \\
\hline
\end{tabular}




\section{Anexo 5. Análisis factorial}

Desempeño de tercerización de los servicios logísticos 3PL

KMO and Bartlett's Test

Kaiser-Meyer-Olkin Measure of Sampling Adequacy.

\section{Communalities}

\begin{tabular}{|c|c|c|}
\hline & Initial & Extraction \\
\hline $\begin{array}{l}\text { TPL1. La empresa tercerizadora de servicios logísticos (3PL) realiza el servicio } \\
\text { prometido satisfactoriamente. }\end{array}$ & 1.000 & .945 \\
\hline $\begin{array}{l}\text { TPL2. La empresa tercerizadora de servicios logisticos (3PL) responde de } \\
\text { manera oportuna y precisa. }\end{array}$ & 1.000 & .957 \\
\hline $\begin{array}{l}\text { TPL3. La empresa tercerizadora de servicios logisticos (3PL) brinda servicios } \\
\text { oportunos para satisfacer necesidades particulares. }\end{array}$ & 1.000 & .662 \\
\hline $\begin{array}{l}\text { TPL4. La empresa tercerizadora de servicios logisticos (3PL) proporciona } \\
\text { entregas a tiempo y confiables. }\end{array}$ & 1.000 & .878 \\
\hline $\begin{array}{l}\text { TPL5. La empresa tercerizadora de servicios logísticos (3PL) lleva los problemas } \\
\text { de servicio a un final satisfactorio. }\end{array}$ & 1.000 & .924 \\
\hline $\begin{array}{l}\text { TPL6. La empresa tercerizadora de servicios logísticos (3PL) maneja requisitos } \\
\text { especiales a corto plazo. }\end{array}$ & 1.000 & .853 \\
\hline $\begin{array}{l}\text { TPL 7. La empresa tercerizadora de servicios logisticos (3PL) acomoda } \\
\text { solicitudes de servicio personalizado de manera oportuna. }\end{array}$ & 1.000 & 916 \\
\hline $\begin{array}{l}\text { TPL8. La empresa tercerizadora de servicios logisticos (3PL) realiza entregas } \\
\text { urgentes de manera oportuna. }\end{array}$ & 1.000 & .721 \\
\hline $\begin{array}{l}\text { TPL9. La empresa tercerizadora de servicios logisticos (3PL) ayuda a mejorar la } \\
\text { eficiencia operativa. }\end{array}$ & 1.000 & .903 \\
\hline $\begin{array}{l}\text { TPL 10. La empresa tercerizadora de servicios logisticos (3PL) explora y brinda } \\
\text { soluciones creativas. }\end{array}$ & 1.000 & .849 \\
\hline $\begin{array}{l}\text { TPL 11. La empresa tercerizadora de servicios logisticos (3PL) personaliza } \\
\text { servicios para eventos inesperados. }\end{array}$ & 1.000 & .880 \\
\hline $\begin{array}{l}\text { TPL 12. La empresa tercerizadora de servicios logisticos (3PL) posee } \\
\text { conocimiento profesional y experiencia en sus empleados. }\end{array}$ & 1.000 & .871 \\
\hline $\begin{array}{l}\text { TPL13. La empresa tercerizadora de servicios logisticos (3PL) proporciona } \\
\text { automatización personalizada y servicio de TI avanzado. }\end{array}$ & 1.000 & .812 \\
\hline $\begin{array}{l}\text { TPL14. La empresa tercerizadora de servicios logísticos (3PL) responde a las } \\
\text { quejas. }\end{array}$ & 1.000 & .923 \\
\hline
\end{tabular}




\begin{tabular}{|c|c|c|}
\hline $\begin{array}{l}\text { TPL15. La empresa tercerizadora de servicios logisticos (3PL) proporciona un } \\
\text { paquete completo de servicio integral. }\end{array}$ & 1.000 & .940 \\
\hline $\begin{array}{l}\text { TPL16. La empresa tercerizadora de servicios logisticos (3PL) posee precios } \\
\text { razonables según la calidad de los servicios prestados. }\end{array}$ & 1.000 & .955 \\
\hline $\begin{array}{l}\text { TPL17. La empresa tercerizadora de servicios logisticos (3PL) posee mejores } \\
\text { precios en comparación con servicios similares de competidores. }\end{array}$ & 1.000 & .941 \\
\hline $\begin{array}{l}\text { TPL18. La empresa tercerizadora de servicios logisticos ( } 3 \mathrm{PL} \text { ) posee mejor } \\
\text { calidad de embalaje entregado. }\end{array}$ & 1.000 & .631 \\
\hline $\begin{array}{l}\text { TPL19. La empresa tercerizadora de servicios logisticos (3PL) posee mejor } \\
\text { calidad de la manipulación de mercancias. }\end{array}$ & 1.000 & .8 \\
\hline
\end{tabular}

Extraction Method: Principal Component Analysis.

\section{Desempeño exportador}

KMO and Bartlett's Test

Kaiser-Meyer-Olkin Measure of Sampling Adequacy.

Approx Chi-Square $\quad 82.104$

Bartlett's Test of Sphericity

df

Sig.

\section{Communalities}

\begin{tabular}{|l|r|r|}
\hline & Initial & Extraction \\
\hline DEXP1. La percepción de la rentabilidad de las exportaciones se encuentra. & 1.000 & .651 \\
DEXP2. La cuota de mercado en los mercados objetivo se encuentra. & 1.000 & .815 \\
DEXP3. El desempeño en las ventas y crecimiento exportador se encuentra. & 1.000 & .808 \\
DEXP4. El logro de metas y objetivos de exportación se encuentra. & 1.000 & .979 \\
\hline
\end{tabular}

Extraction Method: Principal Component Analysis. 
Anexo 6. Coeficiente de Aiken

\begin{tabular}{|c|c|c|c|c|c|c|c|c|c|c|c|c|c|c|}
\hline \multirow{2}{*}{$\begin{array}{l}\text { JUECES } \\
\text { ITEM }\end{array}$} & \multicolumn{4}{|c|}{ JUEZ 1} & \multicolumn{4}{|c|}{ JUEZ 2} & \multicolumn{4}{|c|}{ JUEZ 3} & \multirow[b]{2}{*}{ SUMA } & \multirow[b]{2}{*}{ V AIKEN } \\
\hline & C & $\mathrm{Co}$ & CON & DC & C & $\mathrm{CO}$ & CON & DC & C & $\mathrm{CO}$ & CON & DC & & \\
\hline TPL1 & 5 & 5 & 5 & 5 & 4 & 4 & 4 & 4 & 5 & 5 & 5 & 5 & 56.00 & 0.93 \\
\hline TPL2 & 5 & 5 & 5 & 5 & 4 & 4 & 4 & 4 & 5 & 5 & 5 & 5 & 56.00 & 0.93 \\
\hline TPL3 & 5 & 5 & 5 & 5 & 4 & 4 & 4 & 4 & 5 & 5 & 5 & 5 & 56.00 & 0.93 \\
\hline TPL4 & 5 & 5 & 5 & 5 & 4 & 4 & 4 & 4 & 5 & 5 & 5 & 5 & 56.00 & 0.93 \\
\hline TPL5 & 5 & 5 & 5 & 5 & 4 & 4 & 4 & 4 & 5 & 5 & 5 & 5 & 56.00 & 0.93 \\
\hline TPL6 & 5 & 5 & 5 & 5 & 4 & 4 & 4 & 4 & 5 & 5 & 5 & 5 & 56.00 & 0.93 \\
\hline TPL7 & 5 & 5 & 5 & 5 & 4 & 4 & 4 & 4 & 5 & 5 & 5 & 5 & 56.00 & 0.93 \\
\hline TPL8 & 5 & 5 & 5 & 5 & 4 & 4 & 4 & 4 & 5 & 5 & 5 & 5 & 56.00 & 0.93 \\
\hline TPL9 & 5 & 5 & 5 & 5 & 4 & 4 & 4 & 4 & 5 & 5 & 5 & 5 & 56.00 & 0.93 \\
\hline TPL10 & 5 & 5 & 5 & 5 & 4 & 4 & 4 & 4 & 5 & 5 & 5 & 5 & 56.00 & 0.93 \\
\hline TPL11 & 5 & 5 & 5 & 5 & 4 & 4 & 4 & 4 & 5 & 5 & 5 & 5 & 56.00 & 0.93 \\
\hline TPL12 & 5 & 5 & 5 & 5 & 4 & 4 & 4 & 4 & 5 & 5 & 5 & 5 & 56.00 & 0.93 \\
\hline TPL13 & 5 & 5 & 5 & 5 & 4 & 4 & 4 & 4 & 5 & 5 & 5 & 5 & 56.00 & 0.93 \\
\hline TPL14 & 5 & 5 & 5 & 5 & 4 & 4 & 4 & 4 & 5 & 5 & 5 & 5 & 56.00 & 0.93 \\
\hline TPL15 & 5 & 5 & 5 & 5 & 4 & 4 & 4 & 4 & 5 & 5 & 5 & 5 & 56.00 & 0.93 \\
\hline TPL16 & 5 & 5 & 5 & 5 & 4 & 4 & 4 & 4 & 5 & 5 & 5 & 5 & 56.00 & 0.93 \\
\hline TPL17 & 5 & 5 & 5 & 5 & 4 & 4 & 4 & 4 & 5 & 5 & 5 & 5 & 56.00 & 0.93 \\
\hline TPL18 & 5 & 5 & 5 & 5 & 4 & 4 & 4 & 4 & 5 & 5 & 5 & 5 & 56.00 & 0.93 \\
\hline TPL19 & 5 & 5 & 5 & 5 & 4 & 4 & 4 & 4 & 5 & 5 & 5 & 5 & 56.00 & 0.93 \\
\hline \multicolumn{14}{|c|}{ V AIKEN } & 0.93 \\
\hline
\end{tabular}

CLARIDAD $=\mathrm{C} ;$ CONGRUENCIA $=\mathrm{CO} ;$ CONTEXTO $=$ CON $;$ DOMINIO DE CONSTRUCTO $=$ DC 


\begin{tabular}{|c|c|c|c|c|c|c|c|c|c|c|c|c|c|c|}
\hline \multirow{2}{*}{$\begin{array}{l}\text { JUECES } \\
\text { ITEM }\end{array}$} & \multirow[b]{2}{*}{ C } & \multicolumn{2}{|c|}{ JUEZ 1} & \multirow[b]{2}{*}{ DC } & \multirow[b]{2}{*}{ C } & \multicolumn{3}{|c|}{ JUEZ 2} & \multicolumn{4}{|c|}{ JUEZ 3} & \multirow[b]{2}{*}{ SUMA } & \multirow[b]{2}{*}{ V AIKEN } \\
\hline & & $\mathrm{CO}$ & CON & & & $\mathrm{CO}$ & CON & DC & C & $\mathrm{CO}$ & CON & DC & & \\
\hline DEXP1 & 5 & 5 & 5 & 5 & 4 & 4 & 4 & 4 & 5 & 5 & 5 & 5 & 56.00 & 0.93 \\
\hline DEXP2 & 5 & 5 & 5 & 5 & 4 & 4 & 4 & 4 & 5 & 5 & 5 & 5 & 56.00 & 0.93 \\
\hline DEXP3 & 5 & 5 & 5 & 5 & 4 & 4 & 4 & 4 & 5 & 5 & 5 & 5 & 56.00 & 0.93 \\
\hline DEXP4 & 5 & 5 & 5 & 5 & 4 & 4 & 4 & 4 & 5 & 5 & 5 & 5 & 56.00 & 0.93 \\
\hline \multicolumn{14}{|c|}{ VALOR DE AIKEN } & 0.93 \\
\hline
\end{tabular}

CLARIDAD $=\mathrm{C} ;$ CONGRUENCIA $=\mathrm{CO} ;$ CONTEXTO $=\mathrm{CON} ;$ DOMINIO DE CONSTRUCTO $=\mathrm{DC}$ 


\title{
Anexo 7. Validación de jueces
}

Juez $\mathrm{N}^{\circ} 1$

INSTRUMENTO PARA LA VALIDEZ DE CONTENIDO

(JUICIO DE EXPERTOS)

\begin{abstract}
El presente documento tiene como finalidad validar los cuestionarios de desempeño de tercerización de servicios logísticos $3 \mathrm{PL}$ y desempeño exportador, los mismos que serán aplicados a los gerentes o administradores de las empresas exportadoras de uvas frescas en el Perú que forman parte del estudio "Impacto del desempeño de la tercerización de servicios logisticos en las MYPES exportadoras de uvas a EUA, 2020", que corresponde a un diseño correlacional no experimental transversal.
\end{abstract}

\section{Instrucciones}

La evaluación requiere de la lectura detallada y completa de cada uno de los ítems propuestos a fin de cotejarlos de manera cualitativa con los criterios propuestos relativos a: Claridad de la redacción, Congruencia con el contenido, Contexto correcto del ítem y Dominio del Constructo. Para ello deberá asignar una valoración si el ítem presenta o no los criterios propuestos, y en caso necesario se ofrece un espacio para las observaciones si hubiera.

Juez $\mathrm{N}^{\circ}$ :

Fecha actual:

11 de agosto del 2020

Nombres y Apellidos de Juez: German Urrunaga Canales

Institución donde labora: Genesys Telecommunications Laboratories, Inc.

Años de experiencia profesional o cientifica: 25 años

Grado de Instrucción: _Maestría (International MBA - Instituto de Empresas, Madrid) Puesto que desempeña: Country Manager Perú

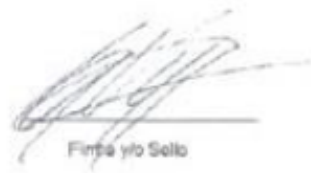




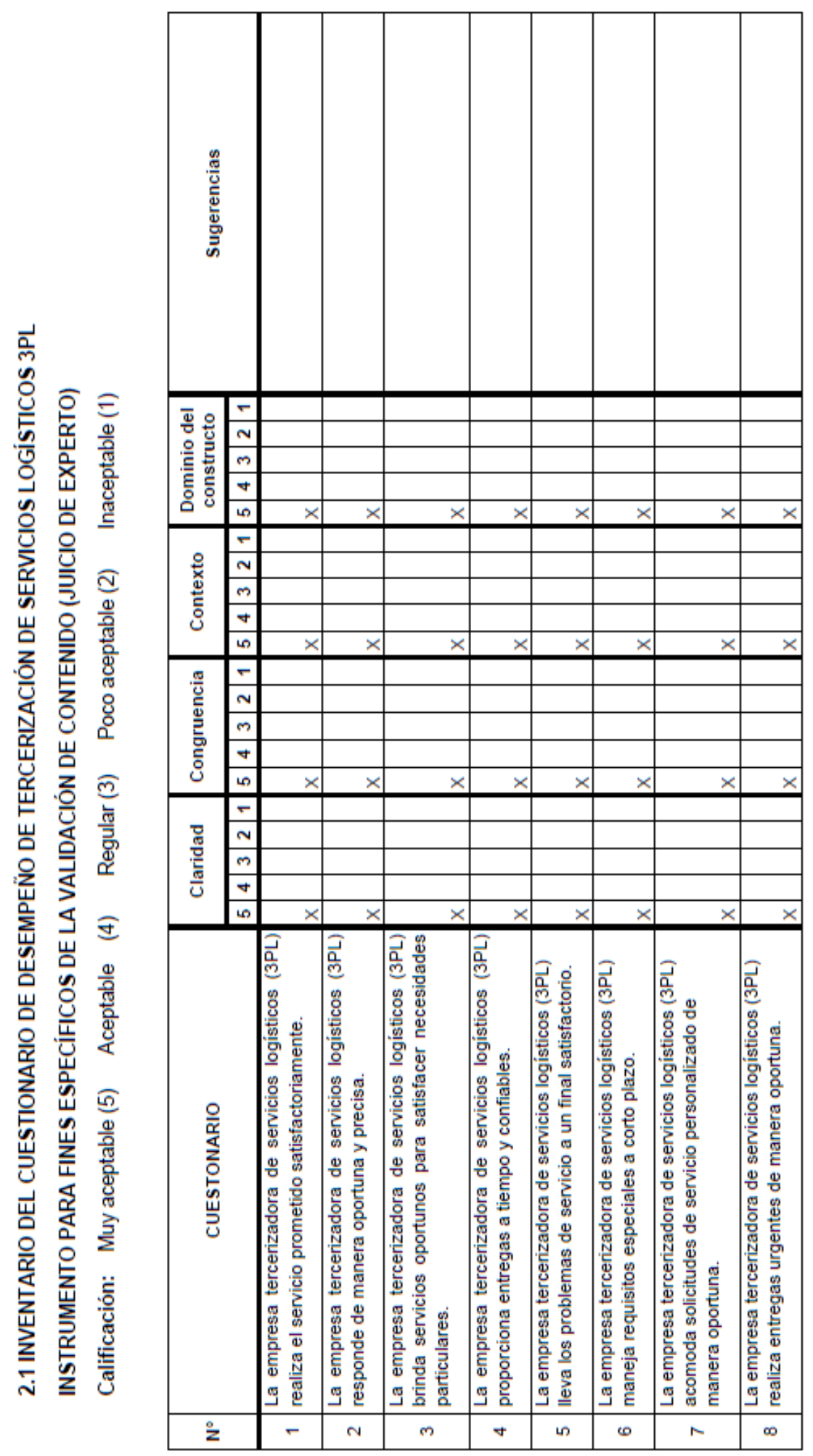




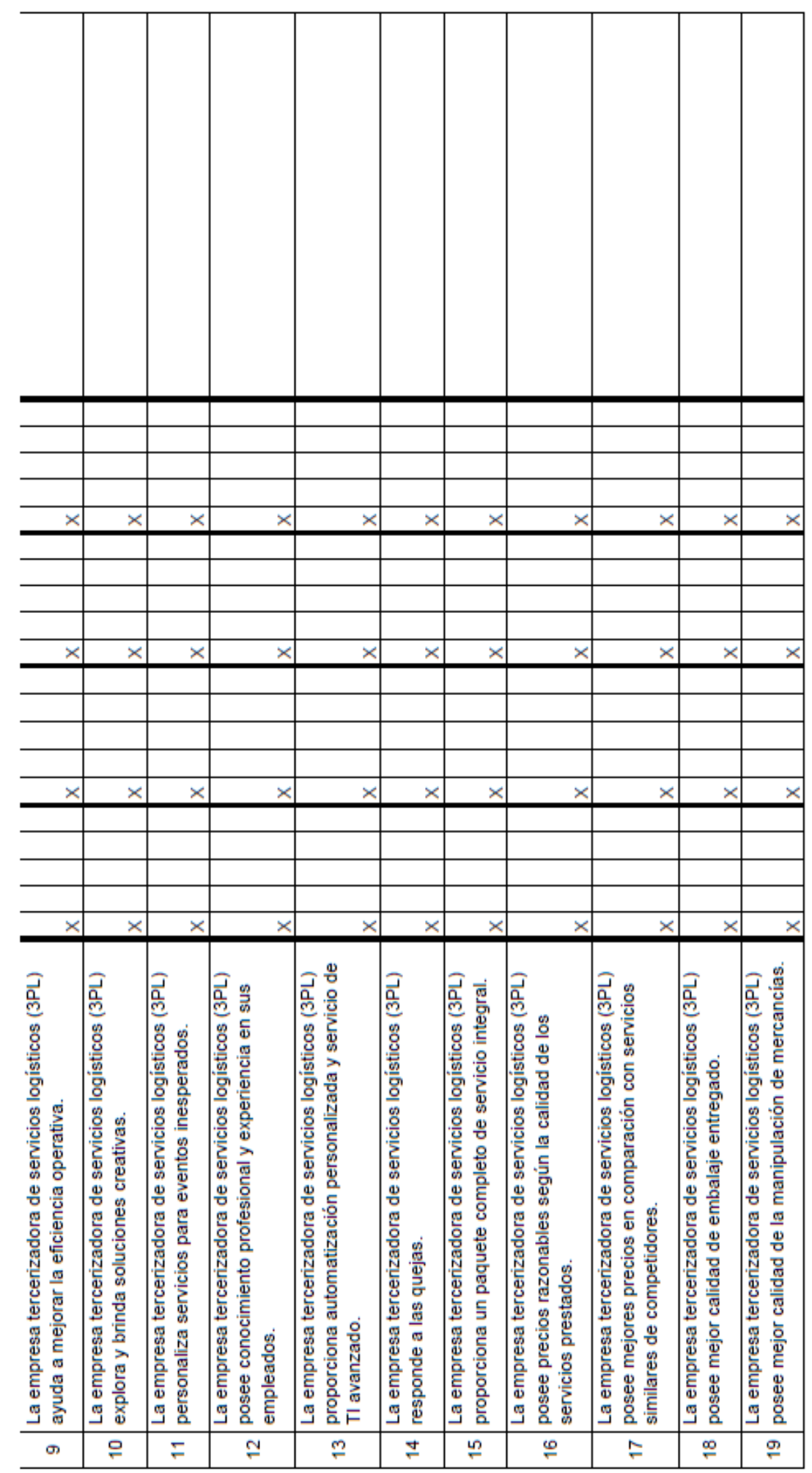




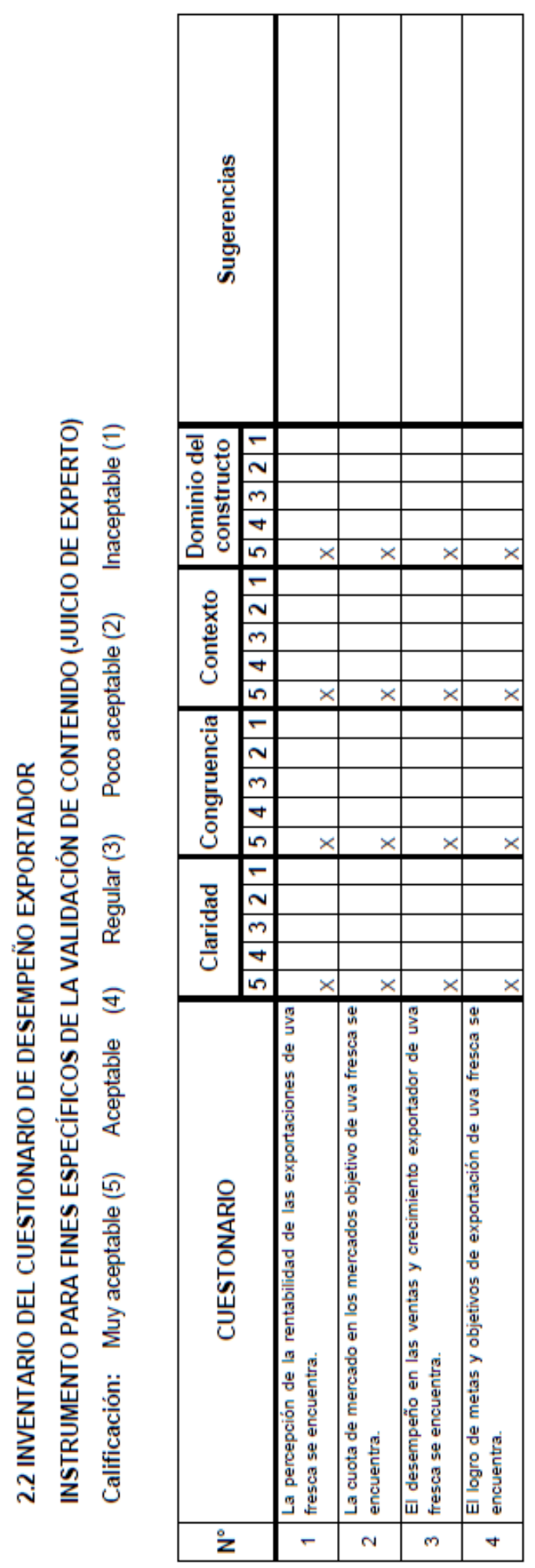


Juez $\mathrm{N}^{\circ} 2$

INSTRUMENTO PARA LA VALIDEZ DE CONTENIDO

(JUICIO DE EXPERTOS)

El presente documento tiene como finalidad validar los cuestionarios de desempeño de tercerización de servicios logísticos 3PL y desempeño exportador, los mismos que serán aplicados a los gerentes o administradores de las empresas exportadoras de uvas frescas en el Perú que forman parte del estudio "Impacto del desempeño de la tercerización de servicios logísticos en las MYPES exportadoras de uvas a EUA, 2020", que corresponde a un diseño correlacional no experimental transversal.

\section{Instrucciones}

La evaluación requiere de la lectura detallada y completa de cada uno de los ítems propuestos a fin de cotejarlos de manera cualitativa con los criterios propuestos relativos a: Claridad de la redacción, Congruencia con el contenido, Contexto correcto del ítem y Dominio del Constructo. Para ello deberá asignar una valoración si el ítem presenta o no los criterios propuestos, y en caso necesario se ofrece un espacio para las observaciones si hubiera.

Juez $N^{0}: 2$

Fecha actual: 10 de agosto del 2020

Nombres y Apellidos de Juez: BRAGGI A. BAMBERGER VARGAS

Institución donde labora: FINANCE CONSULT EIRL

Años de experiencia profesional o cientifica: 22 AÑOS

Grado de Instrucción: DOCTOR EN CONTABILIDAD Y FINANZAS

Puesto que desempeña: CONSULTOR FINANCIERO

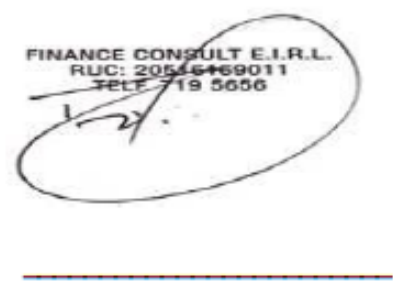

Firma y/o Sello 


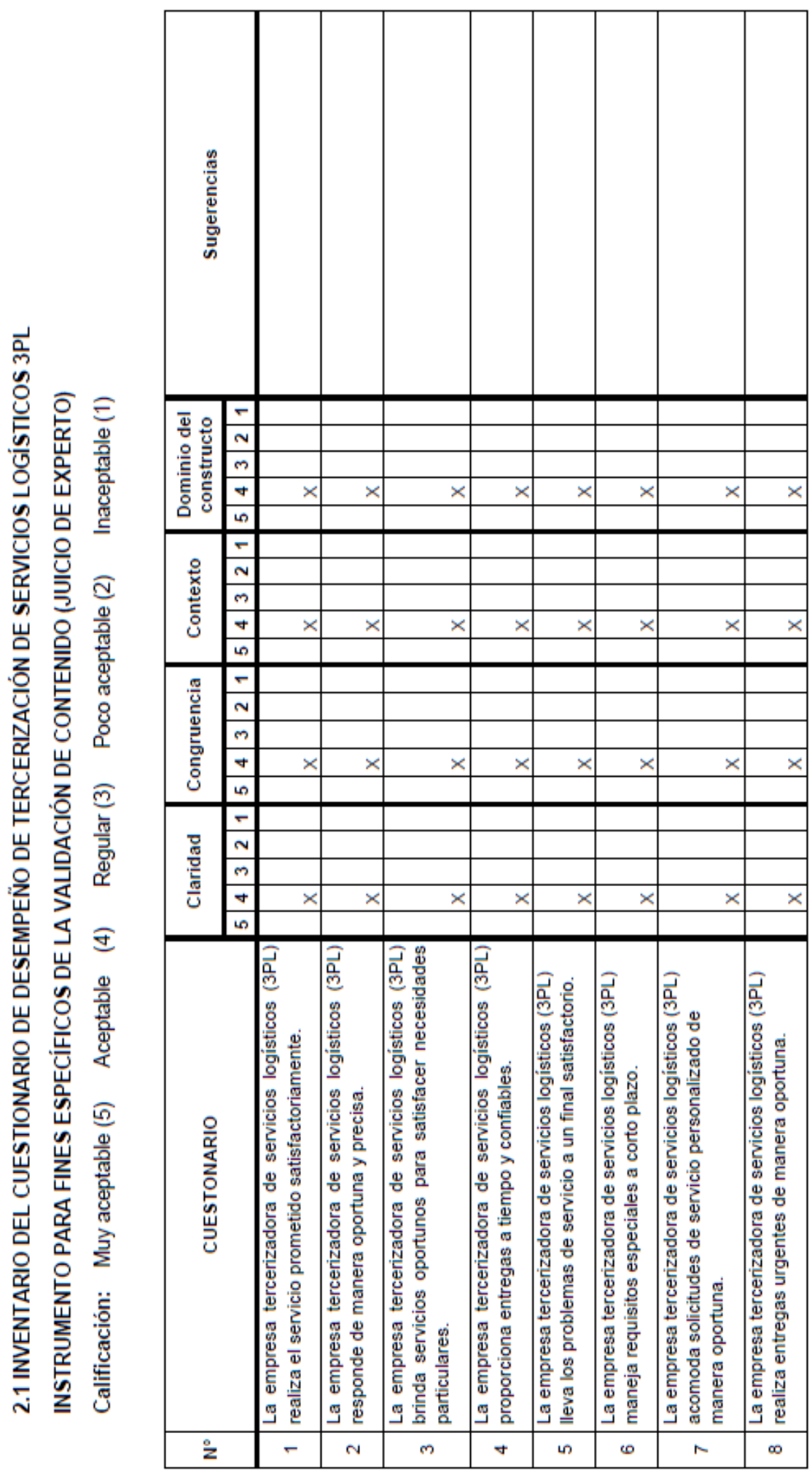




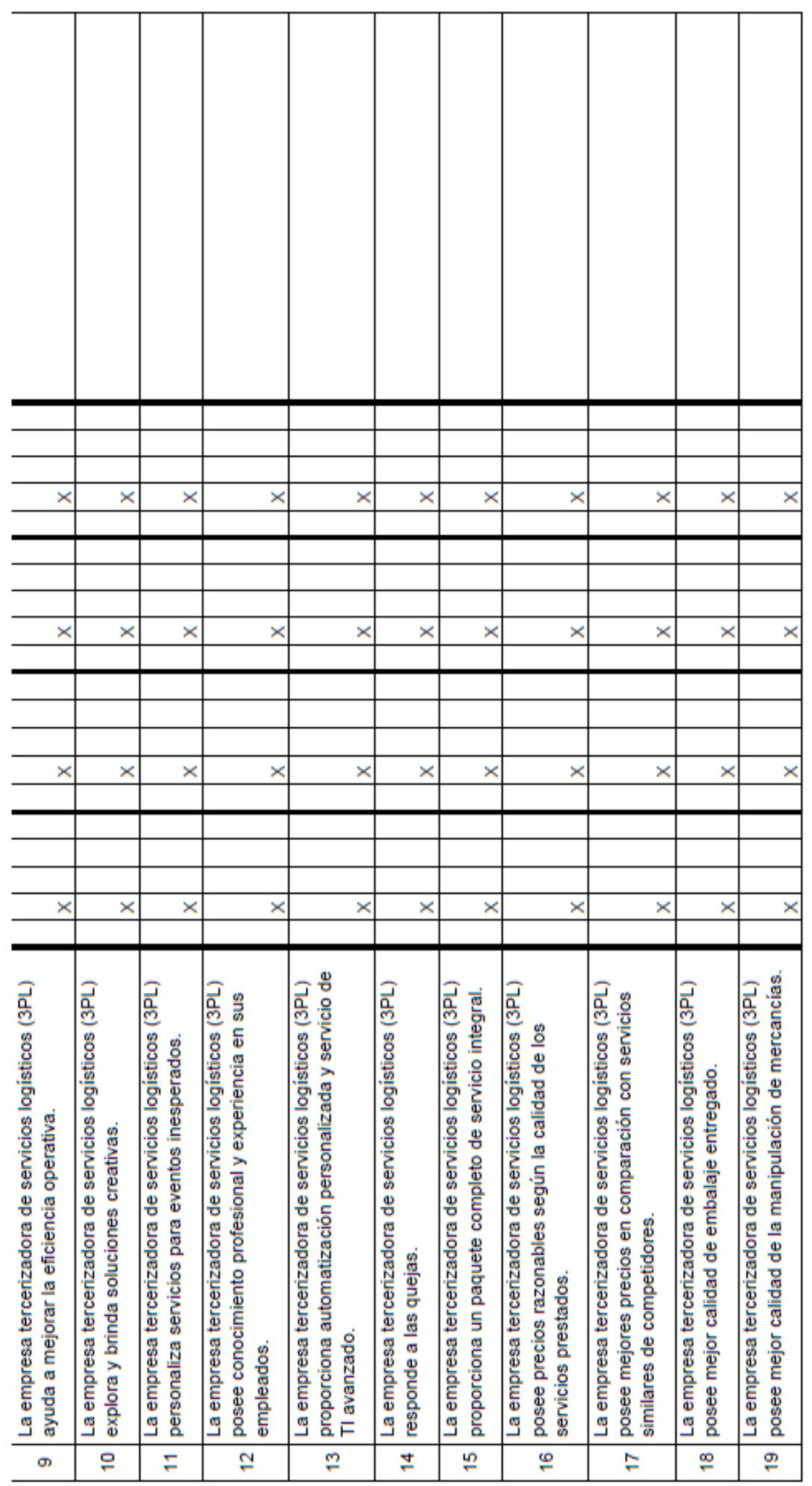




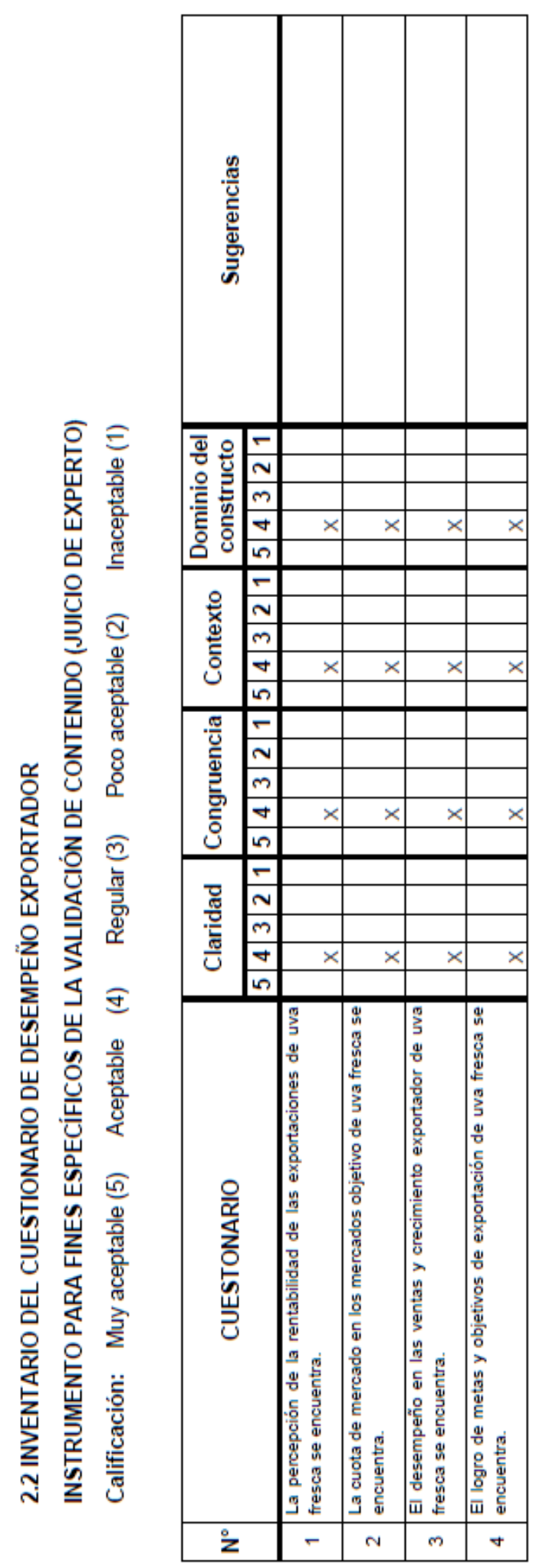


Juez $\mathrm{N}^{\circ} 3$

\section{INSTRUMENTO PARA LA VALIDEZ DE CONTENIDO}

(JUICIO DE EXPERTOS)

El presente documento tiene como finalidad validar los cuestionarios de desempeño de tercerización de servicios logísticos 3PL y desempeño exportador, los mismos que serán aplicados a los gerentes o administradores de las empresas exportadoras de uvas frescas en el Perú que forman parte del estudio "Impacto del desempeño de la tercerización de servicios logísticos en las MYPES exportadoras de uvas a EUA, 2020", que corresponde a un diseño correlacional no experimental transversal.

\section{Instrucciones}

La evaluación requiere de la lectura detallada y completa de cada uno de los ítems propuestos a fin de cotejarlos de manera cualitativa con los criterios propuestos relativos a: Claridad de la redacción, Congruencia con el contenido, Contexto correcto del ítem y Dominio del Constructo. Para ello deberá asignar una valoración si el ítem presenta o no los criterios propuestos, y en caso necesario se ofrece un espacio para las observaciones si hubiera.

Juez $\mathrm{N}^{0}:$

Fecha actual: 12/08/2020

Nombres y Apellidos de Juez: Francisco Javier Chenguayén Rospigliosi

Institución donde labora: Lima Expresa

Años de experiencia profesional o científica: 10

Grado de Instrucción: Master

Puesto que desempeña: Jefe de Operaciones

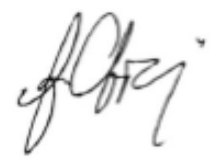

Firma y/o Sello 


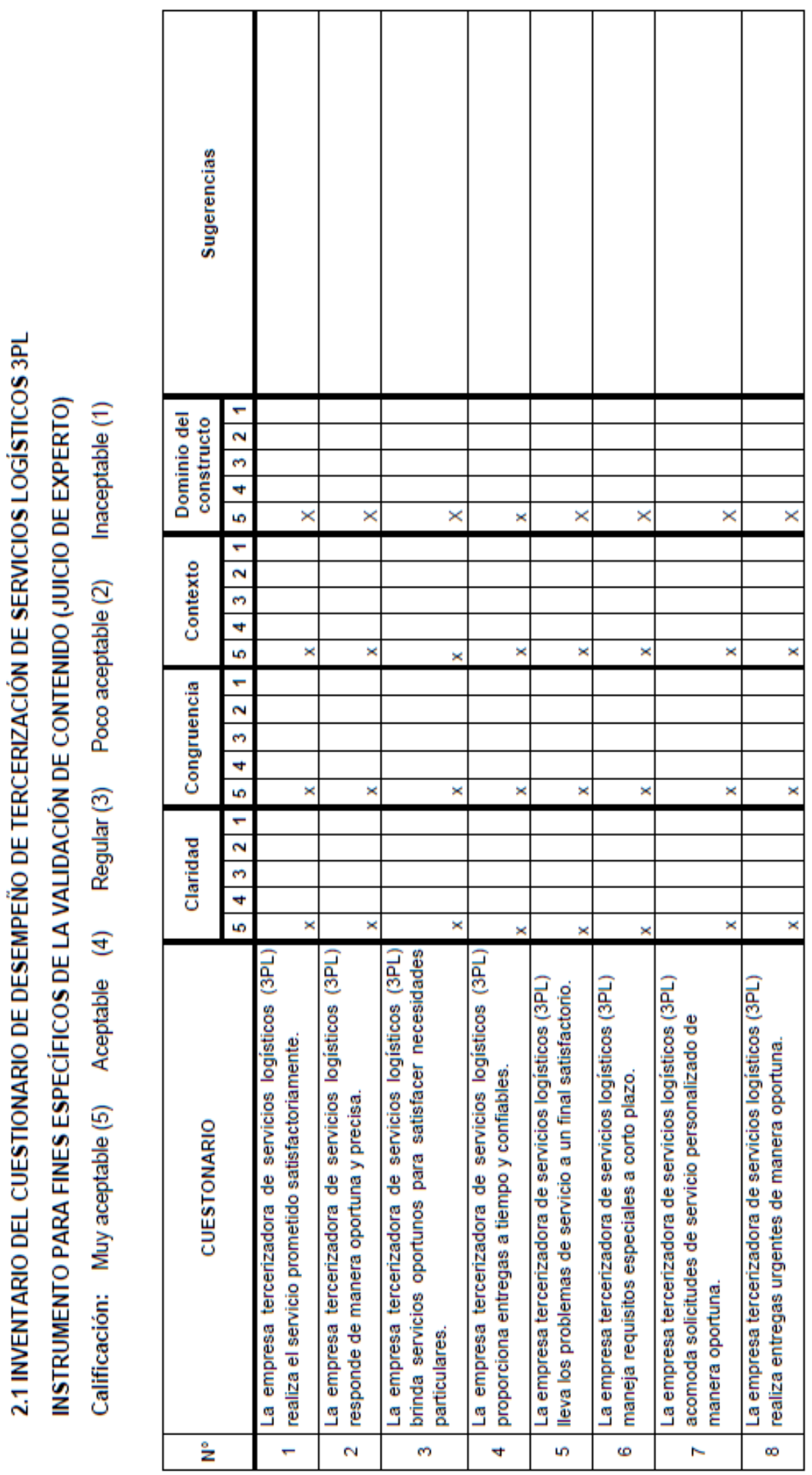




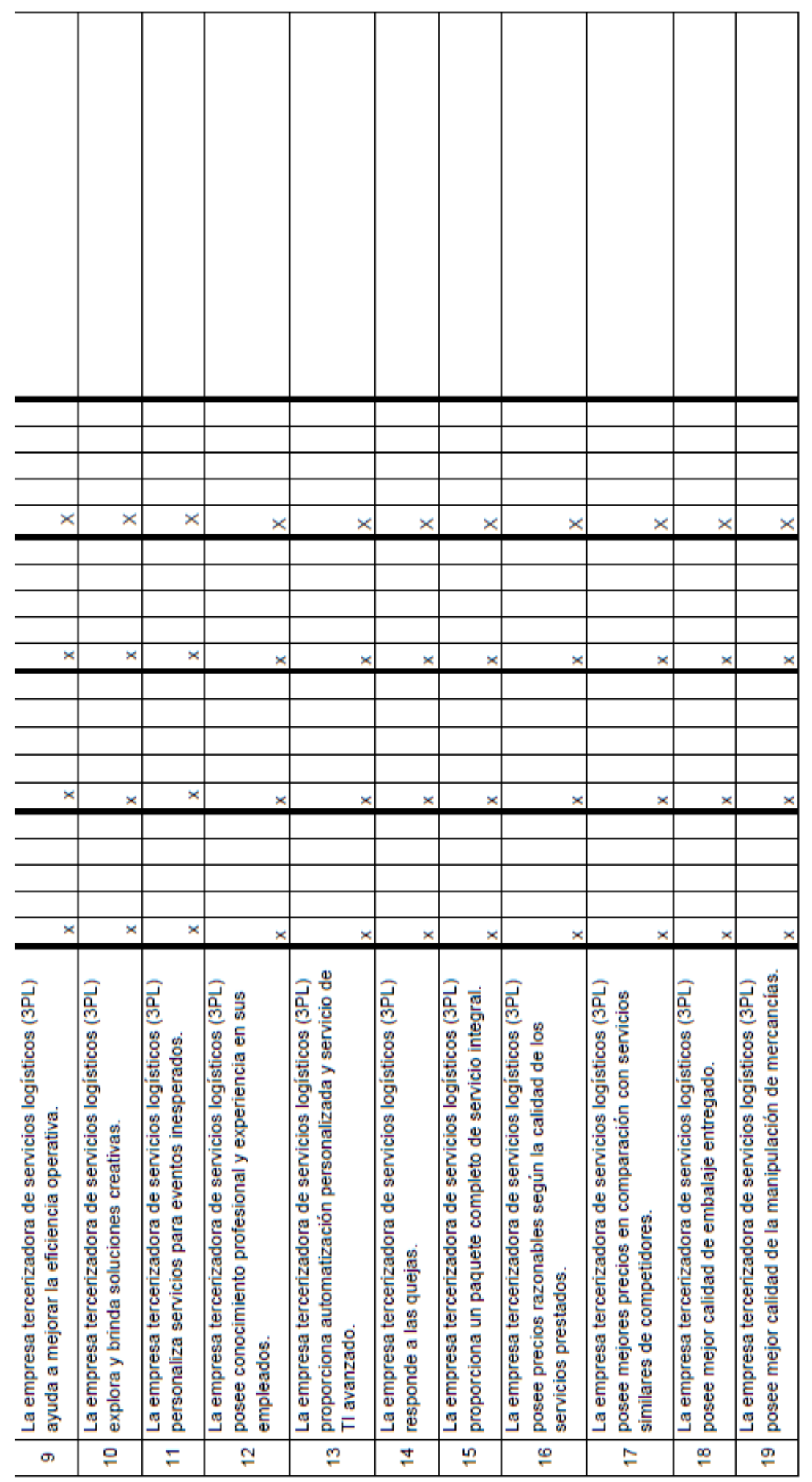




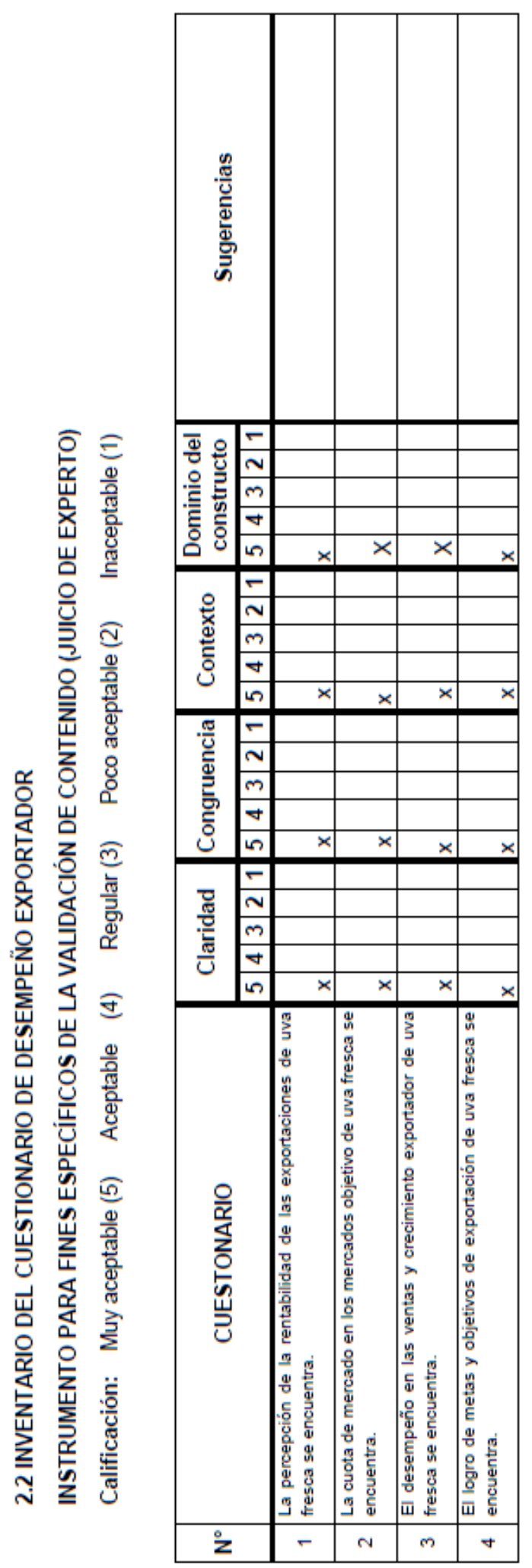

